\title{
Seafloor Observatory Science: a review
}

\author{
Paolo Favali $\left({ }^{1}\right)\left({ }^{2}\right)$ and Laura Beranzoli $\left({ }^{1}\right)$ \\ ( ${ }^{1}$ Istituto Nazionale di Geofisica e Vulcanologia, Roma, Italy \\ ${ }^{2}$ ) Università degli Studi di Roma «La Sapienza», Roma, Italy
}

\begin{abstract}
The ocean exerts a pervasive influence on Earth's environment. It is therefore important that we learn how this system operates (NRC, 1998b; 1999). For example, the ocean is an important regulator of climate change (e.g., IPCC, 1995). Understanding the link between natural and anthropogenic climate change and ocean circulation is essential for predicting the magnitude and impact of future changes in Earth's climate. Understanding the ocean, and the complex physical, biological, chemical, and geological systems operating within it, should be an important goal for the opening decades of the 21 st century. Another fundamental reason for increasing our understanding of ocean systems is that the global economy is highly dependent on the ocean (e.g., for tourism, fisheries, hydrocarbons, and mineral resources) (Summerhayes, 1996). The establishment of a global network of seafloor observatories will help to provide the means to accomplish this goal. These observatories will have power and communication capabilities and will provide support for spatially distributed sensing systems and mobile platforms. Sensors and instruments will potentially collect data from above the air-sea interface to below the seafloor. Seafloor observatories will also be a powerful complement to satellite measurement systems by providing the ability to collect vertically distributed measurements within the water column for use with the spatial measurements acquired by satellites while also providing the capability to calibrate remotely sensed satellite measurements (NRC, 2000). Ocean observatory science has already had major successes. For example the TAO array has enabled the detection, understanding and prediction of El Niño events (e.g., Fujimoto et al., 2003). This paper is a world-wide review of the new emerging «Seafloor Observatory Science», and describes both the scientific motivations for seafloor observatories and the technical solutions applied to their architecture. A description of world-wide past and ongoing experiments, as well as concepts presently under study, is also given, with particular attention to European projects and to the Italian contribution. Finally, there is a discussion on «Seafloor Observatory Science» perspectives.
\end{abstract}

Key words multidisciplinary seafloor observatories - marine science and technology

\section{Introduction}

Much of what we know about the oceans is the result of ship-based expeditionary science dating back to the late 19th century. But, it is now clear that to answer many important questions in the ocean and Earth sciences, a co-ordi-

Mailing address: Dr. Paolo Favali, Istituto Nazionale di Geofisica e Vulcanologia, Via di Vigna Murata 605, 00143 Roma, Italy; e-mail: paolofa@ingv.it nated research effort of long-term investigations is required. Experiments and research programmes, from the 1980 s to the present, reflect the progressive enhancement of monitoring systems in the ocean basins. During this time we have witnessed the achievement and strengthening of the concept of «seafloor observatories» and the integration of earlier, quite simple, stand-alone seafloor mono-parameter monitoring modules inside more complex multi-parameter platforms with extended lifetime and performance. Simple stand-alone modules like OBSs (acronyms and abbreviations are listed before the references), already in use, although with a power autonomy up to 1 year, are characterised by local data storage and a very limited set of sensors, while deployment and re- 
covery are performed either by means of ROVs or by free-fall landing and pop-up procedures.

More complex systems with better performance, namely seafloor observatories, have been developed to overcome the limitations of the stand-alone modules with respect to multidisciplinary monitoring and (near)-real-time communications and integration. Much of seafloor observatory research is interdisciplinary in nature and has the potential to greatly advance the relevant sciences. To obtain further advances, long time-series measurements of critical parameters, such as those collected using seafloor observatories, are needed to supplement traditional seagoing investigations (NRC, 1998a, 1999, 2003c). In 1991 the EC promoted feasibility studies aimed at identifying both the scientific requirements (Thiel et al., 1994) and the possible technological solutions for the development of seafloor observatories, the ABEL concept (Berta et al., 1995). The «Symposium on Seafloor Observatories» (Islamorada, Florida, 2000) was an opportunity to discuss the scientific potential and technical needs associated with the establishment of a network of seafloor observatories. This meeting was followed by the NRC report «Illuminating the Hidden Planet. The future of Seafloor Observatory Science». In this report a complete definition of the term «seafloor observatories» was given for the first time: «[...] an unmanned system, at a fixed site, of instruments, sensors, and command modules connected to land either acoustically or via a seafloor junction box to a surface buoy or a fibre-optic cable [...]» (NRC, 2000). In the fall of 1999, NSF asked NRC to investigate the scientific merit, technical requirements, and overall feasibility of establishing the infrastructure needed for a network of unmanned seafloor observatories. The NRC Committee on Seafloor Observatories was appointed to carry out this task and concluded that seafloor observatories present a promising and in some cases essentially new approach for advancing basic research in the oceans. NSF was thus encouraged to move ahead with plans for a seafloor observatory programme (NRC, 2000). The scientific benefit of seafloor observatory investigations has been recognised for many years, and, as such, numerous independent national and international efforts have been proposed or are underway. Many of these challenging initiatives are described here (see Section 4). Although seafloor observatories have primarily research goals, the data collected by them will also provide an important contribution to operational observing systems such as GOOS (NRC, 1997; GOOS, 1999). This paper reviews the efforts made world-wide in a new emerging science, «Seafloor Observatory Science» and its perspectives, focusing on European and Italian contributions.

\section{Scientific motivation for seafloor observatories}

The question we have to answer is: «Why establish seafloor observatories?». In recent decades oceans, Earth and planetary sciences have been shifting from a discontinuous, expeditionary mode toward a mode of sustained in situ observations. This change in the mode of investigation stems from the realisation that Earth and its oceans are not static, but are dynamic on many time and space scales, not just the short time scales involved in catastrophic events. As examples of catastrophic events we may note the influence on global weather of the El Niño events of 1982-1983 and 1997-1998 or earthquakes, with associated tsunami waves, like the catastrophic earthquake ( $M_{w} 9.5$ main shock) and related tsunami that occurred at the end of December 2004 in the Indian Ocean (Lomnitz and Nilsen-Hofseth, 2005; Merrifield et al., 2005). Understanding Earth and its oceans means investigating processes as they occur. A scientifically powerful component of the observatory concept is the long time-series collection of multiple variables at a single location. These multidisciplinary data sets will enable the enhancement of more traditional methods, giving strong benefits to many disciplines, like geophysics (Favali et al., 2002), physical oceanography (Millot, 2002) and biology (Thiel et al., 1994).

Seafloor observatories could offer Earth and ocean scientists new opportunities to study multiple, interrelated processes over time scales ranging from seconds to decades. Scientific processes with various time scales should benefit from data collected by seafloor observatories. These include: a) episodic processes; b) process- 
es with periods from months to several years; c) global and long-term processes. Episodic processes include, for instance, eruptions at midocean ridges, deep-ocean convection at high latitudes, earthquakes, and biological, chemical and physical impacts of storm events. The category «b» includes processes like hydrothermal activity and biomass variability in vent communities. The establishment of an observatory network will be essential to investigate global processes, such as the dynamics of the oceanic lithosphere and thermohaline circulation.

\subsection{Role of the ocean in climate}

Climate variations have widespread societal, economic, and environmental impact (NRC, 2003b). As a result, vigorous research efforts are currently aimed at improving our understanding of the spectrum of climate system variations. The ocean is a component of Earth's climate system, playing an increasingly important role in determining the nature of climate variability, as time scales expand. The goal is ultimately to predict climate variability and change. Another important issue is to separate natural interannual-tocentennial climate variations from anthropogenically induced climate change. This aspect is critical for predicting future variations and magni- tudes of climatic changes. Therefore, we rely increasingly on models of the climate systems. Even though present ocean circulation models are much improved, our knowledge of ocean physics is not comprehensive enough. A substantially improved observational basis for determining the necessary model enhancements is required. Oceanographic variability has a significant influence on climate. The deep-sea has also recently been warming significantly (e.g., Fuda et al., 2002) and it is very important to understand the causes and its role in a climate change context. It is essential to fully resolve many scales of variability and this requires nested, complementary observing systems. Moreover, such observing systems provide the physical oceanographic context for interpreting biological and chemical distribution. To further our understanding of the role of the ocean in climate, seafloor observatories should be long-term facilities. A fundamental change achieved by pursuing the observatory concept would be the maintenance of existing sites and establishment of new sites. This may be the key to moving from the current focus on long-term science projects, such as JGOFS or CLIVAR, to the implementation of a sustained global ocean-observing system (NRC, 1998a,b; 2004). The main scientific goals achievable by using seafloor observatories are listed in table I. For instance, reliable sam-

Table I. List of scientific goals where the Seafloor Observatory Science is very useful (NRC, 2000).

\begin{tabular}{ll}
\hline \hline Sectors & Scientific goals \\
\hline Role of the ocean & - To test and improve ocean circulation models. \\
in climate & - To understand the physics of the exchange processes between the ocean and atmosphere. \\
- To observe the ocean climate anomalies from generation to destruction. & - To predict climate variability and change. \\
- To monitor, understand and predict: & \\
& $\circ$ the sequestration of carbon dioxide in the ocean; \\
& $\circ$ productivity and biomass variability, including factors controlling chemistry; \\
& $\circ$ the full temporal and vertical evolution of thermohaline structure; \\
& $\circ$ rapid episodic changes of the ocean; \\
& $\circ$ changes in water mass transformation processes; \\
& $\circ$ air-sea exchanges $(e . g .$, heat and gases); \\
& $\circ$ vertical exchanges of heat, salt, nutrients and carbon; \\
& $\circ$ thermohaline variability in the Arctic and Antarctic; \\
& $\circ$ the pathways of ocean transports; \\
& $\circ$ the role of eddies in transport and mixing.
\end{tabular}


Table I (continued).

\begin{tabular}{|c|c|}
\hline Sectors & Scientific goals \\
\hline & $\begin{array}{l}\text { - To provide reference sites for calibration or verification of: } \\
\circ \text { air-sea fluxes for numerical weather prediction models, satellites; } \\
\circ \text { absolute interior and Eckman layer velocities; } \\
\circ \text { remote sensed variables (e.g., sea surface temperature, sea level, wind); } \\
\circ \text { model statistics, physics and parameterisations. }\end{array}$ \\
\hline
\end{tabular}

Fluids and life in the ocean crust
Dynamics of oceanic lithosphere and imaging Earth's interior

Coastal ocean processes

Turbulent mixing and biophysical interactions
- To investigate the chemical and biological response to episodic volcanic and hydrothermal events.

- To inquire into marine food webs on the seafloor.

- To understand the linkages between geological, biological and chemical processes in ocean crust.

- To assess the extent of sub-seafloor biosphere and determine its biological and chemical character.

- To assess the impact of fluid and gas flow and related processes on crustal structure and composition, ocean chemistry, and biological productivity.

- To determine the fluid flow patterns on ridge crests and flanks, and in convergent margins through space and time.

- To directly observe the changes in heat, chemical fluxes, and biological diversity produced by ridge-crest magmatic and tectonic events.

- To determine how hydrothermal-event plumes form and assess their global importance.

- To directly observe how biological productivity and diversity change in response to fluctuations in fluid and chemical fluxes at vents and seeps on ridge crests and flanks, and at convergent margins.

- To assess the extent to which sediment cover and spreading or subduction rates affect fluid chemistry and biological diversity at ridge crests and flanks, and subduction zones.

- To quantify the importance of chemosynthetic productivity on the seafloor.

- To understand the relations between tectonic and fluid processes in subduction zones.

- To determine rates of gas hydrate formation and dissociation in response to perturbations of pressure, temperature, and fluid chemistry and flow rate and determine the influence on ocean chemistry, biology and climate.

- To investigate:

- global Earth structure;

o core-mantle dynamics;

- seismogenesis at subduction zone megathrusts;

- seismogenesis at convergent margins;

- ridge-crest processes and creation of oceanic crust;

- marine volcanism;

$\circ$ upper mantle dynamics;

- oceanic plate kinematics, plate deformation and faulting;

- geo-hazard mitigation.

- To investigate:

- sediment transport;

- coastal eutrophication;

- the impacts of global environmental change on the coastal environment;

$\circ$ fishery;

- the structure and function of coastal ecosystems.

- To observe and understand processes that modulate vertical turbulence statistics.

- To generalise turbulence flux parameterisations.

- To determine the relationships between temporal and spatial distribution of turbulence in the ocean.

- To map sub-surface distribution of mesoscale and sub-mesoscale horizontal turbulence.

- To determine the impacts of turbulent mixing on biochemical distribution. 
Table I (continued).

\begin{tabular}{|c|c|}
\hline Sectors & Scientific goals \\
\hline $\begin{array}{l}\text { Ecosystem dynamics } \\
\text { and biodiversity }\end{array}$ & $\begin{array}{l}\text { - To detect and follow episodic ecological events (e.g., faunal responses to volcanic } \\
\text { eruptions or hydrothermal fluid events). } \\
\text { - To characterise and understand long-term (annual to decadal) ecological cycles. } \\
\text { - To characterise and understand shorter-term (diel, tidal to seasonal) biological cycles. } \\
\text { - To detect and monitor ecosystem responses to anthropogenic perturbations } \\
\text { (e.g., influences of climate change on nutrients, trace metals and trace gases). } \\
\text { - To forecast population and community changes (e.g., forecasting changes } \\
\text { in fisheries stocks). }\end{array}$ \\
\hline
\end{tabular}

pling of the deep-sea environment (over 50\% of the Earth's surface) is important for reconstructing episodes linked to past climatic variability; to do this appropriate tools for sediment sampling and for deep-sea geotechnics are necessary (e.g., Oebius and Gerber, 2002).

\subsection{Fluids and life in the ocean crust}

Although ocean chemistry is greatly influenced by the movement of fluids through oceanic crust, the processes controlling this flow are poorly understood. Four different environments are important for research on fluids and life in the oceanic crust: ridge crests, ridge flanks, convergent margins, and coastal areas on passive margins. Within each of these environments, it is critical to determine the nature and the linkages among tectonic, thermal, chemical, and biological processes at different temporal and spatial scales. Previous observations of fluids related to the ocean crust have been made mainly by deploying single, short-duration experiments that stored data rather than transmitted information in real time. To make significant advances, it is essential to observe co-varying processes by making large-scale simultaneous collections of measurements over a variety of time scales. Furthermore, real-time data collection through seafloor observatories is essential, as it will allow scientists to respond to unusual events or modify experiments if necessary. The chemistry and biology of fluids within the oceanic crust is a cutting edge research field for which seafloor observatories are an essential investigative approach (table I). One of the most exciting scien- tific problems that can be addressed using observatory science concerns the nature of the sub-surface biosphere. This is thought to contain a population of dormant microbes that are periodically driven into a population explosion by input of heat and volatiles into the crust during magma emplacements. Eruptive events on the seafloor can release great volumes of hydrothermal fluid that affect the chemistry and biology of the overlying water and generate a unique type of hydrothermal plume, called an event plume. Although it is not known how event plumes are formed, it is clear that they are produced by a sudden catastrophic release of large quantities of hot water. Eruptions also extrude lavas on the seafloor, creating new habitats for endemic vent faunas and increasing production and export of deep-living microbial populations (Delaney et al., 1998; Summit and Baross, 1998). Initial changes in the water column and the seafloor after an eruption are very difficult to study using expeditionary approaches; a seafloor observatory system near a volcanically active site would provide an important platform for characterising the early stages of an event while also monitoring longer-term changes. A good example is the NeMO Observatory (see Section 4.2). Another exciting and closely related scientific problem concerns the general response of the hydrothermal system and associated biota to seafloor spreading events in which magma is injected into the crust. This research would include the response of seafloor biological communities at convergent margin seepage sites to abrupt changes in fluid and chemical fluxes caused by seismic activity. 
Similarly, the dynamics of gas hydrate formation and dissociation, especially in response to perturbations produced by tectonic cycles or global warming, is a problem of current interest that could be addressed by observatory science. For future studies of fluids and biota in the oceanic crust, access to the sub-surface is a critical requirement. One possibility for sampling and observing fluids and biota in the crust is by drilling, and some seafloor observatory experiments would be conducted in conjunction with boreholes drilled into the crust, like the CORKs observatories (see Section 4.1). Thus, ODP, its continuation IODP and the development of new drilling capabilities will be an essential adjunct to seafloor observatory studies.

\subsection{Dynamics of oceanic lithosphere and imaging Earth's interior}

Geoscience research in the oceans is moving beyond the exploration and mapping of the seafloor and is focusing on the dynamics of the solid Earth system and the interaction of geological, chemical and biological processes through time. Many of Earth's dynamic tectonic systems will be difficult to understand fully without continuous observations provided by the establishment of seafloor observatories. These include the complex magmatic and tectonic systems at ridge crests and submarine volcanoes; the genesis of destructive earthquakes and tsunamis and their relationships to largescale plate motions, strain accumulation, fault evolution, and sub-surface fluid flow; the geodynamics of Earth's interior and the origin of Earth's magnetic field; and the motion and internal deformation of lithospheric plates. Seafloor observatories also have the potential to play a key role in the assessment and monitoring of geo-hazards, as many of Earth's most seismogenic zones and most active volcanoes occur along continental margins.

The short-term expeditionary approach, common in the ocean sciences in the past, is poorly suited to detect or understand longertime changes. Continuous measurements are required with the ability to react quickly to episodic events, such as earthquakes and vol- canic eruptions. Geophysical observatories have long been an integral component of Earth science research on land; advances in technology and our understanding of the oceans now make it feasible to establish long-term observatories on the seafloor, as many experiments and projects have demonstrated (see Section 4 for details). Many areas of Earth science would be advanced through the collection of time-series observations on the seafloor (table I), these include: a) global Earth structure and core-mantle dynamics; b) seismogenesis at subduction zone megathrusts, and at convergent margins; c) ridge-crest processes and oceanic volcanism; d) oceanic plate kinematics, plate deformation, and faulting; e) geo-hazard mitigation. The scientific objectives that can be addressed particularly with geophysical data from long-term ocean-bottom observatories include two broad subject areas: Earth structure and natural hazards. These two areas can each be divided into sub-areas according to the global, regional, and local spatial scale under investigation: a) global scale: mantle dynamics, core studies, moment tensor inversion; b) regional scale (between 500 and $5000 \mathrm{~km}$ ): oceanic upper mantle dynamics, lithosphere evolution, and tsunami warning and monitoring; c) local scale $(<500 \mathrm{~km})$ : oceanic crustal structure, sources of noise, and detailed earthquake source studies (tomography of the source, temporal variations).

For the global Earth structure, there are fundamental scientific questions concerning the dynamics of Earth's mantle and core; for instance, the spatial scale of convection and the existence of distinct mantle geochemical reservoirs. The nature and origin of hotspots and their interaction with the lithosphere are other important questions in mantle dynamics. New paleomagnetic data are inconsistent with the idea of «fixed» hotspots (e.g., Torsvik et al., 2002) and geochemical data appear to be compatible with different origins for hotspots, including the 670$\mathrm{km}$ discontinuity, a boundary in the lower mantle, or the core-mantle boundary (e.g., Zhao, 2001; De Paolo and Manga, 2003). Four centuries after the demonstration by Gilbert that Earth's magnetic field is largely of internal origin, our understanding of the dynamo process responsible for generating the field remains incom- 
plete. Improved spatial sampling provided by long-term seismic and geomagnetic observations in the ocean promises great gains in understanding the geodynamics of Earth's interior and the origin of Earth's magnetic field. Large gaps exist in the global network of seismic and geomagnetic stations, since the oceans cover $7 / 10$ of the whole Earth surface. These gaps can not be filled with island stations only, particularly in the Eastern Pacific and southern oceans. Many authors have recognised the importance of filling these gaps by using seafloor observatories (e.g., Purdy and Dziewonski, 1988; Montagner and Lancelot, 1995; Lowes, 2002). The OSN, first proposed over a decade ago, is envisioned as part of a larger ION, and would include about eight seafloor magnetic observatory sites as necessary for an improved global characterisation of the shortterm behaviour of Earth's magnetic field.

For seismogenesis, plate tectonic theory provides a quantitative framework within which lithospheric deformation and faulting can be understood as well as a first-order explanation of the global distribution of seismicity. However, investigations are focusing on the deformation process itself and the still poorly understood interplay among tectonic stress, rock rheology, fluid distribution and faulting (e.g., Monna et al., 2003 and references therein). Subduction zone megathrusts produce the largest and potentially most destructive earthquakes and tsunamis on Earth. Despite the societal impact of these great earthquakes, little is known about the seismogenic zones. Understanding the origin of major earthquakes at subduction zones, such as offJapan, Central America and Cascadia, is the key focus of the SEIZE international initiative (Moore and Moore, 1998). The scientific strategy employed by SEIZE involves a combination of geophysical imaging, drilling, and long-term monitoring over an earthquake cycle at a few representative subduction zones. These observations, in concert with laboratory experiments on the behaviour of material and theoretical modelling, offer the potential for major advances in our understanding of earthquake processes. A seafloor observatory programme would complement land-based studies by providing the capability to monitor deformation and faulting of offshore active fault systems.
For ridge-crest processes and oceanic volcanism, the volcanism controls the heat flux, mass and volatiles from Earth's interior. The circulation of hydrothermal fluids transfers heat from the crust to the overlying ocean, and modifies ocean chemistry. Hydrothermal processes affect the chemical, thermal and biological balance of oceanic environments. As a result of successful interdisciplinary international programmes, such as RIDGE and InterRIDGE, the importance of understanding the links among geological, physical, chemical, and biological processes in submarine volcanic systems is well established. Current ship-based studies allow only periodic visits, at intervals of months to years. Thus, hydrothermal and biogeochemical processes that occur at and immediately after the time of an eruption have never been observed. The links, mentioned above, can be studied by installing long-term observatory nodes at sites along the global mid-ocean ridge system and at a few oceanic volcanoes.

For oceanic plate kinematics, deformation, and faulting, our picture of plate tectonics is largely based on historical data sets, such as the geomagnetic reversal record averaged over million of years, geomorphologic estimates of transform-fault azimuths, and present-day earthquake slip vectors. These data have provided input to a plate tectonic model. But this model lacks detail because most of the plate boundaries are underwater. Seafloor observatories provide an opportunity to advance the embryonic science of monitoring geodetic motions on the seafloor. It will finally be possible to continuously observe motion near plate boundaries.

For geo-hazard mitigation, as the human population continues to grow, the potential social and economic dislocation provoked by natural hazards, such as earthquakes, volcanoes, submarine landslides and tsunamis, has increased. These impacts are especially detrimental to developing nations. The destructive earthquakes and related tsunamis that occurred at the end of 2004 in the Indian Ocean, and that strongly affected Sumatra, Malaysia, Indonesia, the Andaman Islands, Thailand, Myan Mar, Bangla Desh, Sri Lanka, India and the Maldives in terms of lives and economic impact, are only the most recent examples. Another cause of hazard is the 
natural leakage of gaseous hydrocarbons at the seafloor, gas bubbles in the sediment, leaking hydrates, mud volcanoes on land and on the seafloor, and submarine gas seepage in pockmark fields (Etiope and Favali, 2004). New submarine gas sources are being continuously discovered (e.g., Holland et al., 2003). Off-shore gas leakage has not been adequately explored, but is an important hazard for off-shore oil exploration, exploitation and construction of related infrastructures (Etiope et al., 2002). Autonomous multidisciplinary benthic observatories can be used for reliable characterisation and monitoring of specific sites, like pockmarks (Marinaro et al., 2004). The main advantage of long-term monitoring is to assess the temporal variability of the phenomena.

\subsection{Coastal ocean processes}

An important factor limiting coastal ocean research is the inability to quantify vertical and horizontal transport of water, elements and energy through the coastal ocean system. Long time-series measurements of critical parameters, such as temperature, salinity, nutrients and trace elements, will help to provide the necessary data to remedy this deficiency. The coastal ocean includes estuaries, and the continental shelf and slope, and incorporates a great deal of environmental diversity. Furthermore, the coastal ocean is where terrestrial influences encounter the broader ocean. It is the area of the ocean most strongly affected by anthropogenic impacts, it displays a strong geographic diversity, and it is the most biologically productive part of the ocean and hence is most heavily fished. Some major problems in coastal ocean science are the following: a) coastal ecosystems are extremely productive, but not very well understood in terms of how their structures and functions respond to variations in environmental conditions; b) there are concerns both about how global change might affect littoral areas, and about how the resulting variations within the coastal zone might affect the rest of the ocean; separating natural from anthropogenic changes is essential; c) coastal management issues will require long, high-resolution time se- ries of coastal ocean processes. The need to understand oceanographic change then implies a need to document environmental changes and their potential forcing agents. Because the oceanographic variability can change with time over weeks to years, there is a great need to collect long-time series in order to document important variations in critical parameters (table I). One way of making long-term measurements in the coastal ocean would be to deploy arrays of moorings equipped with a wide spectrum of sensors. A low-cost model for a moored-buoy observatory has been proposed by Frye et al. (1999).

\subsection{Turbulent mixing and biophysical interactions}

Successful modelling of the distribution of organisms and chemical compounds in the ocean depends directly on the predictive quality of circulation models, which are limited by our ability to model turbulent mixing in the ocean. Because turbulent motions result from highly non-linear dynamics acting across a range of time and space scales, progress in understanding these motions is difficult. Advances depend on systematically collecting long-term measurements and resolving small vertical and horizontal scales throughout the range of turbulent regimes that are controlled by extremes of mechanical forcing, buoyancy forcing and topography. Turbulent mixing occurs over a broad spectrum of time and space scales, strongly affecting the distribution of momentum, heat, chemical compounds and living organisms in the ocean. Turbulent mixing at the sea surface mediates airsea exchange of biologically reactive compounds, such as dimethyl sulfide and carbon dioxide. Turbulence in the bottom boundary layer plays a role in benthos-pelagic coupling of nutrients, and affects chemical signalling, habitat choice and genetic exchange in benthic communities. The grand objective is a parameterisation of turbulence statistics as a function of larger scale, more deterministic flows. The physical oceanography community has identified sub-regions of general circulation models that are greatly in need of improvement, including deep 
convection, boundary currents and benthic boundary layers, the dynamics and thermohaline variability of the upper mixed layer, fluxes across the air-sea interface, diapycnal mixing, and topographic effects. There is a strong connection between the understanding of coastal ocean processes and diapycnal mixing. Because of the bottom slopes, flow across depth contours implies a vertical density transport that can determine transport in the boundary layer. Flow near the bottom is important because of its role in the transportation of materials, such as sediments and benthic biota, between shallow and deep water. These bottom flows govern the behaviour of stronger alongshore flows in the overlying water column. As with the diapycnal turbulent fluxes, there is a clear need to improve our knowledge of horizontal turbulence. This research is a new frontier for physical oceanography. Furthermore, in this case also effective tools for sampling the benthic boundary layer can greatly help (e.g., Oebius and Gerber, 2002).

The main challenge for the parameterisation of turbulent mixing is to obtain high-quality turbulence statistics and their variation. To develop a universal parameterisation it is necessary to conduct observational studies in a broad range of environmental conditions (table I). In this context, a seafloor observatory programme would be of great benefit to advance our understanding and parameterisation of mixing in different dynamic regimes. Some of these dynamic regimes that need to be observed include: a) a smooth bottom dominated by steady geostrophic flows; b) rough-bottom topography; c) dense water formation; d) internal tidal solitons; e) sill overflows; f) extreme atmospheric forcing at the near-surface boundary layer; g) double diffusive regime; h) hydrothermal vent fields; i) the continental shelf; j) vortex shedding; k) baroclinic instability; 1) sediment gravity flows.

\subsection{Ecosystem dynamics and biodiversity}

The biological, ecological and biogeochemical questions likely to benefit most from sustained ocean time-series observations are those involving time-dependent processes or episodically triggered events, and those requiring long- term data sets. Seafloor observatories are crucial for addressing many of the major scientific problems (table I). It is also important to note that the observatory approach, while necessary for solving many problems in marine ecology and biological oceanography, is not sufficient alone, and must be used in concert with other approaches. Oceanic ecological observatories will extend into deep water the concept of the LTER network. The mission of LTER is similar to that proposed for seafloor observatories in that it aims to understand ecological phenomena occurring over long temporal and broad spatial scales and to increase our understanding of major natural and anthropogenic environmental perturbations at selected sites. Just as restricting a seismic network only to land limits the ability of geophysicists to understand the dynamics of the Earth, restricting ecological observatories only to land limits the ability of ecologists to fully understand the dynamics of the biosphere. LEO-15 constitutes a good example of a long-term ecosystem underwater observatory (Schofield et al., 2002). In this case, a seafloor observatory is considered in the broadest sense as a system supporting measurements from the seafloor to the ocean surface. An observatory might consist of a series of stationary observatory nodes to monitor the seafloor and the water column and AUVs dispatched to provide broader spatial and temporal coverage. This definition does not include Lagrangian drifters or floats, but their use will greatly complement an array of fixed observatories.

The exploitation of deep-sea resources, begun more than 50 years ago, is expected to increase in the next future. In these activities, impact assessments must be conducted to avoid any misuse of the environment, by using the deep-sea either for waste deposition or for ore mining and hydrocarbon extraction (Thiel, 2002 and references therein).

\section{Technical solutions for seafloor observatory architecture}

The principal characteristic of a seafloor observatory is a two-way communication between platforms and instruments and shore. During the 
last 30 years deep-sea investigations moved from scarce observations to continuous measurements of a wide set of parameters in selected areas. Until the 1980s, deep-sea investigations relied on autonomous bottom landers, in the middle of the 1980s they were based on deep manned submersibles (table II). Starting from the 1990s, the concept of benthic stations and (relocatable and long-term) seafloor observatories appeared (Person et al., 2006). Seafloor observatories are characterised by the following basic elements: a) multiple payload; b) autonomy; c) capability to communicate; d) possibility to be remotely reconfigured; e) accurate positioning; f) data acquisition procedures compatible with those of shore observatories. It is also useful to introduce some definitions:

1) Seafloor observatory is an unmanned station, capable of operating in the long-term on the seafloor, supporting the operation of a number of instrumented packages related to various disciplines. Seafloor observatories can have as possible configurations: autonomous, acoustic linked and cabled.

Autonomous - Observatory in stand-alone configuration for power, using battery packs, and with limited capacity of connection, using, for instance, capsules or an acoustic link from the surface, which can transfer either status parameters or a very limited quantity of data.

Table II. Deep-rated ROVs (R) and manned submersibles (S) for research purposes (operation depth greater than 2000 m) (e.g., NRC, 2000; Romanowicz et al., 2001; Sagalevitch, 2004).

\begin{tabular}{lcccc}
\hline \hline Vehicle & Type & Depth rating $(\mathrm{m})$ & Support research vessel & Operating institution \\
\hline Pisces IV & $\mathrm{S}$ & 2000 & Ka'imikai-o-Kanaloa & NOAA \\
Pisces V & $\mathrm{S}$ & 2000 & Ka'imikai-o-Kanaloa & NOAA \\
Shinkai 2000 & $\mathrm{~S}$ & 2000 & Natsushima & JAMSTEC \\
Aglantha & $\mathrm{R}$ & 2000 & Opportunity & IMR \\
Cyana & $\mathrm{S}$ & 3000 & Opportunity & IFREMER \\
Dolphin 3K & $\mathrm{R}$ & 3000 & Natsushima & JAMSTEC \\
Hyper-Dolphin & $\mathrm{R}$ & 3000 & Kaiyo & JAMSTEC \\
Little Hercules & $\mathrm{R}$ & 4000 & Opportunity & IFE \\
Hercules & $\mathrm{R}$ & 4000 & Opportunity & IFE \\
Quests & $\mathrm{R}$ & 4000 & Opportunity & MARUM \\
MODUS $\left.*^{*}\right)$ & $\mathrm{R}$ & 4000 & Opportunity & TUB \\
Tiburon & $\mathrm{R}$ & 4000 & Western Flyer & MBARI \\
Alvin & $\mathrm{S}$ & 4500 & Atlantis & WHOI \\
ROPOS II & $\mathrm{R}$ & 5000 & Opportunity & CSSF \\
Nautile & $\mathrm{S}$ & 6000 & Nadir/La Thalassa & IFREMER \\
Victor 6000 & $\mathrm{R}$ & 6000 & L'Atalante/La Thalassa & IFREMER \\
Mir-1 & $\mathrm{S}$ & 6100 & Akademik Keldysh & Shirshov Institute \\
Mir-2 & $\mathrm{S}$ & 6100 & Akademik Keldysh & Shirshov Institute \\
Jason II & $\mathrm{R}$ & 6500 & Atlantis/opportunity & WHOI \\
Shinkai 6500 & $\mathrm{~S}$ & 6500 & Yokosuka & JAMSTEC \\
Isis & $\mathrm{R}$ & 6500 & Opportunity & NOC \\
UROV7K & $\mathrm{R}$ & 7000 & Kairei & JAMSTEC \\
Kaiko $(* *)$ & $\mathrm{R}$ & 11000 & Kairei & JAMSTEC \\
\hline (*) & $\mathrm{Pr}$ & & &
\end{tabular}

$\left({ }^{*}\right)$ Primarily designed for GEOSTAR; $\left({ }^{* *}\right)$ lost in 2003. 
Acoustically linked - Observatory able to communicate by acoustics to an infrastructure, such as a moored buoy or another observatory.

Cabled - Observatory having as infrastructure a submarine cable (retired cables, dedicated cables or shared cables devoted to other scientific activities, such as neutrino experiments).

2) Infrastructure is any system providing power and/or communications capacity to an observatory (e.g., a submarine cable, a moored buoy, another observatory); an infrastructure may also serve as support for other instrumented packages.

3) Instrumented package is a sensor or instrument devoted to a specific observation task; it may be hosted inside the observatory, be operated autonomously, be directly connected to an infrastructure or be placed near an observatory and interfaced to it (thus having the observatory as its infrastructure).

The technological issues regarding longterm observatories versus temporary stations are quite similar. However, the technological developments are largely dependent on the period of operation of the station; a long-term observatory is much more difficult to maintain than a temporary ocean bottom station, due to the problems of power supply, failures in data retrieval and transmission, and corrosion and bio-fouling. Long-term observatories can be used as reference stations and as nodes for short-term experiments with a dense coverage of stations (Montagner et al., 2002). These temporary arrays, for instance of $\mathrm{OBS} / \mathrm{H}$, are needed to study seismicity in particular areas. Many experiments have already demonstrated the importance of integrating OBS/OBH with landbased seismic stations or of using a dense array of $\mathrm{OBS} / \mathrm{OBH}$, thereby greatly improving the quality of results (e.g., Hino et al., 1996; Dahm et al., 2002; Montuori, 2004; Shinohara et al., 2004; Barberi et al., 2006; Sgroi et al., 2006). This approach is completely different from the long-term seafloor observatories: it is a sort of mobile network for specific experiments similar to terrestrial ones. The OBS/OBHs are normally deployed in a free-falling mode, and this introduces an uncertainty in the positioning, in the orientation of the three components, and in the coupling of sensors with the seabed. De- pending on the sampling rate, they also have a limited autonomy. Moreover, there is no control of the instrument while it is on the seafloor. Only a posteriori, after recovery with a pop-up system, is it possible to discover if the sensor has worked correctly and to recover the collected data. For studying local seismicity deployments of a few months are sufficient. On the contrary for global tomographic studies 1-2 year deployments are preferable (Bialas et al., 2002).

At present, there are two ways to provide two-way connection: using either a cabled or an acoustic link (e.g., Stojanovic, 1996; Sozer et al., 2000) from the seafloor to a surface buoy that communicates via satellite and/or radio to shore, or using submarine electro-optic cables linked directly to a shore station. The links through cables can be made using either new cable deployments or decommissioned cables (e.g., Nagumo and Walker, 1989). On the other hand, individual nodes established for various scientific purposes can differ in size, complexity, scientific instrumentation, and technical capabilities in order to balance overall network objectives and cost. The actual designs must be driven by science needs. Standardisation is one of the key issues.

Another important issue is to have proper marine logistics for the management of fixed seafloor observatories (ships and ROVs) and joint use of AUVs able to extend the capabilities of mapping and sampling. Other important requirements for establishing a seafloor observatory network are sensors, power and data telemetry. Although many sensors are currently available for underwater use, there is a lack of new sensors, especially for long-term use in the deep-sea environment. One of the most crucial aspects of the seafloor observatory is to furnish and to maintain the necessary power, especially in the autonomous mode. Finally, there are concerns related to data telemetry and management. The energy and telecommunications industries can be involved in many aspects of ocean observatories, from supplying the cables, buoys, and instruments for observatory infrastructure to the ships, ROVs, and support services needed to maintain and operate this infrastructure over the long term (NRC, 2003a). 


\subsection{Autonomous observatories}

This type of observatory is characterised by a stand-alone configuration. Therefore they are powered by battery packs and their autonomy depends on the battery capacity, but lifetimes are typically at least one year. The connection between the seafloor autonomous observatory and the surface is provided through releasable data capsules able to send information on the status of the observatory and a limited quantity of data. Acoustic systems constitute another possibility to provisionally link the seafloor observatory to the surface. These systems are composed of an underwater transducer and acoustic modem, and a surface transducer and surface acoustic unit. Examples are, for instance, the Japanese «mobile seafloor observatory» equipped with data capsules (Momma et al., 2001), GEOSTAR when using the Messengers (Beranzoli et al., 1998, 2000a,b; Marvaldi et al., 2002), or SN-1 and MABEL in experiments where they can be interrogated acoustically from the surface (see Section 4.5).

\subsection{Acoustically linked observatories}

These observatories can have long-term acoustic links either with a moored buoy or another observatory as a node of an underwater network, as in the ORION-GEOSTAR-3 project. In the first option the observatories transmit data to a surface buoy acting as a central communication node, with a satellite and/or direct radio link to shore. This surface buoy is anchored to the seafloor and communicates with the sub-sea nodes acoustically or via an electrical or fibre-optic cable. In contrast to cabled observatories, moored-buoy systems are generally less expensive to install, but the trade-off is a greatly diminished data bandwidth and reduced power availability. Data transfer rate, power consumption, and system stabilisation requirements are all interdependent, but it is possible to obtain high data transfer rates in balance with power and buoy stability. Some satellite systems, because of the need to use a directional antenna, impose strict stability requirements on the surface buoy $(<10$ degrees per second in pitch, roll and yaw). Satellite communications can also consume substantial power. Data transfer requirements range from less than 1 to up to $100 \mathrm{~kb} / \mathrm{s}$. In order to prevent disruption to the time-series data sets, a back-up communication system should be included in the design. Furthermore, the system must have the capacity to store data.

Moored-buoy systems will need to be engineered for deployment in different environments, including those at high latitudes. Deployment location will greatly impact mooring design due to variations of sea state, wind velocity, ocean and air temperatures, water depth and satellite coverage. Furthermore, other factors have to be taken into consideration, such as the suitability of solar panels at high latitudes, potential for vandalism and visibility of the mooring in shipping lanes. It is estimated that, at present, the average maintenance interval for a moored-buoy observatory will be about 12 months.

\subsection{Cabled observatories}

Cabled seafloor observatories use undersea communications cables to supply power, communications, and command and control capabilities to scientific monitoring equipment at nodes along the cabled system (e.g., Chave et al., 2004, 2006). Each node can support a range of devices that may include an AUV docking station. Cabled systems will be the preferred approach when power and data telemetry requirements are great. Early generation commercial optical undersea cables that are soon to be retired will have the communications capacity, but will possibly have insufficient power capability. If these cables are suitably located for seafloor observatory research, their use could reduce the need for expensive new cables. More than $35000 \mathrm{~km}$ of electro-optical telecommunications cables on the ocean floor will be retired in-place by the industry within the next few years, and more are likely to follow during ensuing years (NRC, 2003a). There are many good examples of the re-use of retired cables, such as H2O, GeO-TOC and VENUS (JP) (see Sections 4.2 and 4.3 for details). 
The major components of a cabled observatory are: a) shore station (containing high-power and -voltage, direct-current generation, network and science experiment management); b) undersea cable (containing optical fibres and power conductors); c) undersea observatory nodes (containing power conditioning, network and science experiment management, and standardised interfaces); d) network and science experiment command and control, and communications systems; e) specific sensors and AUVs.

The current generation of commercial optical cables can satisfy all the seafloor observatory data requirements for long (greater than approximately $300 \mathrm{~km}$ ) and short systems. These cables can provide data transfer rates on the order of $500 \mathrm{~Gb} / \mathrm{s}$ per fibre pair. Undersea mateable connectors are currently available. But substantial engineering development will be required for the design and packaging of the power conditioning, network and science experiment management to be placed at the observatory nodes. In order to meet the necessary spec- ification for high system-operational time, low repair costs, and overall equipment lifetime, significant trade-offs will have to be considered between the use of commercially available and custom-built equipments.

\subsection{Ships, ROVs and AUVs}

Ships must have suitable characteristics to execute sea operations related to seafloor observatories, particularly dGPS, navigation system and DP, and adequate A-frame and handling systems. For instance, medium size vessels, like the Italian R/V Urania owned by CNR (fig. 1), have already demonstrated the feasibility of managing seafloor observatories such as GEOSTAR-class observatories in the Mediterranean and in the deep-sea (over $3000 \mathrm{~m}$ w.d.).

The use of vehicles, like ROVs and AUVs, is complementary to seafloor observatories. ROVs are likely to play an important role in installing, servicing, and repairing seafloor observatories,

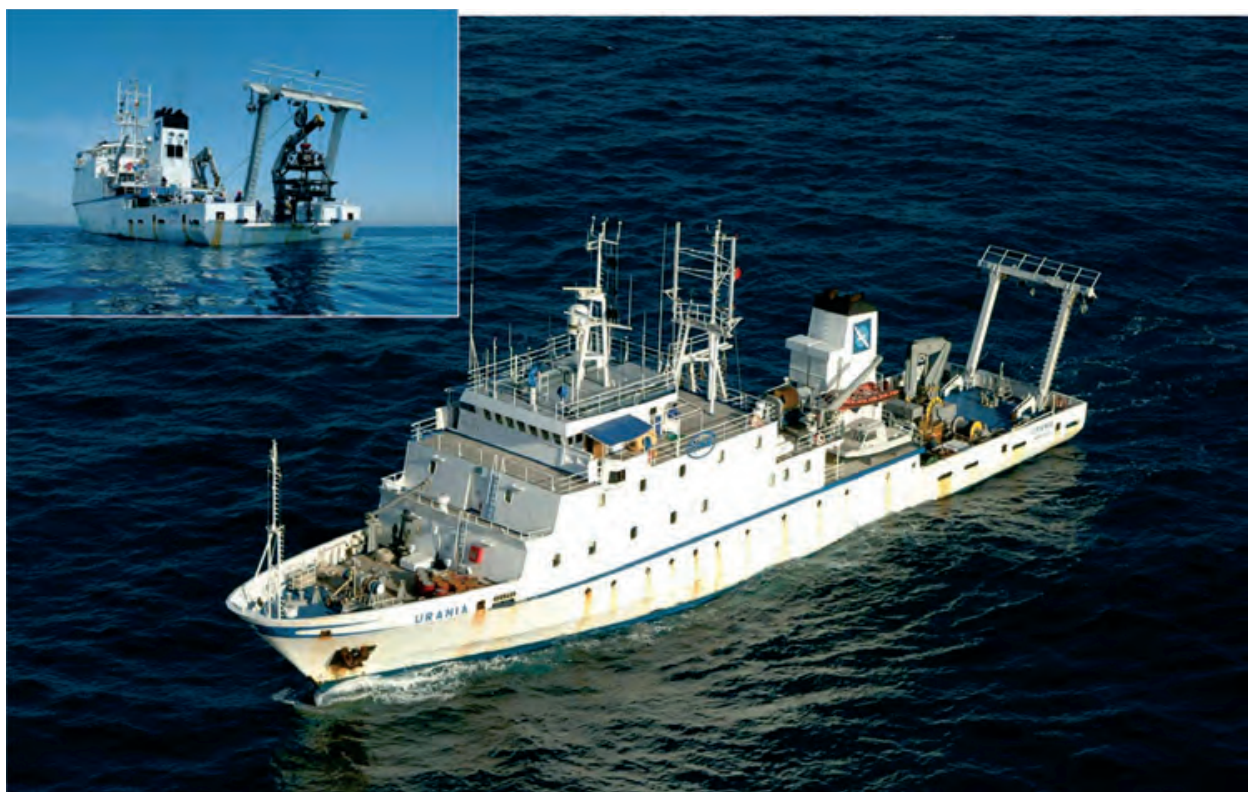

Fig. 1. R/V Urania, a medium-size vessel (overall length: $61 \mathrm{~m}$; gross tonnage: $1100 \mathrm{t}$ ) owned by CNR and managed by SoProMar. The top-left corner shows the ship during the launch of a GEOSTAR-class observatory. 
even if the payload is limited to a few hundred kilos. ROV technology is available with a wide range of capabilities and has been advancing, both within the oceanographic community and industry. The largest pool of ROVs is in the offshore industry, but their depth rating normally does not exceed $2000 \mathrm{~m}$ (3000 m in a few cases). Presently only ROVs specifically developed for scientific applications have depth ratings exceeding $3000 \mathrm{~m}$ (see table II). In fig. 2 the French ROV Victor 6000 is shown as an example. Some common uses for ROVs include: a) high-resolution site mapping (seafloor maps are important for site preparation prior to the seafloor observatory installation; towed vehicles are routinely used for these surveys, but ROVs and AUVs capable of flying precision tracks produce the highest quality maps); b) installation of instrumentation; c) servicing installed instrumentation (instrumentation positioned at depth can experience biofouling or short-term failures); d) servicing node components; e) plugging and unplugging platforms and instruments; f) burying cables and sensors. The oce-

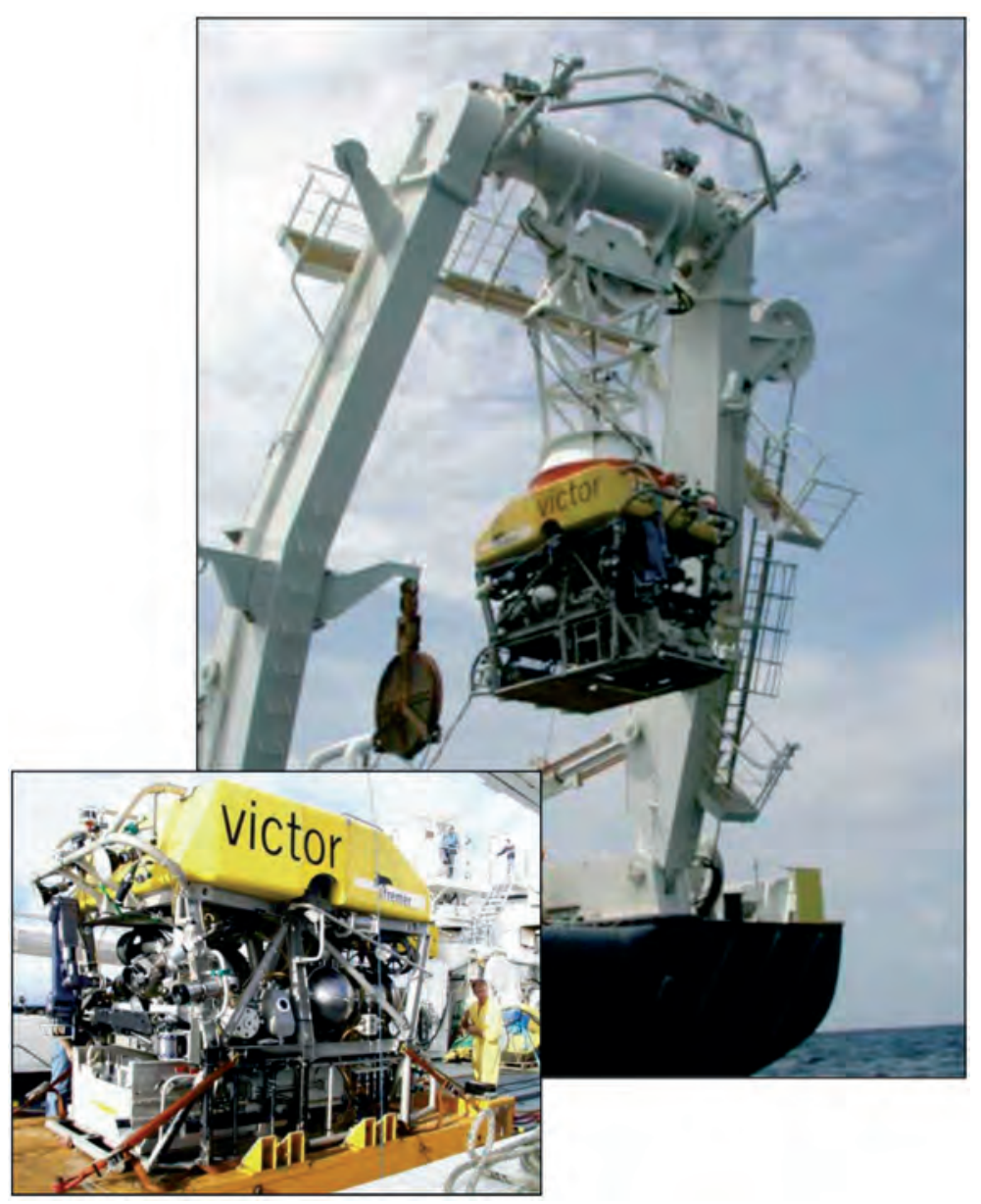

Fig. 2. The French deep-rated ROV Victor 6000 built and managed by IFREMER (see also table II). A detailed view of the ROV is shown in the bottom-left corner. 
anographic community has already demonstrated the use of ROVs in aspects of observatory work, such as Scripps at OSN-1, WHOI for H2O and MBARI for work in Monterey Bay (see Section 4.2).

AUVs have the potential to undertake a variety of mapping and sampling missions while using fixed observatory installations to recharge batteries, off-load data and receive new instructions. A major use for AUVs will be to map seafloor and water-column properties and to document horizontal variability. Another use will be to extend the spatial observational capability of seafloor observatories. Scenarios for employing AUVs as elements of seafloor observatories envision small vehicles, weighing at most a few hundred kilos, with docking capabilities. Vehicle endurance is dictated by survey speeds (typically about $5 \mathrm{~km} / \mathrm{h}$ ) and power consumption by onboard computer and sensor payload. General goals of AUV missions include: a) seafloor mapping (AUVs operate very close to the seafloor and they can collect high-resolution, high-accuracy mapping data, in addition to other geophysical parameters, such as bathymetry and magnetics); b) water-column mapping (AUVs provide the capability to map physical and chemical parameters, horizontally, vertically or in three-dimensions); c) measuring fluxes (AUVs provide this capability at specific locations); d) initialising and constraining models (AUVs are capable of obtaining the physical parameters needed). Recently, the oil and gas industry has demonstrated a growing interest in AUVs for deep-water surveys driven by the combination of the move of off-shore drilling to greater water depths and the increasing maturity of AUV capabilities.

\subsection{Scientific instrumentation}

A wide variety of sensors are already available for undersea research, and there are many instruments that are being deployed for long durations (e.g., thermistors, seismometers, hydrophones and current meters). There are also several types of samplers available for the collection of fluids and biological samples that require shore-based analysis. Many of these sensors and samplers are not suitable for long-term deployments for a variety of reasons (e.g., instability of chemical reagents, sensitivity to biofouling, or loss of calibration). It is clear that development of new sensors will be critical in order for seafloor observatories to be fully effective. Sensor technology (e.g., in chemistry and biology), especially for long-term use in the deep-sea, is not sufficiently advanced to take advantage of the seafloor observatory infrastructure. In addition, enhancements of existing sensors are necessary for unattended operations for a long time. The general requirements for new sensors or for enhanced types are: low power consumption, longterm stability, standard interface and adequate choice of materials. If an ocean observatory infrastructure is to be established, it will be necessary to make substantial parallel investments in sensor technology (e.g., Brewer et al., 2002, 2004) or packages, for example SEABASS developed as a VLF system $(2-50 \mathrm{~Hz})$ to study ambient noise at and below the seafloor (Stephen et $a l .$, 1994), SAPPI an autonomous pore-pressure instrument (Kaul et al., 2004), hydrophone arrays for measuring ocean temperature (ATOC project; Dushaw et al., 1999) or geodetic measurements using both GPS and acoustics (Spiess et al., 1998; Gagnon et al., 2005a,b). Much effort has been made to develop prototypes in parallel with the activities of the EC GEOSTAR and related Italian projects (see Sections 4.4 and 4.5). Each sensor has its own requirements for correct installation and data acquisition in terms of sampling rate (see Favali et al., 2006). An important issue is the synchronisation of all the sensors. It can greatly help to understand better the mutual relationship among different processes when one is comparing data sets acquired by accurately synchronised sensors. This is particularly true for seismometers, where the required clock stability is $<10^{-9} \mathrm{~s}$. Another important issue for seismometers is how to minimise the level of noise recorded in different frequency bands (depending on the noise sources), so as to keep within the high and low background noise reference models (Peterson, 1993). Different modes of sensor installation and of «cleaning» the seismological data using other types of instruments sampled at high rates (like current meters and/or DPGs) are the tools used for minimising noise (e.g., Stakes et al., 
1998a; Webb, 1998; Webb and Crawford, 1999; Crawford and Webb, 2002; Monna et al., 2005; Shinohara et al., 2006).

A challenge for any observatory data management structure will be the processing, distributing and archiving of the large data sets produced (e.g., Momma et al., 2001). A fully integrated plan for data handling should be developed in the early stages for any seafloor observatory programme. Redundancy must always be built in.

\subsection{Technology for power supply}

Power supply is one of the most critical aspects in seafloor observatories, especially those in stand-alone configurations. At present, for these applications primary lithium batteries are normally used, as in GEOSTAR-class observatories (see Section 4.4). This type of battery easily supports multidisciplinary experiments for more than one year. Efforts must be made to develop new sources of energy (e.g., fuel cells) and to design systems that are re-chargeable from the surface using the surface buoy as primary source, or substituting battery packs on the seafloor systems by ROVs.

For a cabled observatory, the power aspects are less critical, but significant engineering development will be necessary to provide sufficient power and to adapt the power transmission schemes used in the sub-sea telecommunications industry. The following developments in seafloor power hardware will be required: a) design of specific direct-current conversion hardware with the required reliability; b) provision of a workable thermal environment for the power conditioning, network and science experiment management (the physical design of the thermal paths from the electronics to seawater need to be carefully engineered); c) the physical power path to the observatory will need to be designed so as to minimise the probability and effects of corona discharge; d) the configuration and hardware for power surge protection need to be designed to provide a fault-tolerant observatory network. These scenarios could be quite complex for an observatory with many nodes and more than one shore station.

\section{World-wide past and ongoing experiments}

The scientific benefits of establishing a seafloor observatory network for geophysical, oceanographic, climatological and meteorological investigations have been recognised for many years. Following the pioneering efforts in the 1960s (Sutton et al., 1965), the importance of filling the existing gaps in the global landbased networks (particularly in the network of seismic and geomagnetic stations) by using seafloor observatories has been recognised (e.g., Purdy and Dziewonski, 1988; Montagner and Lancelot, 1995; Lowes, 2002). Since the 1990s, many important workshops have been organised outlining long-term scientific strategies for the use of observatories: for instance, the three «International workshops on the scientific use of submarine cables» organised in 1990 in Honolulu (Chave et al., 1990), in 1997 in Okinawa (Utada et al., 1997) and in 2003 in Tokyo (Kasahara and Chave, 2003), the international conference «Science-Technology Synergy for Research in Marine Environment: Challenges for the XXI Century» held in Erice (Sicily) in 1999 (Beranzoli et al., 2002), the «Symposium on Seafloor Observatories» held in 2000 in Islamorada (Florida), the OHP/ION Joint Symposium «Long-term observations in the Oceans» in Yamanashi (Japan) (Romanowicz et al., 2001) and OCEANS'04 in Kobe (Yada et al., 2004).

This section aims at reviewing all the relevant past and ongoing experiments, projects and programmes on seafloor observatories in a world-wide context. Table III lists the twentyeight seafloor observatories validated through long-term missions at sea.

\subsection{International}

\subsubsection{Experiments and projects}

CORKs - From 1991 to 1997 ODP installed 13 long-term hydrogeological observatories (CORKs) to study fluid flow processes in situ in two flow regimes: sedimented young oceanic crust and accretionary prisms (e.g., Davis et al., 1992; Becker et al., 1998; Becker and Malone, 
Table III. Twenty-eight seafloor observatories validated at sea; A: autonomous; AL: acoustic linked; C: cabled.

\begin{tabular}{|c|c|c|c|}
\hline Name & Type & Starting year & Country \\
\hline JMA - Omaezaki & $\mathrm{C}$ & 1978 & Japan \\
\hline JMA - Off-Boso & $\mathrm{C}$ & 1985 & Japan \\
\hline JAMSTEC - Off-Hatsushima & $\mathrm{C}$ & 1993 & Japan \\
\hline ERI - Off-Ito City & $\mathrm{C}$ & 1994 & Japan \\
\hline ERI - Off-Sanriku & $\mathrm{C}$ & 1995 & Japan \\
\hline NIED - Hiratsuka & $\mathrm{C}$ & 1995 & Japan \\
\hline LEO-15 & $\mathrm{C}$ & 1996 & U.S.A. \\
\hline GEO-TOC & $\mathrm{C}$ (re-used) & 1997 & Japan \\
\hline HUGO & $\mathrm{C}$ & 1997 & U.S.A. \\
\hline JAMSTEC - Off-Muroto Peninsula & $\mathrm{C}$ & 1997 & Japan \\
\hline MOISE & A & 1997 & U.S.A. \\
\hline NeMO & AL (buoy) & 1997 & U.S.A. \\
\hline $\mathrm{H} 2 \mathrm{O}$ & $\mathrm{C}$ (re-used) & 1998 & U.S.A. \\
\hline Mobile seafloor observatory & A & 1998 & Japan \\
\hline JAMSTEC - Off-Kushiro-Tokachi & $\mathrm{C}$ & 1999 & Japan \\
\hline VENUS (JP) & $\mathrm{C}$ & 1999 & Japan \\
\hline GEOSTAR & AL (buoy) & 2000 & EU \\
\hline MVCO & $\mathrm{C}$ & 2000 & U.S.A. \\
\hline NEREID-1 & $\mathrm{A}$ & 2000 & Japan \\
\hline NEREID-2 & $\mathrm{A}$ & 2000 & Japan \\
\hline WP-2 & $\mathrm{A}$ & 2000 & Japan \\
\hline WP-1 & A & 2001 & Japan \\
\hline MOBB & $\mathrm{A}$ & 2002 & U.S.A. \\
\hline ORION-GEOSTAR-3 (Node 3) & AL (observatory) & 2003 & EU \\
\hline ORION-GEOSTAR-3 (Node 4) & AL (observatory) & 2003 & EU \\
\hline ASSEM (4 nodes) & AL (buoy) & 2004 & EU \\
\hline GMM & $\mathrm{C}$ & 2004 & EU \\
\hline $\mathrm{SN}-1-\mathrm{NEMO}(*)$ & $\mathrm{C}$ & 2005 & Italy-EU \\
\hline
\end{tabular}

(*) SN-1 was used in autonomous configuration in 2002.

2001). These observatories involve sealing a borehole at the throat of the re-entry cone with a sensor string suspended in the hole. A longterm data logger is positioned so as to be accessible by a submersible on the seafloor for periodic data transfer and re-programming. International initiatives like SEIZE, funded within the NSF programme MARGINS, can greatly benefit from permanent observatories including seafloor seismic and fluid flow, and borehole monitoring devices. CORKs can provide a realtime record of sub-surface transient events in temperature, pressure and water chemical data. SEIZE was developed to study the shallow subduction zone interface that is locked and accumulates elastic strain which is periodically released in large or great earthquakes, often tsunamigenic (MARGINS, 2003).

DSDP Legs 52, 88 and 91, and ODP Leg 128 - Borehole seismology was introduced to ocean drilling on DSDP Leg 52 in 1976-1977 at Site 417 in the Atlantic Ocean (Stephen, 1978; Stephen et al., 1980a,b); then on DSDP Leg 88 
in 1982 at Site 581 in the Pacific Ocean with the emplacement of a seismometer built by the Hawaii Institute of Geophysics (Duennebier et al., 1987); and finally on DSDP Leg 91 in 1983 at Site 595 in the Pacific Ocean, during the Ngendie programme (Adair et al., 1987; Jordan et al., 1987). In all cases the Glomar Challenger vessel drilled a cased hole.

In September 1989, a feedback-type accelerometer capsule was installed in Hole 794D in the Japan Sea during ODP Leg 128 (Ingle et al., 1989; Suyehiro et al., 1995). The instrument recorded a teleseismic event $\left(m_{b} 5.4\right.$ at about 4000-km epicentral distance) that clearly showed a surface wave dispersion train (Tamaki et al., 1992).

Technologies for re-entering boreholes with observatory style sensors have played a vital role in the evolution of the seafloor observatory concept. These include the IFREMER Nadia systems (versions 1 and 2) (Legrand et al., 1989; Gable, 1992) and the SIO wireline re-entry system (Spiess et al., 1992; Stephen et al., 1994; Becker et al., 2004).

NERO (ODP Leg 179) - ODP Leg 179 in April-June 1998 set out with two primary objectives (Pettigrew et al., 1999). One of these was to prepare the NERO site where researchers could establish a GOBO as part of the future network of seafloor observatories proposed in the ION programme, drilling a cased re-entry hole into basaltic basement on the Ninety East ridge. This objective specifically included drilling a single hole as deep as possible into the basement, and installing a re-entry cone and casing beyond basement to prepare for the future installation of the observatory. The depth of penetration below the seafloor $(493.8 \mathrm{~m})$ in a water depth of $1648 \mathrm{~m}$ as well as the firm attachment of casing to the basement, should isolate the instrument from noise. Geophysical observatories currently operating world-wide share a common attribute and shortcoming in that they are only emplaced on continents or islands. Since the world's oceans cover more than two-thirds of the planet's surface, the coverage given by observatories on oceanic islands is incomplete. Installation of a downhole observatory at this location in the East Indian Ocean will fill one of the major gaps in global seismic monitoring coverage. The NERO project is a joint initiative among JAMSTEC, IFREMER and IPGP.

ODP Leg 186 - Two borehole geophysical observatories were installed (about $1100 \mathrm{~m}$ below the seafloor) in August 1999 on the deepsea terrace of the Japan Trench during ODP Leg 186 at Site 1150 (NEREID-1; 39 $11^{\prime} \mathrm{N}$, $143^{\circ} 20^{\prime} \mathrm{E}$ ) and at Site 1151 (NEREID-2; $38^{\circ} 45^{\prime} \mathrm{N}, 143^{\circ} 20^{\prime} \mathrm{E}$ ) (Sacks et al., 2000). The sites are located in areas with contrasting seismic characteristics. The northern site is within a seismically active zone where microearthquakes are frequent and $M 7$ earthquakes recur. The southern site is within an aseismic zone where no microearthquakes are observed. These features coexist within the seismogenic zone of the Japan Trench plate subduction zone, where the $>100$-Ma portion of the Pacific plate is subducting at a fast rate $(\sim 9 \mathrm{~cm} / \mathrm{yr})$ beneath Northern Japan causing major earthquakes along the trench. Leg 186 is the first scientific venture to succeed in installing state-of-the-art strain, tilt, and seismic sensors for long-term operation in seafloor boreholes. The systems started collecting data in September 1999. These stations make invaluable additions to the existing geophysical network over the Western Pacific. This type of multiple-sensor seismo-geodetic observatory can now be emplaced by the JOIDES Resolution drilling vessel in many other areas where active processes wait to be monitored. Although not always the case, normal coring objectives and observatory objectives often overlap and are interrelated as in this leg or recent CORK legs. Once an observatory is established, ways and means to recover the data and to keep the station running become necessary. Such tasks are not easily undertaken even if a site only needs servicing once a year. A new fibre-optic cable owned by the University of Tokyo already exists and currently terminates near Site 1150. Once Site 1150 proves to be functioning, connections will be made to supply power, send commands, and retrieve data in real time on land. Furthermore, a $50-\mathrm{km}$ cable extension is planned to connect Site 1151 as well. The borehole geophysical observatories at 
Sites 1150 and 1151 greatly improve source location (particularly depth) and focal mechanism and rupture process determinations for earthquakes near the Japan Trench (Nishizawa et al., 1990, 1992; Suyehiro and Nishizawa, 1994; Hino et al., 1996). Near-field data, obtained from these observatories with the aid of ocean bottom seismographs, will particularly improve the resolution of source mechanisms for very slow rupture events such as tsunami earthquakes (Hino et al., 2001; Hirata et al., 2003), or tsunamis generated by submarine landslides (e.g., Driscoll et al., 2000), contributing to better constraint simulation (e.g., Ohmachi et al., 2001).

ODP Leg 191 - ODP Leg 191 (July-September 2000) had two main goals: to drill and case a borehole at a site in the north-west Pacific Ocean between Japan and the Shatsky Rise and to install therein a borehole seismic observatory (Kanazawa et al., 2001). The seismic observatory was successfully installed at Site 1179 (called WP-2) and left ready for activation by a future ROV cruise. A high priority for ION has been to install a station beneath the deep seafloor of the north-west Pacific to gain a better understanding of regional earthquake patterns and to enhance tomographic images of the Earth's interior. The seismometer augments a regional network consisting of land stations in Eastern Asia, Japan, and the Western Pacific islands and borehole seismometers installed during ODP Leg 186 (Sacks et al., 2000) and planned at that time for ODP Leg 195 (see below). Owing to its location, the Site 1179 seismometer will provide critical seismic observations from the seaward side of the Japan Trench. The objective is to understand the processes driving Earth's dynamic systems from a regional to a global scale by imaging the Earth's interior with seismic waves. Unfortunately, few seismometers are located on the $71 \%$ of the Earth's surface covered by oceans. The asymmetry and non-uniformity of seismic station distribution makes high-resolution imaging of some parts of the mantle nearly impossible. Ocean-bottom seismometers are needed to accomplish the goals of international geoscience programmes that use earthquake data.
Downhole instruments for these Western Pacific borehole observatories have been developed under the ongoing Japanese OHP programme (see Section 4.3). Aside from plugging an important gap in the global seismic array, the Site 1179 observatory produces high-quality digital seismic data (Shinohara et al., 2006). Tests with other borehole seismometers show that the background noise level for oceanic borehole instruments is much less than most of their counterparts on land (e.g., Stephen et al., 1999).

ODP Leg 195 - ODP Leg 195 (March-May 2001), among three distinct objectives, dedicated the first segment to coring and setting a longterm geochemical observatory (CORK) at the summit of South Chamorro seamount (Site 1200). The second segment was devoted to coring and casing a hole in the Philippines Sea abyssal seafloor (Site 1201) and the installation of broad-band seismometers for a long-term sub-seafloor borehole observatory (Salisbury et al., 2002). The drilling and observatory installation at Chamorro was designed to: a) examine the processes of mass transport and geochemical cycling in the subduction zones and forearcs of non-accretionary convergent margins; b) ascertain the spatial variability of slabrelated fluids in the forearc environment; c) study the metamorphic and tectonic history of non-accretionary forearc regions; d) investigate the physical properties of the subduction zones as controls over dehydration reactions and seismicity; e) investigate biological activity associated with subduction zones. A high-quality digital seismic observatory was therefore installed in the West Philippine Basin as an important component of the ION seismometer net. The observatory (called WP-1) allows more precise study of the seismic structure of the crust and upper mantle in the Philippine plate, as well as better resolution of earthquake locations and mechanisms in the north-west Pacific subduction zone. The observatory is designed as a stand-alone system with its own battery pack and recorder on the seafloor so that it can be serviced and interrogated by a ROV, like the borehole observatories installed at Sites 1150 and 1151. However, there is a coaxial TPC-2 cable near Site 1201 (Shinohara et al., 2006) 
and there are plans to connect data, control and power lines to this cable. This will also be done under the auspices of OHP (see Section 4.3).

ODP Leg 196 - Leg 196 was the second of a two-leg program of coring, logging, and installing ACORK long-term subseafloor hydrogeological observatories in the Nankai Trough, a convergent margin accreting a thick section of clastic sediments (Mikada et al., 2002). The Nankai subduction zone off southwest Japan forms an «end-member» sediment-dominated accretionary prism. The Philippine Sea plate underthrusts the margin at a rate of about $4 \mathrm{~cm} / \mathrm{yr}$ along an azimuth of $310^{\circ}-315^{\circ}$ (Seno et al., 1993) down an interface dipping $3^{\circ}-7^{\circ}$ (Kodaira et al., 2000), causing repeated great earthquakes (magnitudes $>8$ ) with an average recurrence interval of about 180 years (Ando, 1975). Although the role of fluid is thought to be a key factor in the study of seismogenic zones (Hickman et al., 1995), the magnitude and location of active fluid flow in this accretionary prism and the potential linkage to the Nankai seismogenic zone are not clearly defined. The investigation of this system motivated the deployment of long-term hydrogeological and geochemical monitoring systems. Leg 196 (May-July 2001) focused on logging while drilling and installing ACORKs at two sites (808 and 1173) near the toe of the Nankai prism.

ODP Leg 203 - The ODP Leg 203 science programme is part of a multidisciplinary project that primarily represents the interests of the NSF's component of the international DEOS ${ }^{(\mathrm{b})}$ planning effort, and ION (Orcutt et al., 2003). The Leg (May-July 2002) drilled a cased re-entry hole (Hole 1243A, OSN-2, $3882 \mathrm{~m}$ w.d. at $5^{\circ} 18^{\prime} \mathrm{N}, 110^{\circ} 4^{\prime} \mathrm{W}$ ) in the eastern equatorial $\mathrm{Pa}$ cific, the location of a future DEOS multidisciplinary observatory. The drill site was located in 10- to 12-Ma lithosphere. The hole was drilled to a total depth of $224 \mathrm{~m}$, which included $121 \mathrm{~m}$ of sediment and $103 \mathrm{~m}$ of basement penetration. Hole 1243A will subsequently be used to install an observatory-quality broadband three-component seismometer (0.001-5 $\mathrm{Hz})$ as well as a high-frequency three-component seismometer $(1-20 \mathrm{~Hz})$ to ensure high-fi- delity recording over the range of frequencies normally recorded by the terrestrial GSN. The seismic system, as well as other instrumentation associated with the observatory, will be connected to a DEOS ${ }^{(\mathrm{b})}$ mooring, for both power and high-speed data telemetry, to a land station and to the Internet. The equatorial site satisfies two scientific objectives of crustal drilling: a) it is located in one of the high-priority regions for the OSN and $\operatorname{DEOS}^{(\mathrm{b})}$; b) it is in oceanic crust created by fast seafloor spreading, providing a rare opportunity to examine crustal genesis, evolution, and crust/mantle interaction for a seafloor-spreading end-member responsible for generating the majority of the oceanic lithosphere. The drilling and establishment of a cased legacy hole at the remote equatorial $\mathrm{Pa}$ cific ION multidisciplinary observatory site provides an ideal location for the initial installation of a moored observatory. This site is one of the high-priority prototype observatories for the OSN (Purdy, 1995) (see Section 4.2).

ODP Leg 205 - Costa Rica is an important area for studies of the seismogenic zone and subduction factory for several reasons. Science objectives for Leg 205 (September-November 2002) had two primary foci, both related to seismogenic zone and subduction factory questions. The first was to determine the igneous and alteration history of the uppermost part of the downgoing plate at reference Site 1253. The second was to characterise and monitor two of the three hydrological systems: in basement at Site 1253 and along the décollement (or upper fault zone) at Sites 1254 and 1255 (Morris et al., 2003). These goals were accomplished by 1) targeted coring at selected intervals, 2) downhole temperature and pressure measurements, 3 ) logging at Site 1253, and (4) installation of long-term observatories (CORK-IIs) to monitor temperature and pressure and to sample fluids and gases in each of the hydrologic systems. Installation of long-term seafloor observatories was a major focus of Leg 205. Two boreholes were drilled on the Costa Rica subduction zone to study the geochemical fluxes and related processes. The holes (1253A and 1255A) were outfitted with modified CORKs (CORK-IIs) that include instruments capable of fluid sam- 
pling and measuring flow rates, temperature, and pressure (Jannasch et al., 2003).

\subsubsection{Programmes}

ION - The ION committee was established in June 1993 and the IASPEI executive committee granted it Commission status. It is an international association affiliated to IUGG (Romanowicz and Suyehiro, 2001). ION was formed to foster synergies among different disciplines, and to promote international co-operation in the development of critical elements of the seafloor observing systems, harmonisation of those elements of the system that would allow shared maintenance of the observatories and development of common plans for the use of international resources (e.g., GOOS, IODP). ION was originally created for the purposes of the seismological community; the seismic data from a WWSSN, established in the early 1960s, accelerated advances in seismology and were a great resource for new discoveries till the 1970s. During the past 15 years, our knowledge of the processes of the deep Earth has been greatly improved by the development of new generations of global monitoring networks in seismology and geodesy and by the continuation of long-term observations in geomagnetism (e.g., GEOSCOPE, IRIS, GeoFon, and MedNet). Improvements in the observatory locations for seismology, geodesy, and geomagnetism, particularly in the oceans, can greatly enhance our understanding of the Earth's interior. ION emphasises that «oceans are seismic deserts» (this also applies to geomagnetic observatories). Except for a few stations on oceanic islands, very large zones are unmonitored, particularly in the Pacific, South Atlantic, and East Indian Oceans. In 1995 participation in ION was enlarged to include the geoscience community, and in 2001 to include the oceanographic community. During its meetings ION has formulated recommendations, among the most important of which are: a multidisciplinary approach to ocean observatories is essential; extension of observing systems to the oceans is essential not only for solid Earth geosciences, but also in other disciplines such as biology. At the end of 2004 ION gained an inter-association status. Under its umbrella several experiments have been performed, among them MOISE and NERO, and many observatories installed in boreholes have been supported.

\subsection{U.S.A./Canada}

\subsubsection{Experiments and projects}

LEO-15 - The LEO-15 real-time cabled underwater observatory was established in August 1996 in $15 \mathrm{~m}$ of water $7 \mathrm{~km}$ off-shore of Great Bay (New Jersey). One of the major goals of LEO-15 is to develop a real-time capability for rapid environmental assessment and physical/ biological forecasting in coastal waters (Glenn et al., 2000). It provides communications and power for different instruments at many sub-sea nodes via a cable, and shore facilities. Continuous measurements made at each node are used to model and to aid biologists in their research into benthic communities and phytoplankton ecology (Traykovski et al., 1999; Howe et al., 2002; Schofield et al., 2002).

MVCO - Another coastal observatory (MV$\mathrm{CO}$ ) has recently been installed starting in 2000 by WHOI off the south coast of Martha's Vineyard (Massachusetts) to monitor coastal atmospheric and oceanic conditions (Edson et al., 2000; Austin et al., 2002). The observatory is able to provide scientists with direct access to the coastal environment and to allow continuous measurements of environmental parameters. Based on a telemetry system, the observatory has been designed to be in operation for a minimum of 25 years with minimal maintenance. Spare power conductors and optical fibres in the main cable provide for significant expansion capability for future nodes, AUV docking stations and other special experiments.

HUGO - The University of Hawaii developed the HUGO project, a seafloor observation system cabled to an on-shore station by means of a 47-km fibre-optic cable (Duennebier et al., 2002a). HUGO was installed in 1997 and aimed at creating a permanent multidiscipli- 


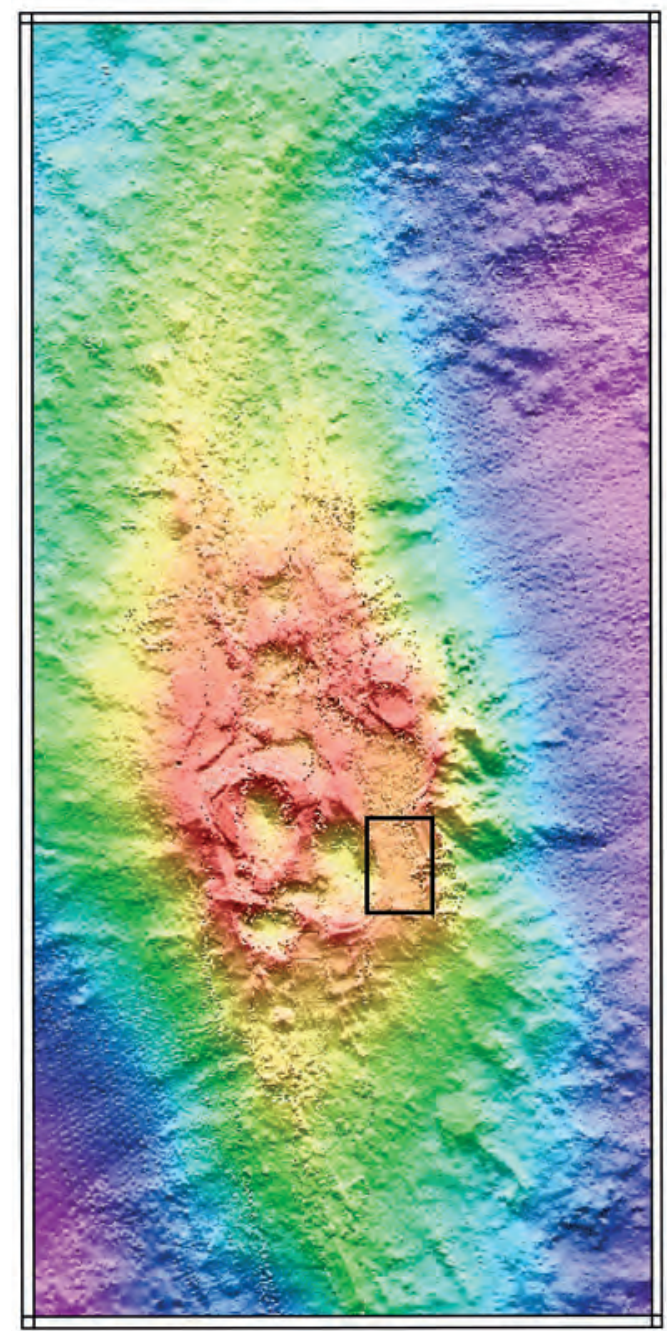

nary ocean-floor laboratory at the top of the Loihi submarine active volcano through the integration of marine electro-optical cables with existing sensor technologies (fig. 3). HUGO has the potential of supporting experiments from many disciplines, including volcanology, biology and geochemistry. The main components of HUGO are the shore station, supplying power to the observatory and recording data; the electro-optical cable; the junction box; the power distribution and data collection centre on Lahoi; multiplexing nodes and secondary dis-

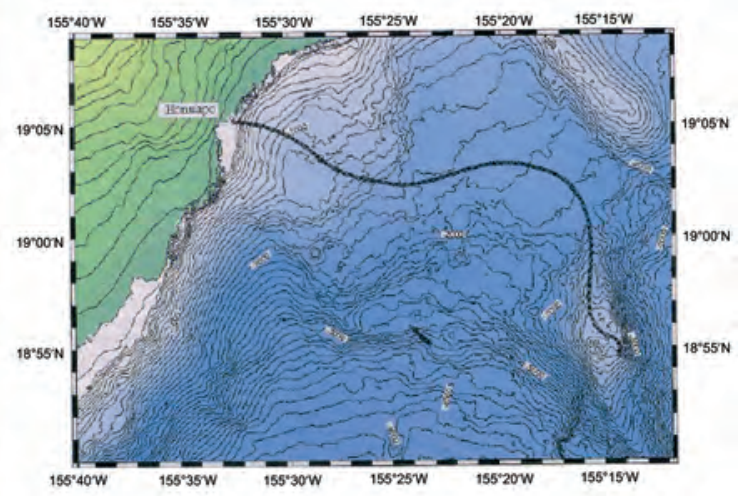

Fig. 3. A multibeam map of the summit of the submarine volcano Loihi (Hawaii) where the HUGO experiment was performed (rectangle). The route of the 47-km fibre-optic cable is shown on the right (Duennebier et al., 2002a).

tribution points. HUGO could potentially supply electrical power, command capability and real-time data services to more than 100 instruments connected to and removed from the ocean floor by submersible or ROV. Unfortunately in April 1998 the main HUGO cable developed a short circuit to sea water and a new cable must be obtained and installed. Despite the failure, this experiment accomplished several important tasks, among them the transmission of high-rate, high-fidelity data from the top of Loihi. 
$H 2 O$ - In mid 1998 a similar experiment was undertaken for the development of $\mathrm{H} 2 \mathrm{O}$ based on a retired commercial submarine telephone cable (Burns, 1999; Butler et al., 2000; Chave et al., 2002; Petitt et al., 2002). It consists of a cable termination and a junction box in $4979 \mathrm{~m}$ of water placed in the Eastern Pacific, roughly half-way between California and Hawaii $\left(141.6^{\circ} \mathrm{W}, 28.5^{\circ} \mathrm{N}\right)$. In fig. 4 a photograph of the junction box is shown, together with a map of its location and the route of the decommissioned cable used, an AT\&T telephone cable system that originally connected San Luis Obispo, California, and Makaha, on Oahu Island, Hawaii. Instruments are connected by means of a ROV to the junction box, which provides two-way digital communication at variable data rates and a total of about $500 \mathrm{~W}$ for both junction box systems and user equipment. There are two shallow buried seismometers $(\sim 1 \mathrm{~m}$ below the seafloor), consisting of a modified Guralp CMG-3T broad-band seismometer and a conventional $4.5 \mathrm{~Hz}$ three-component geophone (Duennebier et al., 2002b). This sensor has been transmitting seismic data to shore (Oahu) continuously and in real time for $>2$ years. The seismic data are forwarded to the IRIS Data Management Center in Seattle and are included in the GSN database for use in global and regional earthquake studies. To reduce the noise level significantly (Collins et al., 2001), it was decided in future to place the broad-band seismometer in a borehole. During ODP Leg 200 (December 2001-January 2002) a re-entry hole was drilled and cased into basement near the existing Hawaii-2 cable and the $\mathrm{H} 2 \mathrm{O}$ junction box in order to establish a longterm borehole geophysical observatory for continuous real-time seismic monitoring, as well as for other geophysical experiments. The longterm $\mathrm{H} 2 \mathrm{O}$ site satisfies three scientific objectives of crustal drilling: 1) it is located in one of the high-priority regions for the OSN; 2) its proximity to the Hawaii- 2 cable and the $\mathrm{H} 2 \mathrm{O}$ junction box makes it a unique site for realtime, continuous monitoring of geophysical, microbiological, and geochemical experiments in the crust; and 3) it is on fast-spreading Pacific crust $(71 \mathrm{~mm} / \mathrm{yr}$ half-rate) (Stephen et al., 2003a).

MOISE and MOBB - As part of the MBARI Margin Seafloor Experiment, conducted from 1996 through 1999, the MOISE experiment deployed a suite of geophysical and oceanographic instruments by means of the ROV Ventana ( $<2000 \mathrm{~m}$ operative depth) on the western side of the St. Andreas fault system off-shore of
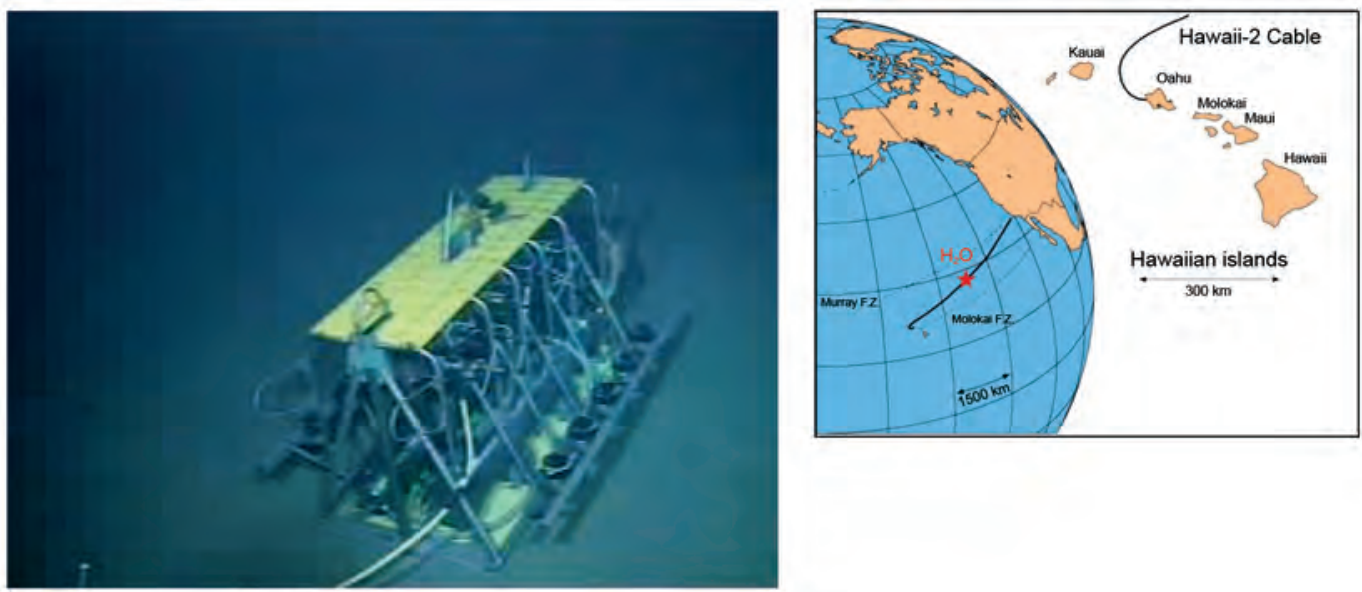

Fig. 4. The $\mathrm{H} 2 \mathrm{O}$ junction box (on the left). A map of the $\mathrm{H} 2 \mathrm{O}$ location and the route of the retired cable used is shown on the right (Chave et al., 2002). 


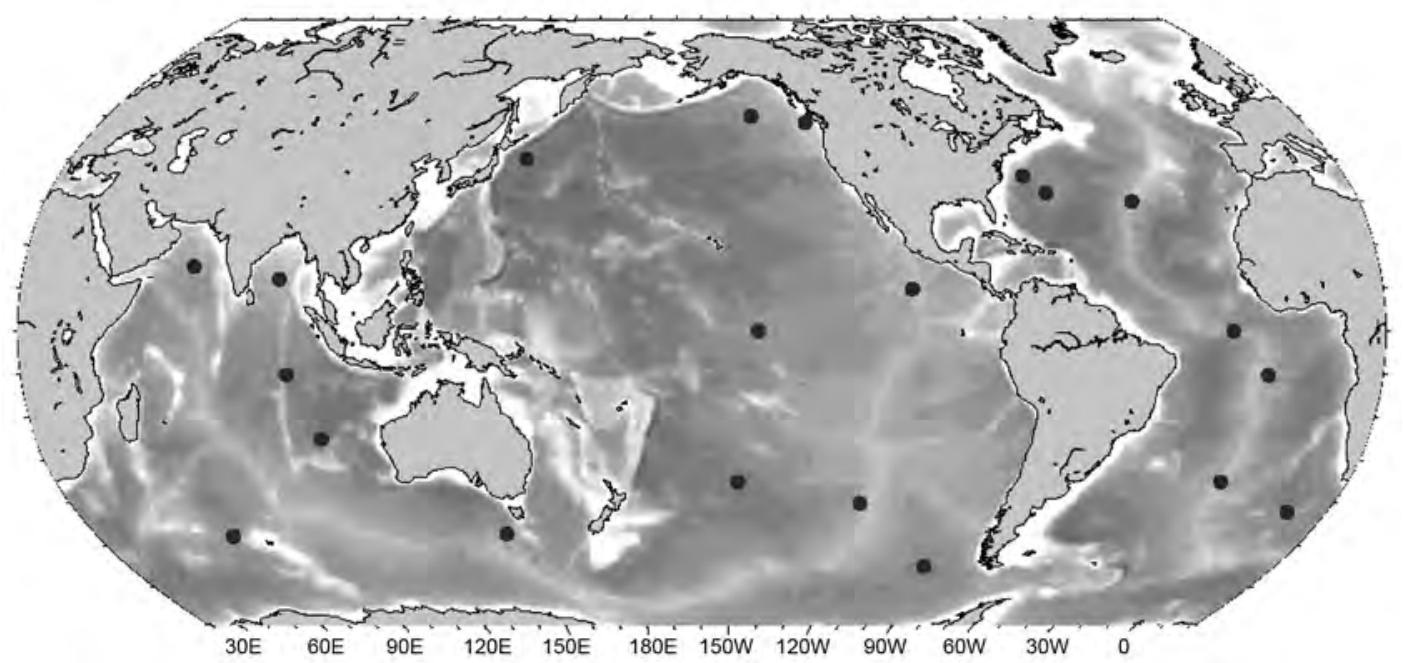

Fig. 5. Location of proposed OOI global observatory network sites (NRC, 2003a).

Central California. The experiment ran in autonomous mode at around $1000 \mathrm{~m}$ w.d. and collected three months of data in the summer of 1997, having developed a corehole seismometer for low-noise seismic data (Stakes et al., 1998a) to constrain continental margin seismicity by extending the seismic network to offshore sites (Begnaud and Stakes, 2000). Periodical ROV reconnection to MOISE's logger permitted data download from the sensor package (Romanowicz et al., 1998; Stakes et al., 1998b, 2002; Stutzmann et al., 2001). In April 2002, MBARI also installed MOBB at $1000 \mathrm{~m}$ w.d., $40 \mathrm{~km}$ off-shore, using a ROV, as a direct follow-up of MOISE. This observatory was buried and besides a broad-band three-component seismometer comprises a current meter and a DPG. The ultimate goal is to link MOBB by continuous telemetry to the shore, so that it becomes part of BDSN. This awaits the installation of the MARS cable (Romanowicz et al., 2003, 2006). In the next IODP Leg 312 (October-November 2005) an engineering leg is planned for the development of a borehole observatory as part of the MARS activity. MBARI is also testing several high-risk technologies associated with a cable-linked moored buoy observatory at the MOOS test mooring site in $1860 \mathrm{~m}$ of water (NRC, 2003a).
$D E O S$ - The DEOS ${ }^{(a)}$ seafloor observatory initiative, concentrating on geophysics, started in 1997. Initially the focus was on deep-water geo-observatories, but this was subsequently expanded to include near-shore observatories and water-column studies. To reflect this effort to engage the wider oceanographic community, the acronym was changed in 1999 to $\operatorname{DEOS}^{(\mathrm{b})}$. The DEOS ${ }^{(b)}$ steering committee includes representatives of the major U.S.A. geo-science observatory programmes and additional members from the microbiological community. The DE$\mathrm{OS}^{(\mathrm{b})}$ planning initiative in the U.S.A. and the U.K. (supported by NSF and NERC respectively), in co-ordination with partners in several member states of the EU and Japan, represented by IASPEI/ION, has identified a network of sites for multidisciplinary observatories focused on the atmosphere, ocean, and the Earth beneath it. Whereas for centuries observatories have been commonly used on land for many purposes, long-term continuous observations of natural phenomena in the oceans represent a new frontier for the sciences. A component of DE$\mathrm{OS}^{(\mathrm{b})}$ seeks to establish a global network of 20 moored-buoy ocean observatories that could comprise the global network component of the OOI (fig. 5; NRC, 2003a). In other locations, generally those closer to land, DEOS ${ }^{(\mathrm{b})}$ calls for 
the use of direct submarine cable connections to shore. The DEOS ${ }^{(\mathrm{b})}$ ocean observatory planning initiative was launched to foster a long-term continuous observational presence at the air-sea interface, throughout the water column, on the seafloor, and below. DEOS ${ }^{(\text {b) }}$ transitioned into OOI/ORION (see below). Another major international ocean observatory programme with close ties to the NSF's OOI is the B-DEOS programme (NRC, 2003a). The B-DEOS programme plan calls for the establishment of multidisciplinary moored ocean observatories at 3 sites: south of the Azores on the Mid-Atlantic ridge, on the Reykjanes ridge south of Iceland, and in the Drake Passage-East Scotia RiseSouth Sandwich Islands area.

NEPTUNE - One major component of the DEOS $^{(\text {b) }}$ and OOI/ORION planning effort is NEPTUNE, a project to establish a lithospheric-plate scale multidisciplinary observatory network on the Juan de Fuca Plate, located a few hundred kilometres off the US-Canadian west coast, and connected to two land-based research laboratories (shore stations) using highspeed, fibre-optic submarine communications cables (fig. 6; Delaney et al., 2000; NEPTUNE, 2000). The project started in June 1998 with the U.S.A. NEPTUNE feasibility study, completed and published in June 2000. The Canadian NEPTUNE feasibility study started in June 1999 and was completed and published in October 2000. The deployment of a 3000-km cable, largely along the margins of the Juan de Fuca plate is planned, with approximately 30 nodes spaced roughly at $100-\mathrm{km}$ intervals and «extension cords» to permit the location of instruments $50 \mathrm{~km}$ or more from a node (Massion et al., 2004). The multidisciplinary approach covers as preliminary examples: a) cross-margin particulate fluxes; b) seismology and geodynamics, seafloor hydrogeology and biogeochemistry; c) ridge-crest and subduction zone processes (fluid venting and gas hydrates); d) deep-sea ecology; e) water-column processes; f) fisheries and marine mammals. The system has been designed to provide real-time data transmission, interactive control and power to instruments and vehicles. The planned lifetime is 30 years. In 2002-2003 both cabled-observa-

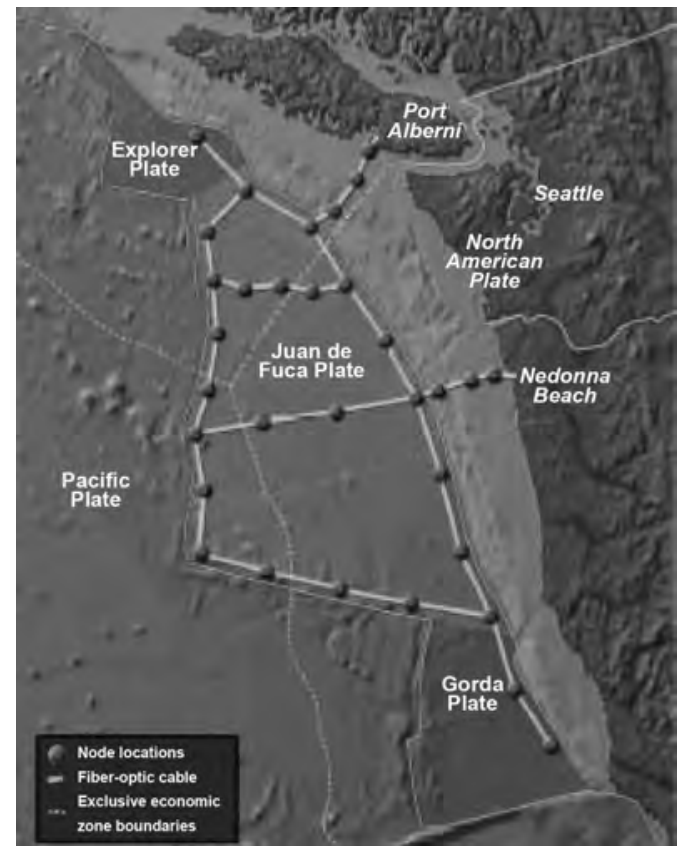

Fig. 6. Picture of the $3000-\mathrm{km}$ cable planned in the NEPTUNE project to establish a lithospheric-plate scale multidisciplinary observatory network on the Juan de Fuca Plate (Delaney et al., 2000; NEPTUNE, 2000).

tory test beds, VENUS (CAN) in the Strait of Georgia, the Strait of Juan de Fuca and Saanich Inlet, British Columbia (3 different cables), and MARS in Monterey Bay (a 62-km cable down to $1220 \mathrm{~m}$ w.d.) were funded (NRC, 2003a).

$\mathrm{NeMO}$ - The NeMO Observatory was established in autumn 1997 at the axial seamount (1520 m w.d.) on the Juan de Fuca ridge (Weiland et al., 2000), and will form part of the future NEPTUNE network. NeMO is acoustically linked to a surface buoy and has the objective to monitor and sample geophysical, geochemical, and microbial variability on an active segment of a mid-ocean ridge system to determine of the relationships between sub-seafloor magma movement, faulting, and changes in the biologic, chemical and physical properties of the subsurface biosphere (e.g., Daughney et al., 2004). 
$O S N$ - Another major component of DEOS $^{(\mathrm{b})}, \mathrm{OOI} / \mathrm{ORION}$ and ION programmes is the establishment of a permanent OSN consisting of about 20 sites throughout the world's oceans for improved geophysical imaging of the internal structure of Earth, as part of the IRIS/GSN networks (Orcutt and Stephen, 1993). The intention is to deploy sensor packages reentering in boreholes, such as ODP holes, using a special thrustered tool. These planetary-scale fixed ocean observatories may also serve as long-term measurement sites for other types of oceanographic and climate studies, such as those envisioned by the GEO system of moorings, now called OceanSITES. The OceanSITES goal is to establish oceanographic observatories at selected sites around the world's oceans for the collection of time-series measurements of surface meteorology; air-sea exchanges of heat, fresh water and momentum; and full-depth profiles of water properties, including temperature and salinity, and ocean velocity. Time-series measurements will be an essential element of the strategy developed to build accurate fields of air-sea fluxes. These observation stations have been proposed as an important component of GOOS. As part of the OSN activity, between February and June 1998 OSNPE collected data over 115 days from a broad-band borehole seismometer at ODP Site 843B in $4407 \mathrm{~m}$ w.d. offOahu about $200 \mathrm{~km}$ south-west of Hawaii (called OSN-1) (Stephen, 1998; Stephen et al., 1999, 2003b; Collins et al., 2001, 2002; Sutherland et al., 2004).

\subsubsection{Programmes}

ORION-OOI - The NSF's Division of Ocean Science established the ORION in 2003 Programme to operate and manage existing and future ocean observing sites funded by NSF some of which will be constructed using funds for OOI. The total 5-year construction costs are budgeted at 208 M USD for the period 20062010 (NRC, 2003a). The OOI infrastructure is an integrated observatory with three elements: 1) a regional cabled network consisting of interconnected sites on the seafloor spanning several geological and oceanographic features and processes, such as NEPTUNE; 2) relocatable deep-sea buoys that could also be deployed in harsh environments, such as the Southern Ocean; 3) new construction or enhancements to existing facilities leading to an expanded network of coastal observatories (NRC, 2003a; Isern, 2005). The research-focused observatories enabled by the OOI will be networked, becoming an integral part of the proposed IOOS, that is an operationally-focused national system and in turn will be a key to enable the U.S.A. contribution to the international GOOS and the GEOSS (Summerhayes, 2002). The ORION Programme will also co-ordinate the science driving the construction of this research observing network as well as the operation and maintenance of the infrastructure; development of instrumentation and mobile platforms and their incorporation into the observatory network; and planning, co-ordination, and implementation of educational and public outreach activities. The ORION Programme will be the most complex initiative that ocean scientists have undertaken within the U.S.A. and it will revolutionise the way that oceanographers study the sea. The NSF-supported OOI will have close ties to ocean and Earth observing systems supported by other agencies including NOAA, NASA and USGS (Isern, 2005). In addition to the programmes listed above, there are other international research programmes that include significant observatory related research initiatives which OOI infrastructure could facilitate. Examples include: 1) the InterRIDGE initiative for long-term monitoring of the Northern MidAtlantic ridge (MoMAR); 2) the InterMARGINS international consortium to understand seismogenic zones in subduction settings; 3) ION activities to co-ordinate global network observatory efforts; 4) the international OceanSITES for studying climate and ecosystems in the world's oceans; and 5) IODP.

\subsection{Japan}

In 1978, Japan started to manage cabled seafloor observatories for scientific use, and also for real-time monitoring for seismic and tsunami warning. Submarine cable-based seismic moni- 
toring began in five sea areas as part of the national earthquake preparedness efforts (Asakawa et al., 2003) following the recommendations of the Headquarters for Earthquake Research Promotion. For instance, in 1993, off-Hatsushima Island a cable connected multidisciplinary observatory was installed by JAMSTEC (Momma et $a l ., 1998)$. The observatory was equipped with geophysical and oceanographic sensors and video-cameras. Continuous observations were made for about six years. In July 1999 the observatory stopped working because of a short circuit of the submarine cable. Since then the replacement of the primary observatory and the design of a new one, enhanced to acquire additional measurements (e.g., tsunami pressure gauge, $\gamma$ ray spectrometer) and based on new technologies, has been completed. In 2000 a new observatory was deployed with a new cable. At pres-

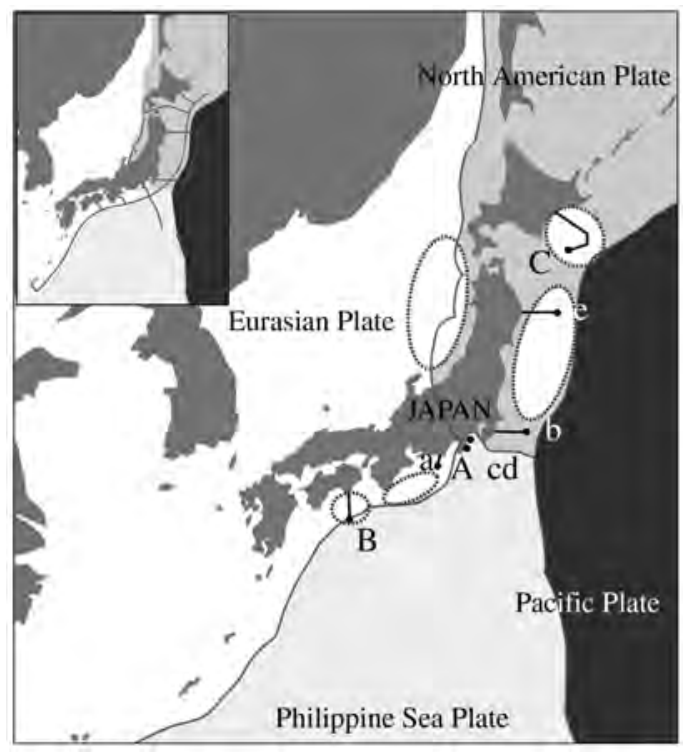

Fig. 7. Map of the cable-connected ocean bottom observatories in Japan (Shirasaki et al., 2003): a) JMA - Omaezaki; b) JMA - Off-Boso; c) ERI - OffIto City; d) ERI - Off-Sanriku; e) NIED - Hiratsuka; A) JAMSTEC - Off-Hatsushima; B) JAMSTEC Off-Muroto Peninsula; C) JAMSTEC - Off-KushiroTokachi. A map of the planned ARENA cable is shown in the top-left corner. ent, eight cabled experiments are running (table III and fig. 7) and all these experiments will be part of a larger project based on cable technology, called ARENA (Massion et al., 2004) and proposed in 2002 by IEEE-Oceanic Engineering Society of Japan. ARENA plans to deploy electro-optical cables all around Japan including in this network all the eight existing experiments. A feasibility study is presently ongoing for the development of the ARENA project. ARENA will be used for many scientific fields such as seismology, geodynamics, oceanography, marine environmental sciences, ecology, biology and exploitation of mineral resources. The ARENA architecture will be based on a mesh-like network, connecting underwater observatories and terrestrial stations, and covering the vast research area with $3600 \mathrm{~km}$ of cable powering the observation nodes. To satisfy the power requirements a new current-to-current converter has been proposed (Asakawa et al., 2005). When fully operational, the system will be equipped with 320 observation nodes (one every $20-50 \mathrm{~km}$ ) over a total cable length of $16000 \mathrm{~km}$ (Shirasaki et al., 2003). A wide-band optical system to transmit high-definition images will also be developed. Finally, expandable and mobile real-time monitoring systems for deep-sea use have also been developed (Kawaguchi et al., 2001, 2002).

GeO-TOC and VENUS (JP) - Although long-term (a few months) seafloor experiments have been carried out with mobile stations (e.g., Momma et al., 2001), the main trend of the scientific and technological research has been toward the use of underwater cables. While all the submarine cables described above have been specifically deployed for scientific purposes, the utilisation of decommissioned underwater telecommunications cables for scientific observation has also been considered. The use of these latter cables makes possible a low-cost implementation of scientific submarine cable systems. Typical examples of the utilisation of a submarine communications cable are the GeO-TOC project using the Japan-U.S.A. cable TPC-1, which connects Ninomiya and Guam, and VENUS (JP) which uses the TPC-2 cable running between Okinawa and Guam islands. A map of the two cables is shown in fig. 8 (Kasahara et al., 1995, 
1998a,b, 2000; Hirata et al., 2002; Kasahara, 2002). In January 1997, as part of the GeO-TOC project, a multidisciplinary observatory was deployed on the forearc slope of the Izu-Bonin Trench at $2708 \mathrm{~m}$ w.d. The observatory included a hydrophone, accelerometers and a quartz pressure and temperature sensor. Under the VENUS (JP) project, in August-September 1999 a multidisciplinary observatory was installed at a depth of $2170 \mathrm{~m}$ on the slope of the Ryukyu Trench, and attached to the Okinawa-Guam cable. The observatory was equip-ped with a triaxial broadband seismometer, a tsunami pressure sensor, a hydrophone array, a precision range meter for crustal movement observations, an ad hoc observation system, a potentiometer, a magnetometer and a video-camera. These instruments were connected to the junction box via an underwater mateable connector using a deep-towed unit, ROV and manned submersible (fig. 8; Kasahara et al., 2006). This arrangement allows the maintenance of instruments by means of a ROV and future up-grading of sensors to those with new

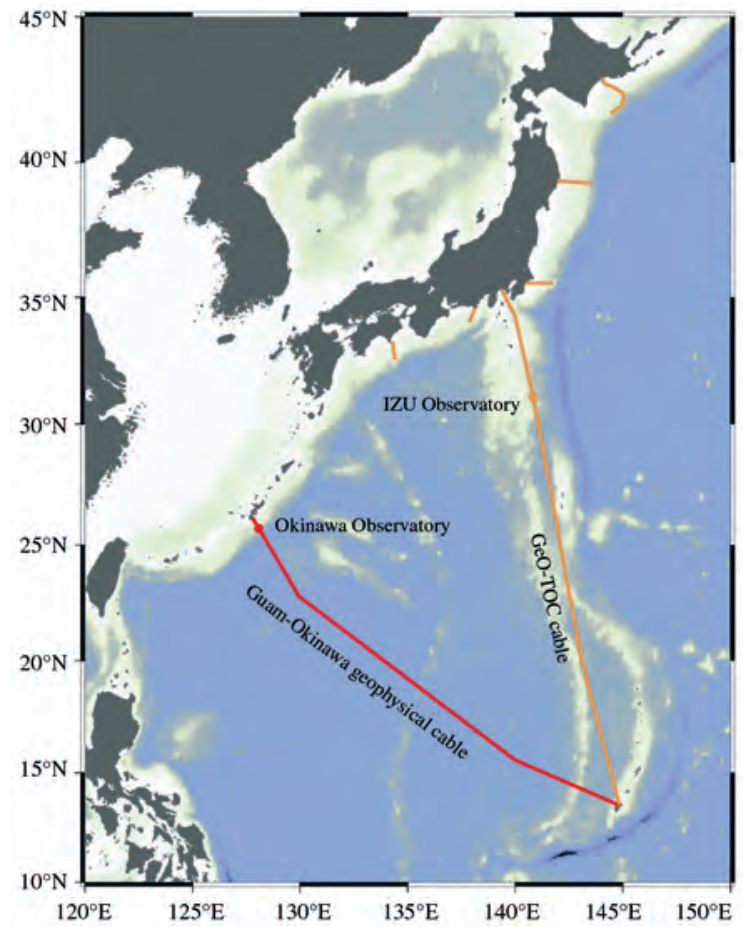

functions. In addition, it is planned to insert sensors into the GeO-TOC system. The VENUS (JP) system enabled the continuous acquisition of observational data from sensors installed on the ocean floor until a break down in communications occurred after several months caused by the failure of an underwater connector on the junction box.

$O H P$ - The OHP project plans to cover the East Asia-West Pacific area by a permanent geophysical network. OHP is a long-term multidisciplinary project funded by the Ministry of Education, Culture, Sports, Science and Technology and started in April 1996. The OHP aims to study and to build a new concept of the structure and dynamics of the Earth's deep interior by constructing a global network of multidisciplinary geophysical observations on the hemisphere including the whole of the Pacific Ocean. This network consists of three components: seismic, electromagnetic and geodetic. Each network is further composed of observations using different

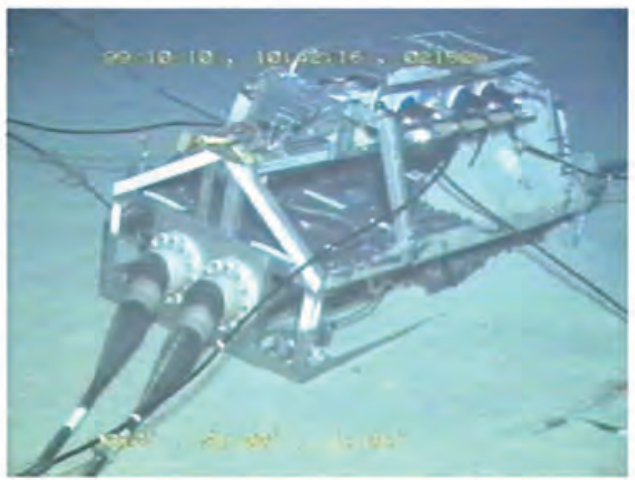

Fig. 8. Map of the TPC- 1 and TPC- 2 cables. The junction box used in the VENUS (JP) experiment is shown on the right (Kasahara et al., 2006). 
technologies and/or methods. OHP will improve and expand the broad-band seismic network in the north-western Pacific region, unifying the observation system, and also deploying semibroad-band OBSs, such as the experiment in the Philippines Sea (nine months in 2000-2001). Another goal of the project has been the installation of four seafloor borehole geophysical stations (NEREID-1, NEREID-2, WP-1 and WP-2; see previous Section 4.1.), established by ODP and managed by JAMSTEC (Suyehiro et al., 2002; Shinohara et al., 2006). This type of installation of a long-term observatory has shown that a properly cemented ocean-floor borehole in bedrock can also be very quiet at long periods (Araki et al., 2004). Moreover, under OHP three types of long-term OBS have been developed for seafloor observations: 1) LT-VBB (360-0.05 s); LT-BB (30-0.05 s); LT-OBS (1-0.05 s). The geoelectromagnetic network aims to study the electrical conductivity structure of the Earth's mantle, Earth's main magnetic field variations and core-mantle dynamics, using the same type of magnetometer. The distribution of permanent geomagnetic observatories is not dense enough. Therefore to improve the spatial resolution three types of temporary stations were established: OBEM, MT and SFEMS (Toh et al., 1998; Shinohara et al., 2006). In the last case OHP uses trans-continent submarine retired coaxial cable for measuring geoelectrical potentials, in collaboration with the IRIS Consortium (IRIS, 1994).

Finally, geodetic measurements were performed by a permanent network of 10 GPS stations, called WING (Kato et al., 1998), and by seafloor instruments. As part of OHP, instruments for seafloor geodesy have been developed and tested (Fujimoto et al., 1998; Osada et al., 2005) jointly with SIO, which was the first to develop precision acoustic transponders with a sub-cm resolution in 4-5 km (Spiess et al., 1998; Gagnon et al., 2005a,b).

\subsection{Europe}

ECORD-JEODI - ESF has created a European research structure, ECORD that will serve as the basis for all aspects of scientific ocean drilling research in Europe as part of the IODP Programme. Recently (from 2001) the EC has funded a thematic network (JEODI) to implement ECORD and move towards a single research and operational funding structure for science in Europe enabled by ocean drilling.

$O F M$ - As part of the French efforts to contribute to the establishment of «permanent» seafloor observatories (Montagner et al., 1998), the technical goal of the French Pilot Experiment OFM conducted in April and May 1992 (Montagner et al., 1994a-c) was to show the feasibility of installing and recovering two sets of threecomponent broad-band seismometers, one inside an ODP borehole and another inside a benthosphere in the vicinity of the hole. All the logistic support for the sea operations was provided by IFREMER; the oceanographic vessel Nadir, the submersible Nautile and the re-entry logging system Nadia-2 were used. Secondary goals were to obtain the seismic noise level to conduct a comparative study of broad-band noise on the seafloor, downhole, and in continental regions, and to determine the detection threshold of seismic events on the seafloor. After the installation of both sets of seismometers, seismic signals were recorded continuously for 10 days. It was observed that the noise level tends to decrease as time goes by for both ocean-bottom and borehole seismometers, which means that the equilibrium stage had not yet been attained by the end of the experiment (Beauduin et al., 1996a,b). The characteristics of microseismic noise in oceanic and continental areas are completely different. The background microseismic noise is shifted toward shorter periods for ocean-bottom and borehole seismometers compared to a continental station. This might be related to the difference in the crustal structure between oceans and continents. The experiment was a technical and scientific success and demonstrated that the installation of a permanent broad-band seismic and geophysical observatory on the seafloor as well as in a borehole is possible and can provide the scientific community with high-quality seismic data.

EC feasibility studies - As already mentioned (see Introduction), since the early 1990s the EC has promoted feasibility studies aimed at 
identifying the scientific requirements (Thiel et $a l ., 1994)$ and the possible technological solutions for the development of seafloor observatories (ABEL; Berta et al., 1995). In particular, ABEL proved the feasibility of the concept of a benthic laboratory managed by a surface deployer. The configuration proposed by Tecnomare (a member of the Eni Group) was a network of co-operating fixed nodes associated with an AUV that can interact with the fixed observing station nodes and extend their capabilities by surveying the area investigated (Berta et al., 1995; Gasparoni et al., 2002). Such a configuration has inspired the EC GEOSTAR, GEOSTAR-2 and ORION-GEOSTAR-3 projects (see below). In parallel, other studies and activities, such as DESIBEL (Rigaud et al., 1998), have been carried out at EC level, aimed at defining the needs and expectations for longterm investigations at abyssal depths. Within DESIBEL four concepts have been investigated: a) an active docking system with a mobile hook; b) an active docking system with a special ROV; c) a light scientific ROV; d) a free swimming vehicle. The main outcomes of the feasibility studies ABEL and DESIBEL were the Victor 6000 ROV of IFREMER, and a special ROV able to deploy and recovery heavy payloads on the deep seafloor. This ROV, called MODUS, was built as part of the GEOSTAR projects (Clauss and Hoog, 2002; Clauss et al., 2004).

GEOSTAR and GEOSTAR-2 - Starting in 1995, after the feasibility studies described above, the EC supported the GEOSTAR and GEOSTAR-2 projects aimed at the development and testing in actual deep-sea conditions of a single-frame seafloor autonomous observatory for long-term (up to one year) multidisciplinary monitoring at abyssal depths (at present, the maximum operative depth is $4000 \mathrm{~m}$ ). The power supply is provided by a primary lithium battery. Beranzoli et al. (1998) describe the main sub-systems: a) Bottom Station; b) MODUS; c) the communications systems. The Bottom Station (i.e. the seafloor observatory) manages all the scientific payload, provides the power supply, and hosts the underwater part of the communications system. The data acquisition is driven and controlled by a central unit called DACS (Gasparoni et al., 2002) using a single clock signal to provide a common reference and quickly compare the different time series. MODUS is the deployment/recovery vehicle, which is lighter and smaller than traditional ROVs. Although lacking manipulation devices, MODUS takes care of the observatory from the sea surface to the sea bottom and during the deployment/recovery operations is also the primary communications link with the observatory. The GEOSTAR communications are based on different parallel systems: data capsules (MESSENGERS) releasable upon surface command or automatically in case of emergency, that can transmit their position on the sea surface and small quantities of data via ARGOS; acoustic seafloor-sea surface links with a buoy or a portable surface station on a ship of opportunity (Marvaldi et al., 2002). Near-realtime communication with the observatory on the seafloor is assured by a surface buoy able to link by acoustics with the Bottom Station, and by radio/satellite links with an on-shore station. Details of the GEOSTAR sub-systems and characteristics of the sensors used can be found in Clauss and Hoog (2002), Gasparoni et al. (2002), Marvaldi et al. (2002), Clauss et al. (2004) and Favali et al. (2006). Figure 9a-d shows all the GEOSTAR sub-systems.

In 1998, a demonstration mission was carried out in the shallow waters of the Northern Adriatic (42 m; Jourdain, 1999; Beranzoli et al., 2000a) collecting multiparameter data (Beranzoli et al., 2000b). The analysis of the data demonstrated the complete reliability of the whole system, including MODUS functionality, and in particular demonstrated the scientific potentiality of unique time-referenced multiparameter data (Beranzoli et al., 2003). Also the effect of the observatory structure on the reliability of the measurements was considered (Fuda et al., 2006). In 2000-2001 the first long-term deep-sea mission (GEOSTAR-2 project) took place at about 2000 m w.d. in the Southern Tyrrhenian Sea for seven months. A surface buoy was deployed in the vicinity of the mission site to test the near-real-time communication with the observatory on the seafloor. The long-term mission validated the ability of the system to work properly in actual deep-sea conditions. The quality of 


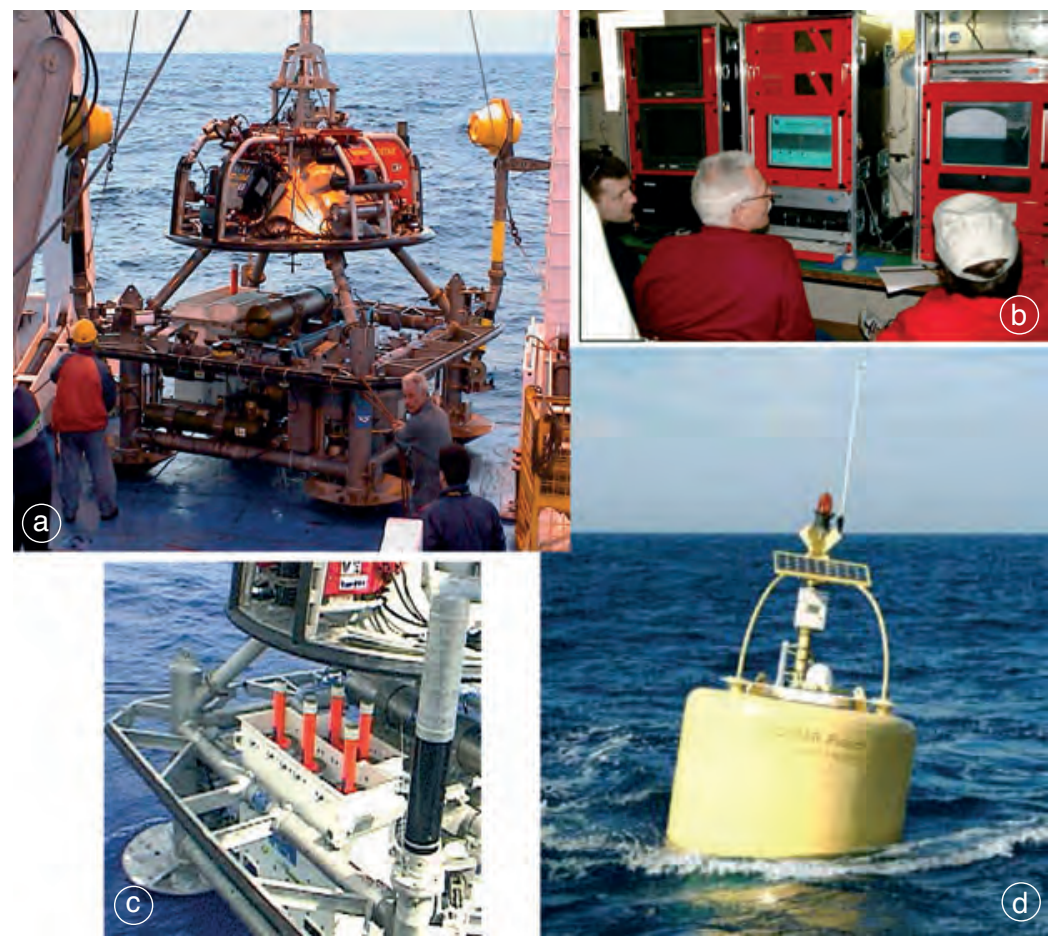

Fig. 9a-d. The complete GEOSTAR sub-systems: a) Bottom Station, which includes DACS, power supply, underwater acoustic communications and scientific payload, with MODUS on the top; b) MODUS ship-based remote control system; c) surface communication buoy (GEOSTAR-2 configuration); d) five MESSENGERS within the Bottom Station, the orange ARGOS antennas are visible (see also Favali et al., 2006).

the data collected was also high, as shown, for instance, by magnetic (De Santis et al., 2006), gravimetric (Iafolla et al., 2006), and geochemical and oceanographic data that evidenced ocean-lithosphere interactions in the benthic boundary layer (Etiope et al., 2006). All the marine operations, either for the Adriatic shallowwater or for the Tyrrhenian deep-sea missions, were managed by the R/V Urania.

Also during the GEOSTAR-2 deep-sea mission fourteen OBSs and OBHs were deployed in an area between Ustica Island and the Aeolian Islands as far as Stromboli to better monitor the seismicity of that area. The experiment, called TYDE, lasted six months from the end of November 2000 to the middle of May 2001. Details can be found in Dahm et al. (2002). Some scientific results of TYDE are presented and discussed in Montuori (2004), Sgroi et al. (2006) and Barberi et al. (2006).

A significant example of technological spin-off from the GEOSTAR projects is the use of MODUS for the management of an instrumented frame, called SCIPACK, for exploratory surveys (casts and profiles) as part of the EC BIODEEP project. In particular, the exploration of the deep (>3000 m w.d.) hypersaline anoxic basins of the Eastern Mediterranean Sea has been conducted by acquiring real-time video images, measurements and accurate videoguided samplings (Malinverno et al., 2006).

The GEOSTAR projects represent the starting point of a set of European and Italian initiatives, which have led in around 10 years to the development and operation of other GEOSTARclass observatories. The next step, promoted in 

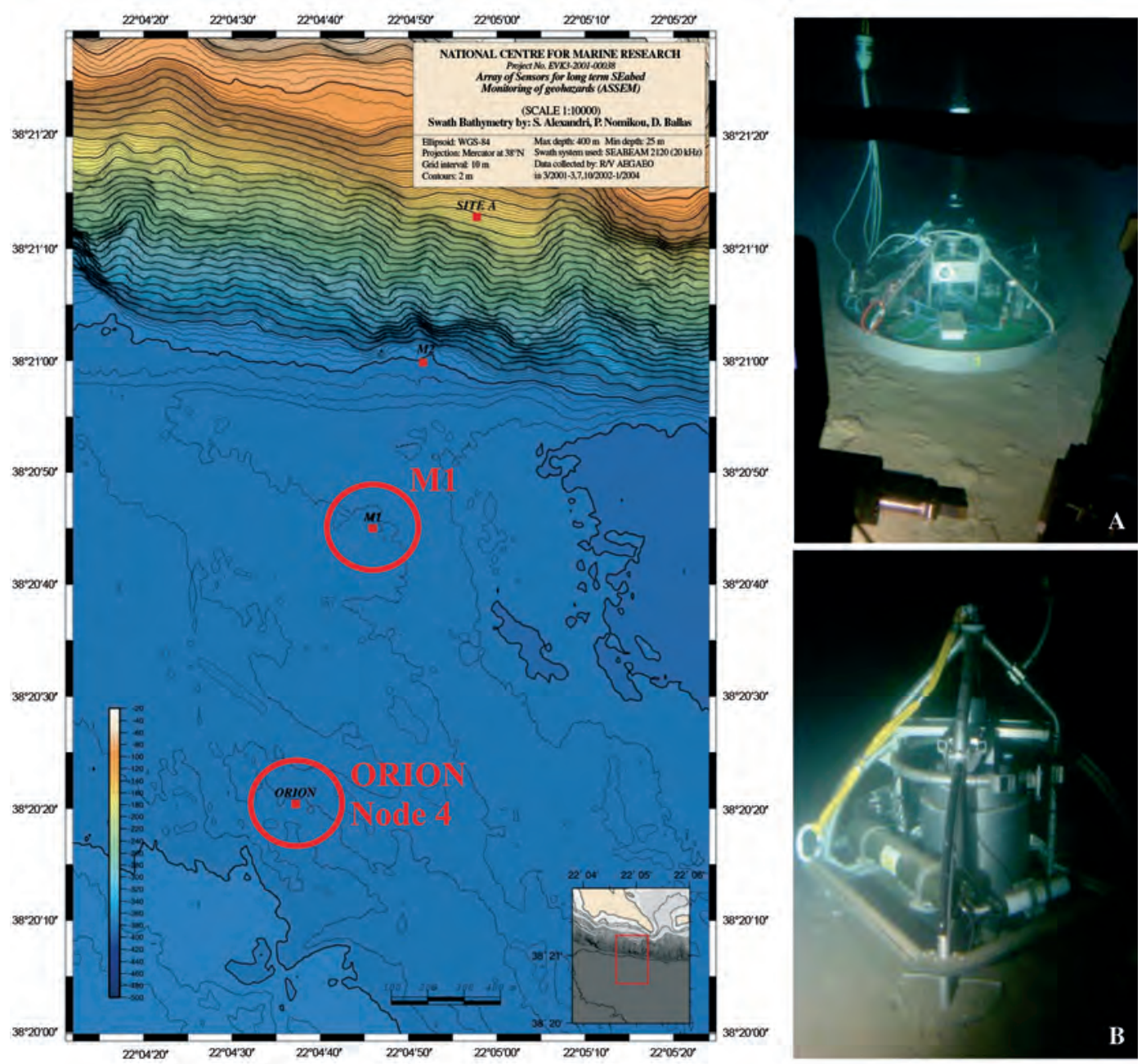

Fig. 10. Bathymetric map of the Gulf of Corinth where one of the ASSEM pilot experiments was carried out. The dots represent the locations of the underwater nodes, the two red circles indicate the M1 node (A, underwater photograph on the right); and the ORION-GEOSTAR-3 Node 4 (B, underwater photograph on the right) (Blandin et al., 2003).

2002 by the EC, was to move from a single benthic observatory to seafloor observatory networks. The two EC projects ASSEM and ORION-GEOSTAR-3 have such a goal.

ASSEM - ASSEM is a project funded by the EC in the period 2002-2004 which developed a seafloor network for the long-term monitoring of geotechnical, geodetic and chemical param- eters over a seabed area with maximum extent of $1 \mathrm{~km}^{2}$ (Blandin et al., 2003). The network consists of light nodes able to communicate with a surface buoy and providing power supply and data logging resources to a set of sensors placed inside or around the node frame. One of the monitoring nodes also acts as a gateway for the data transmission to the buoy and land stations for processing and access through 
the Internet. The network deployment and recovery requires the use of traditional ROVs with manipulation functionalities to assist the operations on the seafloor.

ASSEM nodes were deployed in 2004 down to $400 \mathrm{~m}$ in the Gulf of Corinth, down to $40 \mathrm{~m}$ in the Patras Gulf (both sites in Greece) and down to $50 \mathrm{~m}$ at Finneidfjord (off-shore Norway). The experiments lasted in total seven months. In the Gulf of Corinth the array included three nodes equipped with geodetic sensors based on acoustic distance meterzzs and tiltmeters, CTD methane and oxygen sensors. The array was integrated with a guest station (Node 4) developed as part of the ORION-GEOSTAR-3 project, to demonstrate the full compatibility between the two networks,
ASSEM and ORION-GEOSTAR-3 (see below). Figure 10 shows the bathymetric map of the Gulf of Corinth in which the experiment was carried out and the location of the nodes. An additional node, GMM, was developed and deployed within a methane-bearing pockmark in the Patras Gulf at $40 \mathrm{~m}$ w.d. This module was equipped with three methane sensors, a $\mathrm{H}_{2} \mathrm{~S}$ sensor and CTD and was linked to shore by submarine cable for real-time data transmission (Marinaro et al., 2004).

ORION-GEOSTAR-3 - The ORIONGEOSTAR-3 EC project (2002-2005) has the objective to make a significant step forward in ocean networking starting from the results of

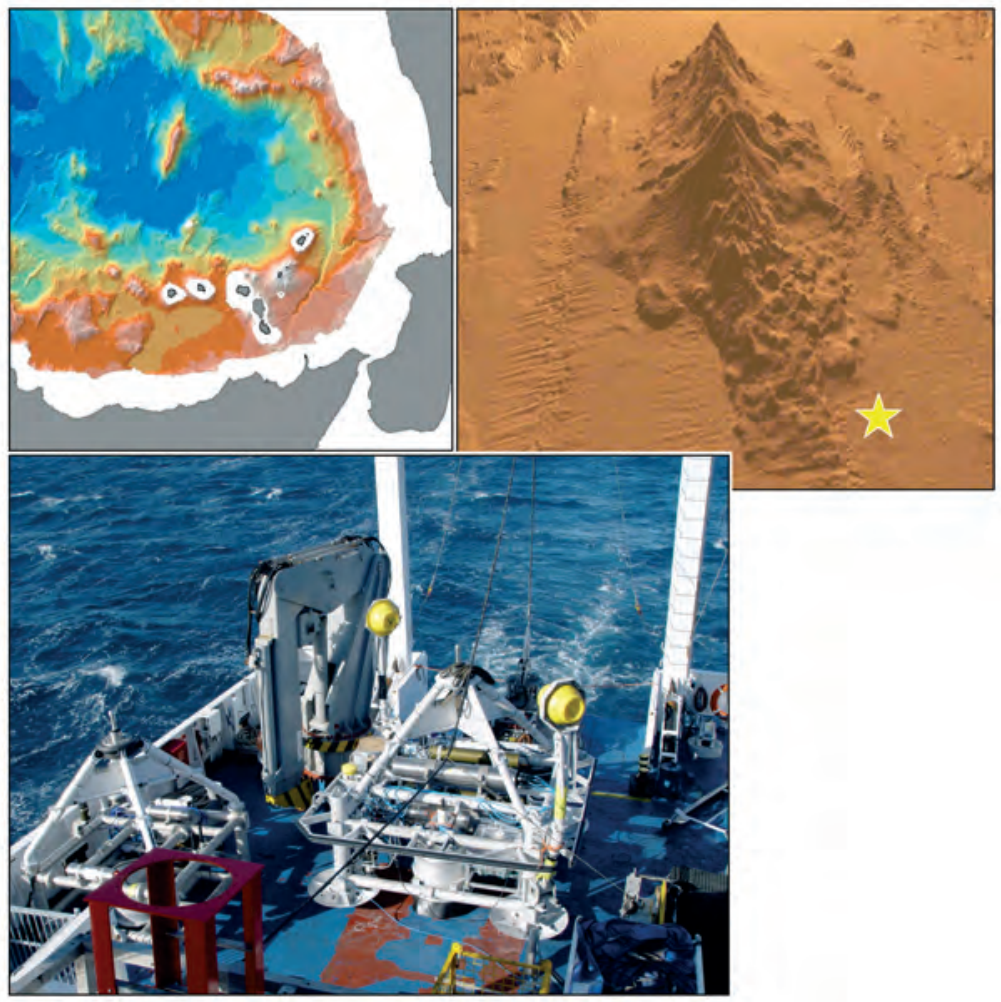

Fig. 11. Swath bathymetry of the Southern Tyrrhenian Sea, on the right a 3D picture viewed from the north of the Marsili underwater volcanic seamount (Central Tyrrhenian bathyal plain) (Marani et al., 2004). The yellow star indicates the site of the ORION-GEOSTAR-3 experiment at the NW base of the seamount (over $3300 \mathrm{~m}$ w.d.). Photographs of GEOSTAR (right) and Node 3 (left) are shown at the bottom of the figure. 
the GEOSTAR projects (Beranzoli et al., 2004). As part of ORION-GEOSTAR-3, GEOSTAR was upgraded to operate as the gateway node of a seafloor network, two satellite observatories were developed (named ORION Nodes 3 and 4) and horizontal acoustic telemetry was developed to provide a bi-directional communications link between GEOSTAR and the satellite nodes. Communication between the seafloor network and land is once again performed by the GEOSTAR surface buoy via radio/satellite link to a shore station. The deployment/recovery of each network node is made by MODUS. This opens a large perspective in the standardisation of observatory management.

The long-term pilot experiment ran from December 2003 at over $3300 \mathrm{~m}$ w.d. NW of the Marsili volcanic seamount (Southern Tyrrhenian Sea) (fig. 11; Marani et al., 2004) involving GEOSTAR, an additional node placed $1 \mathrm{~km}$ away (ORION Node 3), the improved GEOSTAR buoy, and a shore-station, sited in the INGV observatory of Gibilmanna (Northern Sicily). The surface buoy allows the automatic transmission to the shore station of periodic messages coming from Node 3 to the gateway (GEOSTAR node) via horizontal acoustics and then via vertical acoustics from the gateway. The buoy-shore link is by radio through the relay station on Salina Island (Aeolian Islands) and/or by satellite (IRIDI$\mathrm{UM})$. It is also possible to retrieve pieces of waveforms collected by the seismometer by interrogating either the GEOSTAR node or ORION Node 3 from the shore. Although the experiment was ongoing at the time of preparation of this paper, the full set of multiparameter data related to the period December 2003-April 2004 was recovered during a maintenance intervention. The $\mathrm{R} / \mathrm{V}$ Urania has been used for all the sea operations in this project.

As part of the ASSEM experiment in the Gulf of Corinth, one of the ORION-GEOSTAR-3 nodes (ORION Node 4) was deployed and integrated as far as the communications were concerned. The demonstration of the compatibility of the two networks was required by the EC to favour the synergy between similar projects and to enhance the results of individual projects. This can assess the capability of European research and technology to provide advanced systems for marine monitoring in (near)-real-time from coast to deep-sea.

The results of the ORION-GEOSTAR-3 project open a new perspective for safe and relatively inexpensive management of seafloor observatories and for the potentiality of a multiparameter approach to the improvement of our knowledge of processes in the benthic boundary layer.

ESONET - The ESONET project promotes activities to develop the multidisciplinary «seafloor segment» of the ESA-EC GMES Pro-

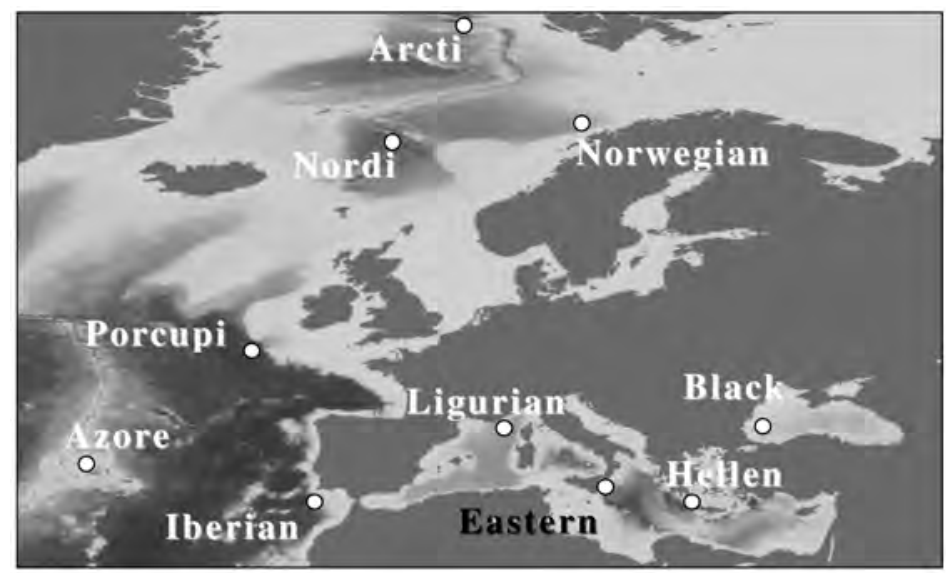

Fig. 12. Map of the «key-sites» of the European ocean margins proposed by ESONET (Priede et al., 2003, 2004). 
gramme. These activities are particularly aimed at contributing to research into geo-hazards, global change and biodiversity. ESONET has produced guidelines for the establishment of a European seafloor network of observatories from the Baltic Sea to the Black Sea. In this context one of the most important outcomes has been the definition of «key-sites» (fig. 12) at which cabled multidisciplinary observatories should be deployed (Priede et al., 2003, 2004). At several sites several scientific activities have been running for a long time in preparation for the introduction of cabled observatories. Among these sites, the one in Eastern Sicily is already operative in real-time, having, at the end of January 2005, connected the SN-1 observatory to an electro-optical cable and acquired data at the shore station (see Section 4.5 for details). At other sites, such as Porcupine (off-shore Western Ireland), actions to acquire and deploy an electro-optical cable are being developed (Waterworth, 2004).

\subsection{Italian initiatives}

The Italian coasts have in some cases been affected by tsunamis (Tinti et al., 2004), most of them directly linked to earthquakes or to volcanic eruptions and consequent submarine landslides (e.g., Tinti et al., 1995; Piatanesi and Tinti, 1998; De Martini et al., 2003), as at the end of 2002 when an unusual eruption of Stromboli (Aeolian Islands, Southern Tyrrhenian Sea) occurred together with the collapse of a flank of the volcano. This collapse caused submarine slumping associated with tsunami waves. INGV has recently established a permanent laboratory on Stromboli, which is an ideal natural laboratory, and an extensive interdisciplinary programme is being planned (Chiappini et al., 2002). One of the most exposed areas to tsunami hazard is Eastern Sicily, where the biggest Italian earthquakes have occurred, often associated with tsunamis $(1693, M 7.4 ; 1908, M 7.1$; Boschi et al., 1997; Tinti et al., 2004). Therefore, the first pilot station of the Italian tsunami warning system has been installed there, as a result of the EC GITEC-TWO project (19961998) (Maramai et al., 2002). The seafloor ob- servatory SN-1 has also been installed and connected in real time to the shore in that area (see below).

SN-1 - In the period 2000-2004 the Italian GNDT funded a project proposed by INGV to set up and operate off-shore Eastern Sicily in the Western Ionian Sea (Central Mediterranean) a multiparameter deep-sea observatory, SN-1, mainly devoted to seismological and oceanographic measurements. SN-1 is a GEOSTARclass observatory with reduced size compared with GEOSTAR and represents the effort of Italian marine research towards the realisation of a seafloor network in the seas surrounding the peninsula (fig. 13). The site of $\mathrm{SN}-1$ was chosen as the first one, because it is the most

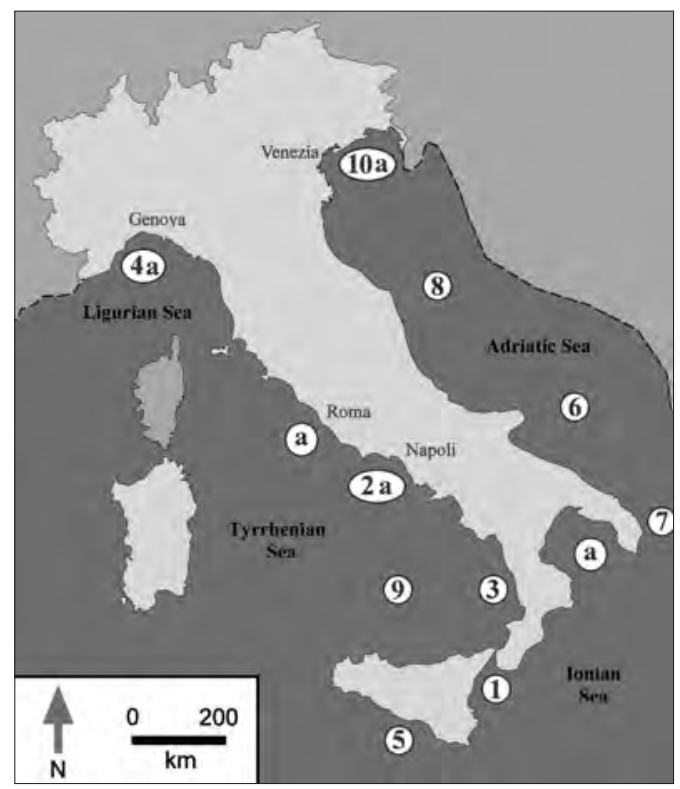

Fig. 13. Map of the nodes of the future Italian «permanent» multidisciplinary seafloor network. The numbers indicate the sites of geophysical (particularly seismological and/or volcanological) interest in order of priority from 1 to 10 , while the letter «a» indicates sites of environmental interest. The number 1 represents the SN-1 location, the first existing realtime connected node. 
exposed in Italy to destructive earthquakes and the tsunamis that are often connected with them (Boschi et al., 1997; Tinti et al., 2004).

$\mathrm{SN}-1$ has basically the same features of GEOSTAR: it is deployed/recovered by MODUS, it hosts a set of sensors, and is equipped with a DACS providing data streams with a unique time reference. In contrast to GEOSTAR, SN-1 has a standard vertical acoustic system enabling the surface unit to control its status and to retrieve portions of data and it is not supported by a surface moored buoy. From October 2002 to May 2003 SN-1 successfully completed its first longterm mission at $2105 \mathrm{~m}$ w.d. off-shore Catania. During this mission, SN-1 acquired, in autonomous mode, around $10 \mathrm{~Gb}$ of data, $7.65 \mathrm{~Gb}$ of which were collected by a $100 \mathrm{~Hz}$ sampling rate broad-band seismometer (Favali et al., 2003). SN-1 has demonstrated the improvement of seismic event detection obtainable with an observation site at sea. In fact, it acquired hundreds of events not recorded on land, fully demonstrating that seismicity in marine areas is poorly monitored and localised by the on-shore network on- ly (Favali et al., 2004b). Moreover, the relatively simple procedure, already used in previous GEOSTAR experiments, of de-coupling the seismometer housing from the frame, protecting the housing with another external bell, and coupling the instrument with the seabed has been definitively validated and has resulted in the collection of high-quality seismological data (Monna et al., 2005).

At the end of January 2005, the SN-1 observatory was again deployed at the same site (about $25 \mathrm{~km}$ east of Etna volcano at $2060 \mathrm{~m}$ w.d.) and connected to a submarine cable owned by INFN (fig. 14). The sea operations have been carried out by the $\mathrm{C} / \mathrm{V}$ Pertinacia, owned by Elettra Tlc; the SN-1 connection to the cable termination was made through a ROV mateable connector managed by the deep-rated ROV available on board. In this way SN-1 receives power from shore and is able to communicate in real-time with a shore station. This makes possible the integration of $\mathrm{SN}-1$ with the existing Italian land-based network, providing a significant contribution to our knowledge of a

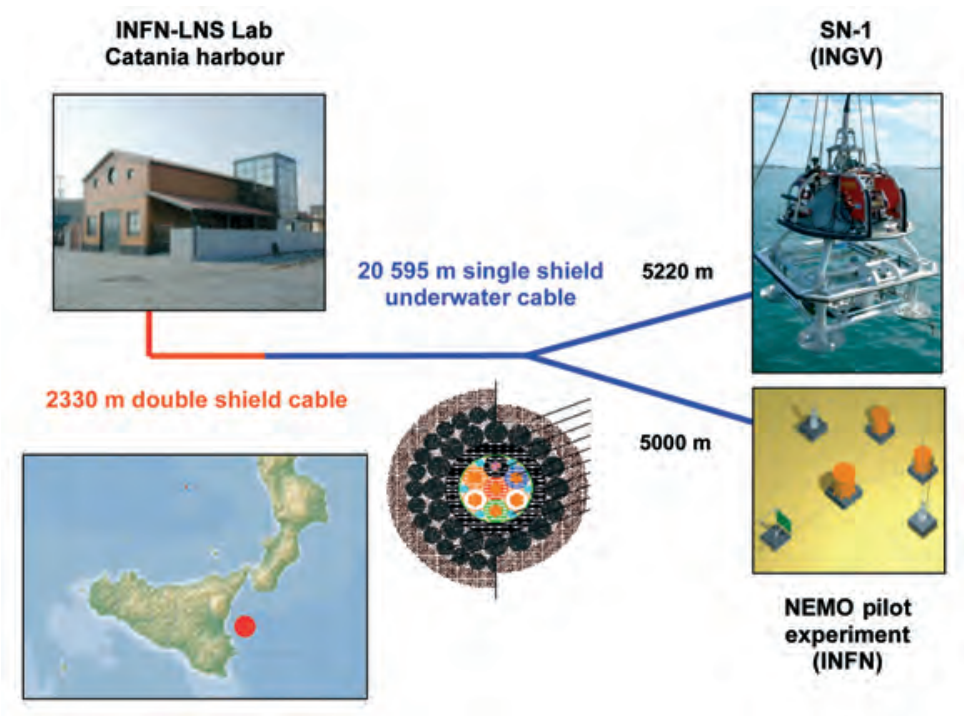

Fig. 14. Sketch of the INFN cable from the shore laboratory in Catania harbour to a plateau of the Malta escarpment located about $25 \mathrm{~km}$ east of Etna volcano (>2000 m w.d.). A photograph of SN-1 is also shown in the top-right corner (Favali et al., 2003). The geographic location of the observatory is indicated by a red dot on the map in the bottom-left corner (2060 m w.d.). 
key sector of Central Mediterranean geodynamics. The INFN cable will also carry out a scientific experiment to detect natural neutrinos in deep-sea waters (NEMO Pilot Experiment, see Section 4.6). These scientific achievements have been achieved through joint activities between INGV and INFN, regulated by a specific MoU. Moreover, SN-1 is also one of the keysites defined by the ESONET project around the European ocean margins as sites for the development of seafloor observatories connected in real time to the shore (Priede et al., 2003, 2004). SN-1 is the first operative cabled observatory in Europe.

$M A B E L$ - MABEL is a deep-sea multiparameter observatory for polar seas under development as part of PNRA (Calcara et al., 2001). It is designed to acquire geophysical, geochemical, oceanographic and environmental time series, and to operate autonomously for one year. Because MABEL is a GEOSTAR-class observatory with the same dimensions of $\mathrm{SN}-1$, the launch and recovery of the observatory will be managed by MODUS. The first long-term mission has started at the end of 2005 in the Weddell Sea, using the R/V Polarstern. The use of this vessel is regulated by a MoU between INGV and AWI. The mechanical and electronic behaviour of the whole system at low temperatures has been tested in the HSVA Basin, where it is possible to simulate polar water and air conditions and therefore to indicate the weak points that must be overcome (Cenedese et al., 2004).

Sensor prototypes - An intense parallel activity has been planned and carried out to develop sensor prototypes suitable for long-term use in deep-sea single-frame multiparameter platforms, such as GEOSTAR-class observatories. In particular, a triaxial fluxgate magnetometer (De Santis et al., 2006), a very sensitive gravity meter (Iafolla and Nozzoli, 2002) and an automatic chemical electrode analyser have been developed, tested and used in long-term missions down to over $3300 \mathrm{~m}$ w.d.

The main characteristics of the scientific payload, the dimensions and weights of the available GEOSTAR-class platforms are summarised in Favali et al. (2004a, 2006).

\subsection{Neutrino telescopes}

In the last few years high energy particle physicists have become very interested in carrying out experimentsto detect neutrinos in the deep oceans. Solar and supenova physics have indicated the specific role of neutrinos in the processes involved in stellar evolution, opening the way to so-called «low energy neutrino astrophysics». The underwater/ice Cerenkov technique is widely considered to be the most promising experimental approach to building high energy neutrino detectors. The first generation of underwater/ice neutrino telescopes, BAIKAL (Belolaptikov et al., 1997) and AMANDA (Andres et al., 2001), despite their limited sizes, have already set the first constraints on $\mathrm{TeV}$ neutrino astrophysical models. The construction of $\mathrm{km}^{2}$ size detectors has already started: at the South Pole the ICECUBE neutrino telescope is under construction (Ahrens et al., 2004); the ANTARES (Katz et al., 2004), NEMO (Capone et al., 2002) and NESTOR (Zhukov et al., 2004) collaborations are working towards the installation of a neutrino telescope in the Mediterranean Sea. Neutrino detectors must identify faint astrophysical neutrino fluxes against a diffuse atmospheric background. The cosmic muon flux, which at sea surface is about 10 orders of magnitude higher than the number of neutrino-induced up-going muons, strongly decreases below the sea surface as a function of depth and of zenith angle, falling to zero near the horizon and below. For this reason astrophysical neutrino signals are searched for among upward-going muons. At $3000 \mathrm{~m}$ depth, an underwater neutrino telescope is hit by a cosmic muon flux that is about 106 times greater than the up-going atmospheric neutrino signal. Another background source is the optical noise in seawater. This background is due to the presence of bioluminescent organisms and radioactive isotopes. Radioactive elements in water (mainly ${ }^{40} \mathrm{~K}$ ) produce electrons above the Cerenkov threshold. The expected number of detectable high energy astrophysical neutrino events is of the order of 10-100 per $\mathrm{km}^{2}$ per year (Gaisser et al., 1995; Bahcall and Waxman, 2001) and only detectors with an effective area $\left(A_{\text {eff }}\right)$ of order $1 \mathrm{~km}^{2}$ would allow the identification of their 
sources. After the pioneering work carried out by the underwater DUMAND collaboration offshore Hawaii Island (Roberts, 1992), starting in the second half of the 1990s, two small-scale neutrino telescopes, the underwater BAIKAL $\left(A_{\text {eff }}=104 \mathrm{~m}^{2}\right.$; Belolaptikov et al., 1997) and the under-ice AMANDA $\left(A_{\text {eff }}=0.1 \mathrm{~km}^{2}\right.$; Andres et al., 2001), have demonstrated the possibility of using the underwater/ice Čerenkov technique to track $E_{v}>100 \mathrm{GeV}$ neutrinos and thus measuring the atmospheric neutrino spectrum at high energies. BAIKAL was the first underwater neutrino telescope and, after more than ten years of operation, it is still the only neutrino telescope located in the Northern Hemisphere. BAIKAL is an array of 200 photomultipliers, moored between 1000 and $1100 \mathrm{~m}$ depth in Lake Baikal (Russia). AMANDA is currently the largest neutrino telescope. In the present stage, AMANDA II, the detector consists of 677 optical modules of pressure-resistant glass hosting downward-oriented photomultipliers and readout electronics. The optical modules are arranged in 19 vertical strings, deployed in holes drilled in the ice between 1.3 and $2.4 \mathrm{~km}$ depth. The success of these two experiments has opened the way to the construction of $\mathrm{km}^{3}$ underwater neutrino telescopes. ICECUBE (Ahrens et al., 2004), which will extend the AMANDA detectors to $\mathrm{km}^{3}$ size at the South Pole, will be deployed starting in austral summer 2004-2005, to be completed by 2010 . When completed it will consist of 4800 photomultipliers deployed in 80 strings.

In the Northern Hemisphere three collaborations, ANTARES, NEMO and NESTOR, are building demonstration detectors and prototypes, aimed at the construction of $\mathrm{a} \mathrm{km}^{3}$ detector in the Mediterranean Sea. The simultaneous observation of the whole sky with at least two neutrino telescopes in opposite hemispheres of the Earth is essential for the study of transient phenomena.

NESTOR (Zhukov et al., 2004) the first collaboration to operate in the Mediterranean Sea, will deploy a modular detector at $3800 \mathrm{~m}$ depth in the Ionian Sea, near the Peloponnese coast (Greece).

ANTARES (Katz et al., 2004) will be a demonstration neutrino telescope with an effective area of $0.1 \mathrm{~km}^{2}$ for astrophysical neutrinos. It is located at a marine site near Toulon (France), at $2400 \mathrm{~m}$ depth. Between December 2002 and March 2003 the collaboration has deployed a junction box and two prototype lines equipped with oceanographic instruments and optical modules. The construction of $\mathrm{km}^{3}$ scale neutrino telescopes requires detailed preliminary studies: the choice of the underwater installation site must be carefully investigated to optimise detector performance; the readout electronics must have a very low power consumption; the data transmission system must allow data flow as high as 100 $\mathrm{Gb} / \mathrm{s}$ to shore; the mechanical design must allow easy detector deployment and recovery, and the deployed structures must be reliable over more than 10 years. In order to propose feasible and reliable solutions for the $\mathrm{km}^{3}$ installation the NEMO collaboration has been conducting intense research and development on all the above subjects since 1998 (Capone et al., 2002; Migneco et al., 2004). NEMO has intensively studied the oceanographic and optical properties at several deep-sea sites (depth $\sim 3000 \mathrm{~m}$ ), close to the Italian coast. Results indicate that a large region located $80 \mathrm{~km}$ SE of Capo Passero (Sicily) is excellent for the installation of the $\mathrm{km}^{3}$ detector.

In recent years many innovations have been applied to underwater technology. DWDM is permitting a large increase in the speed and bandwidth of optical fibre data transmission; newly developed materials can improve the long-term underwater reliability of complex deployed structures; deep-sea operations with ROVs or AUVs have been standardised. The design of the Mediterranean $\mathrm{km}^{3}$ telescope will directly profit from these advanced technologies. In order to test the technical solution for the $\mathrm{km}^{3}$ installation, the INFN installed a deep-sea test site at over $2000 \mathrm{~m}$ depth deploying an electrooptical cable, $25 \mathrm{~km}$ E of the harbour of Catania (Sicily) supported by the infrastructure of LNS (fig. 14). An underwater station consisting of a basic NEMO module (junction boxes, towers and data acquisition system) will be installed by 2007. The neutrino telescopes can provide infrastructures that support other experiments and seafloor observatories, as the NEMO test site has already demonstrated. In fact it also hosts other experiments such as geophysical ones through the deployment and real-time connec- 
tion to the cable of the SN-1 multidisciplinary observatory (Favali et al., 2003) made at the end of January 2005 (see Section 4.5).

The research and development activities conducted by the three Mediterranean collaborations have provided valuable experience in the construction of the underwater $\mathrm{km}^{3}$ detector, which will be the result of their efforts. A step in this direction is represented by their joint effort in the EC KM3NET project for a design study of the $\mathrm{km}^{3}$ Mediterranean Neutrino Telescope. Further details on neutrino telescopes can be found in this volume (Migneco et al., 2006).

\section{Conclusions and perspectives}

The establishment of a network of seafloor observatories will represent a new direction in ocean science research, and it will require a major investment of human and economic resources over many decades.

Potential benefits and risks are envisaged (NRC, 2000).

The potential risks include:

- Installation of poorly designed and unreliable observatory systems.

- Potential for interference between experiments.

- Lack of standardisation and inter-operability.

- Inefficient use of resources if important technological questions are not adequately resolved.

- Possible compromise in system performance if critical technologies are not available when needed.

The potential benefits include:

- Establishment of a basis for new discoveries and major advances in the ocean sciences.

- Advances in relevant areas of research, such as marine biotechnology, the ocean's role in climate change, and the assessment and mitigation of natural hazards (like earthquakes and/or tsunamis).

- Improved access to oceanographic and geophysical data, enabling researchers to study the ocean and Earth in real-time or near-realtime by providing multidisciplinary observatory infrastructures.
- Establishment of permanent observation sites over the $70 \%$ of Earth's surface covered by oceans to provide truly global geophysical and oceanographic coverage.

- Enhancement of interdisciplinary research for improving the understanding of interactions between physical, chemical and biological processes in the oceans.

- Increased public awareness of the oceans by proving new educational opportunities for students at all levels using seafloor observatories as a platform for public participation in real-time experiments.

Carefully evaluating the potential risks and benefits, seafloor observatories represent a promising approach for advancing basic research in the Earth and ocean sciences. However, adequate resources are required, estimated at several tens of million Euros per year. A comprehensive sea-floor observatory programme should include both cabled and moored-buoy systems to adapt to the diverse possible applications. Because of the scientific need to study transient events, it is also important to develop rapidly deployable observatory systems. Applications demanding high telemetry bandwidth and large amounts of power will preferably use submarine communication cables. Retired cables may become available from time to time in areas of scientific interest. Alternatively, new cables may be deployed as part of a seafloor observatory programme. Moored-buoy observatories will be the preferred approach at remote sites, when bandwidth and telemetry requirements are modest, or when the duration of experiment does not justify the cost of a fibre-optic cable. Scientific benefit should be the leading factor influencing the future technological developments in marine instrumentation. Needs for the future may be summarised: a) extend the number and type of platforms, with particular reference to landing systems, benthic observatories and ROVs; b) extend in time the acquisition of time series by more traditional stations (like buoys or moorings); c) collect in real time, increase the number and type of instrumented packages. A promising perspective is the linking of fixed observatories with AUVs, which have the potential of being more cost effective than survey ships. The need for more technological developments related to long-term 
multidisciplinary deep-sea observatories promises a more fruitful relationship between scientific institutions and industries that are moving into deeper waters. Standardisation is one of the key issues for globality, modularity, common installation and recovery tools, and could provide easier maintenance procedures (Ollier et al., 2002). The first step in establishing a seafloor observatory system should be the development of a detailed programme and project implementation plan. This includes a management structure to ensure access to observatory infrastructure. This last requirement is likely to be similar to other large, co-ordinated programmes in the Earth, ocean and planetary sciences (e.g., JOIDES, IRIS and NA-SA). A phased implementation strategy should be developed, with adequate prototyping and testing, before deployment of sea-floor observatories on a large scale. A seafloor observatory programme should include funding for three key elements: observatory infrastructure, new sensors and AUV technology. It is essential that this programme be only one component of a much broader ocean research strategy. New mechanisms should be developed for the evaluation of highly interdisciplinary proposals requiring long time-series observations. An open data policy should be agreed upon to support information centres for archiving observatory data and disseminating data products and information. Also an active public outreach and education programme should be a high-priority component of a seafloor observatory programme. The seafloor observatory programme must include co-operation within international initiatives, like ION.

\section{Acknowledgements}

First of all, we are indebted to the EC which has supported «Seafloor Observatory Science» in Europe by funding many projects as part of the MAST and Environment Programmes (FP 4, 5 and 6).

The Authors also wish to thank their Partners in the European and Italian projects:

GEOSTAR (EC): INGV (co-ordinator; Paolo Favali, Giuseppe Smriglio); ISMAR-CNR (Michael P. Marani); Tecnomare-ENI SpA
(Francesco Gasparoni); TUB (Günther Clauss); TFH (Hans W. Gerber); IFREMER (Jean Marvaldi); LOB-CNRS (Claude Millot); ORCA Instrumentation, now SERCEL-Underwater Acoustic Division (Jean-Michel Coudeville).

GEOSTAR-2 (EC): INGV (co-ordinator; Paolo Favali, Giuseppe Smriglio); ISMARCNR (Michael P. Marani); Tecnomare-ENI SpA (Francesco Gasparoni); TUB (Günther Clauss); TFH (Hans W. Gerber); IFREMER (Jean Marvaldi); LOB-CNRS (Claude Millot); ORCA Instrumentation, now SERCEL-Underwater Acoustic Division (David Fellmann); IPGP (Jean-Paul Montagner).

ASSEM (EC): IFREMER (co-ordinator; Jean-Francois Rolin, Jerome Blandin); IPGP (Pierre Briole); INGV (Giuseppe Etiope); HCMR (Vasilios Lykousis); Patras University (George Ferentinos); CAPSUM Technologie GmbH (Michel Masson); NGI (James Strout); FUGRO Engineers (David Cathie).

ORION-GEOSTAR-3 (EC): INGV (co-ordinator; Paolo Favali, Laura Beranzoli); ISMARCNR (Fabiano Gamberi); Tecnomare-ENI SpA (Francesco Gasparoni); TUB (Günther Clauss); TFH (Hans W. Gerber); IFREMER (Jean Marvaldi); ORCA Instrumentation, now SERCELUnderwater Acoustic Division (Michel Nicot); IFM-GEOMAR (Ernst R. Flueh).

TYDE (EC): INGV (co-ordinator; Paolo Favali); ISMAR-CNR (Michael P. Marani); IFM-GEOMAR (Ernst R. Flueh); University of Hamburg (Torsten Dahm).

ESONET (EC): University of Aberdeen Oceanlab (coordinator; Monty Priede, Martin Solan), INGV (Paolo Favali), Tecnomare-ENI SpA (Francesco Gasparoni); ISMAR-CNR (Nevio Zitellini); University of Troms $\varnothing$ (Jürgen Mienert, Stephanie Guidard); IFREMER (Roland Person); Royal NIOZ (Tjeerd C.E. van Weering); IFM-GEOMAR (Olaf Pfannkuche, Peter Linke); CSA Group Ltd. (Nick O'Neill, Ed Slowey, Martin Davies, Eamonn Kelly); IMBC (Anastasios Tselepides); IUB (Laurenz Thomsen); AWI (Michael Klages, Thomas Soltwedel); MARUM (Christoph Waldmann); LOB-CNRS (Claude Millot); TFH (Hans W. Gerber); CGUL (Jorge M. A. de Miranda).

SN-1 (GNDT): INGV (Laura Beranzoli); Tecnomare-ENI SpA (Francesco Gasparoni); 
TUB (Günther Clauss); TFH (Hans W. Gerber); University of Roma-3 (Claudio Faccenna); University of Catania (Stefano Gresta); University of Messina (Giancarlo Neri); University of Palermo (Dario Luzio); OGS (Marino Russi); ISMAR-CNR (Fabiano Gamberi, Michael P. Marani); IFSI-INAF (Valerio Iafolla).

MABEL (PNRA): INGV (Paolo Favali, Massimo Calcara); Tecnomare-ENI SpA (Francesco Gasparoni); OGS (Renzo Mosetti); TUB (Günther Clauss); TFH (Hans W. Gerber); Collaborations: AWI (Wilfried Jokat); DNA-IAA (José Febrer).

Special thanks to Claudio Viezzoli and Marcantonio Lagalante (marine logistics); Capts. Emanuele Gentile and Vincenzo Lubrano and the crew of R/V Urania, vessel owned by CNR and managed by SoProMar; Capt. Alfio Di Giacomo and the crew of M/P Mazzarò, vessel owned by Gestione Pontoni SpA; Capt. Vincenzo Primo and the crew of $\mathrm{C} / \mathrm{V}$ Pertinacia, owned by Elettra Tlc SpA (Giuseppe Mauge-ri, chief of mission).

The Authors are grateful to reviewers for their help to improve the quality of the paper and to David Barraclough for his comments and revision of the text.

This paper is dedicated to the Memory of Giuseppe Smriglio and Luc Floury, who pioneered this science and clearly recognised its novelty and its great potential many years ago.

\section{List of acronyms and abbreviations used in the text}

ABEL: Abyssal BEnthic Laboratory.

ACORKs: Advanced Circulation Obviation Retrofit Kits.

AGU: American Geophysical Union (WWW site: http:// www.agu.org).

AMANDA: Antarctic Muon And Neutrino Detector Array (WWW site: http://amanda.uci.edu).

ANTARES: Astronomy with a Neutrino Telescope and Abyss environmental RESearch (WWW site: http:// antares.in2p3.fr).

ARENA: Advanced Real-time Earth monitoring Network in the Area (WWW site: http://homepage.mac.home/ ieee_oes_japan/arena).

ARGOS: Advanced Research and Global Observation Satellite (WWW site: http://www.cls.fr/html/argos/ welcome_en.html).

ASSEM: Array of Sensors for long-term SEabed Monitoring of geo-hazards (WWW site: http:// www.ifremer.fr/ assem).
ATOC: Acoustic Thermometry of Ocean Climate (WWW site: http://atoc.ucsd.edu).

AT\&T: American Telephone and Telegraph (WWW site: http://www.att.com)

AUV: Autonomous Underwater Vehicle (WWW site: http:// www.cacs.lo-uisiana.edu/ kimon/auv).

AWI: Alfred-Wegener-Institut für Polar- und Meeresforschung (WWW site: http://www.awi-bremerhaven.de).

B-DEOS: British-Dynamics of Earth and Ocean Systems (WWW site: http://www.deos.org).

BDSN: Berkeley Digital Seismic Network (WWW site: http://quake.geo.berkeley.edu/bdsn).

BIODEEP: BIOtechnologies for the DEEP (WWW site: http:// www.geo.uni-mib.it/BioDeep).

CGUL: Centro de Geofisica da Universidade de Lisboa (WWW site: http://www.cgul.ul.pt).

CLIVAR: CLImate VARiability and predictability programme (WWW site: http://www.clivar.org).

CNR: Consiglio Nazionale delle Ricerche (WWW site: http://www.cnr.it)

CNRS: Centre National de la Recherche Scientifique (WWW site: http://www.cnrs.fr)

CORKs: Circulation Obviation Retrofit Kits (WWW site: http://www.rbr-global.com/cork.htm).

CSSF: Canadian Scientific Submersible Facility (WWW site: http://www.ropos.com/cssf/cssf.htm).

CTD: Conductivity, Temperature and Depth.

C/V: Cable Vessel.

DACS: Data Acquisition and Control System.

DEOS $^{(\mathrm{a})}$ : Deep Earth Observatories on the Seafloor (WWW site: http:// www.coreocean/deos).

DEOS $^{(\mathrm{b})}$ : Dynamics of Earth and Ocean Systems (WWW site: http:// www.deos.org).

DESIBEL: DEep-Sea Intervention on future BEnthic Laboratory (WWW site: http://dbs.cordis.lu/cordis-cgi/ srchidadb?caller=projadvancedsrch\&srch\&qf_ep_rcn_ $a=27267$ \&action $=d$ ).

dGPS: Differential Global Positioning System (WWW site: http://chartmaker.ncd.noaa.gov/staff/dgps.htm).

DNA-IAA: Direccion Nacional del Antartico-Istituto Antartico Argentino (WWW site: http://www.dna.gov.ar).

DP: Dynamic Positioning.

DPG: Differential Pressure Gauge.

DSDP: Deep-Sea Drilling Project (WWW site: http:// www-odp.tamu.edu)

DUMAND: Deep Underwater Muon And Neutrino Detection (WWW site: http:// www.phys.hawaii.edu/dmnd/ dumand.html).

DWDM: Dense Wavelength Division Multiplexing (WWW site: http://www.iec.org/online/tutorials/dwdm).

EC: European Commission (http://europa.eu.int/comm).

ECORD: European Consortium for Ocean Research Drilling (WWW site: http://www.ecord.org).

ENI: Ente Nazionale Idrocarburi (WWW site: http:// www.eni.it)

ERI: Earthquake Research Institute (Tokyo) (WWW site: http://www.eri.u-tokyo.ac.jp).

ESA: European Space Agency (WWW site: http:// www.esa.int).

ESF: European Science Foundation (WWW site: http:// www.esf.org).

ESONET: European Seafloor Observatory NETwork (WWW site: http://www.abdn.ac.uk/ecosystem/esonet). 
EU: European Union (WWW site: http://europa.eu.int).

FP: Framework Programme (WWW site: http:// europa.eu.int/ comm/research).

GEO: Global Eulerian Observatories (WWW site: http:// www.oceantimeseries.org/oceansites).

GEOFon: GEOForschungsNetz (WWW site: http://www.gfzpotsdam.de).

GEOSCOPE: Réseau Geoscope de sismologie globale (IPGP Programme) (WWW site: http://geoscope.ipgp.jussieu.fr).

GEOSS: Global Earth Observing System of Systems (WWW site: http://earthobservations.org)

GEOSTAR: GEophysical and Oceanographic STation for Abyssal Research (WWW site: http://www.ingv.it/ geostar/geost.htm).

GEOSTAR-2: GEOSTAR 2nd Phase: deep-sea mission (WWW site: http://www.ingv.it/geostar/geost2.htm).

GeO-TOC: Geophysical and Oceanographic Trans Ocean Cable (WWW site: http://wwweprc.eri.u-tokyo.ac.jp/ kaiiki/geo_eng.html).

GeV: Giga electronVolt.

GITEC-TWO: Genesis and Impact of Tsunamis on the European Coasts-Tsunami Warning and Observations.

GMM: Gas Monitoring Module (WWW site: http:// www.ifremer.fr/assem/corinth/photo_gallery/photo_ gallery.htm).

GMES: Global Monitoring for Environment and Security (WWW site: http://www.gmes.info).

GNDT: Gruppo Nazionale per la Difesa dai Terremoti (WWW site: http://gndt.ingv.it).

GOALS: Global Ocean-Atmosphere-Land System (WWW site: http://www.nap.edu/books/0309051800/html).

GOBO: Geophysical Ocean-Bottom Observatory.

GOOS: Global Ocean Observing System (WWW site: http://ioc.u-nesco.org/goos).

GPS: Global Positioning System (WWW site: http:// gps.losangeles.af.mil)

GSN: Global Seismographic Network (WWW site: http:// www.iris.edu/ about/gsn).

HCMR: Hellenic Centre for Marine Research (WWW site: http://www.hcmr.gr).

HSVA: Hamburgische Schiffbau-VersuchsAnstalt $\mathrm{GmbH}$ (WWW site: http://www.hsva.de).

HUGO: Hawaii Undersea Geo-Observatory (WWW site: http://www.soest.hawaii.edu/hugo).

H2O: Hawaii-2 Observatory (WWW site: http:// www.soest.hawaii.edu/h2o).

IASPEI: International Association for Seismology and Physics of the Earth Interior (WWW site: http:// www.iaspei.org).

IEEE: Institute of Electrical and Electronics Engineers (WWW site: http://www.ieee.org).

IFE: Institute For Exploration (WWW site: http:// www.mystica-quarium.org/).

IFM-GEOMAR: Leibniz-Institut für Meereswissenschaften an der Universität Kiel (WWW site: http://www.ifmgeomar.de).

IFREMER: Institut Français de Recherche pour l'Exploitation de la Mer (WWW site: http://www.ifremer.fr).

IFSI-INAF: Istituto di Fisica dello Spazio InterplanetarioIstituto Nazionale di Astrofisica (WWW site: http:// www.inaf.it).

IMBC: Institute of Marine Biology of Crete (WWW site: http://www.imbc.gr).
IMR: Institute of Marine Research (Norway) (WWW site: http://www.imr.no).

INFN: Istituto Nazionale di Fisica Nucleare (WWW site: http://www.infn.it).

INGV: Istituto Nazionale di Geofisica e Vulcanologia (WWW site: http://www.ingv.it).

INSU: Institut National des Sciences de l'Univers (WWW site: http:// www.insu.cnrs.fr).

InterRIDGE: International Ridge InterDisciplinary Global Experiments (WWW site: http://interridge.org).

IODP: Integrated Ocean Drilling Programme (WWW site: http://www.iodp.org).

ION: International Ocean Network (WWW site: http:// www.iaspei.org/commissions/ion.html).

IOOS: Integrated and sustained Ocean Observing System (WWW site: http://www.ocean.us).

IPCC: Intergovernmental Panel on Climate Change (WWW site: http://www.ipcc.ch).

IPGP: Institut de Physique du Globe de Paris (WWW site: http://www.ipgp.jussieu.fr).

IRIS: Incorporated Research Institutions for Seismology (WWW site: http://www.iris.washington.edu).

ISMAR: Istituto di Scienze Marine-CNR, Sezione di Geologia Marina di Bologna (WWW site: http:// www.bo.ismar.cnr.it).

IUB: International University Bremen (WWW site: http:// www.iu-bremen.de).

IUGG: International Union of Geodesy and Geophysics (WWW site: http://www.iugg.org).

JAMSTEC: JApan Marine Science and TEchnology Centre (WWW site: http://www.jamstec.go.jp).

JEODI: Joint European Ocean Drilling Initiative (WWW site: http://www.ecord.org/about/j/jeodi1.html).

JGOFS: Joint Global Ocean Flux Study (WWW site: http:// usj-gofs.whoi.edu)

JMA: Japan Meteorological Agency (WWW site: http:// www.jma.go.jp).

JOI: Joint Oceanographic Institutions (WWW site: http:// www.joi-science.org).

JOIDES: Joint Oceanographic Institutions for Deep Earth Sampling (WWW site: http://poseidon.palaeoz.geomar.de).

KM3NET: $\mathrm{km}^{3}$ NETwork (WWW site: http://www.km3net. org).

LDEO: Lamont-Doherty Earth Observatory (WWW site: http://www.ldeo.columbia.edu).

LEO-15: Long-term Ecosystem underwater Observatory, $15 \mathrm{~m}$ b.s.l. (WWW site: http://marine.rutgers.edu/nurp/ factech.html).

LNS: Laboratori Nazionali del Sud (WWW site: http:// www.lns.infn.it).

LOB: Laboratoire de Océanologie et de Biogeochemie (WWW site: http://www.com.univ-mrs.fr/lob).

LTER: Long-Term Ecological Research Network (WWW site: http://lternet.edu)

LT-BB: Long-Term Broad Band.

LT-OBS: Long-Term Ocean Bottom Seismometer.

LT-VBB: Long-Term Very Broad Band.

MABEL: Multidisciplinary Antarctic BEnthic Laboratory (WWW site: http://www.ingv.it/geostar/mabel.html).

MARGINS: Margins Programme (WWW site: http:// www.mar gins.wustl.edu).

MARS: Monterey Accelerated Research System (WWW 
site: http://www.mbari.org/mars).

MARUM: Zentrum für marine Umweltwissenschaften (WWW site: http://www.marum.de).

MAST: MArine Science and Technology (WWW site: http://www.cor-dis.lu/mast).

MBARI: Monterey Bay Aquarium Research Institute (WWW site: http://www.mbari.org).

MedNet: Mediterranean Network (WWW site: http:// mednet.ingv.it).

MOBB: Monterey bay Ocean Broad-Band observatory (WWW site: http://quake.geo.berkeley.edu/bdsn/ mobb.overview.htm).

MODUS: MObile Docker for Underwater Sciences.

MOISE: Monterey bay Ocean bottom International Seismic Experiment (WWW site: http://www.mbari.org/ shake/MOISE).

MoMAR: Monitoring the Mid-Atlantic Ridge (WWW site: http://www.momar.org).

MOOS: Monterey bay Ocean-Observing System (WWW site: http:// www.mbari.org/moos).

MoU: Memorandum of Understanding.

M/P: Moto Pontoon.

MT: Magneto Telluric (array).

MVCO: Martha's Vineyard Coastal Observatory (WWW site: http://www.whoi.edu/mvco).

NASA: National Aeronautic and Space Administration (WWW site: http:// www.nasa.gov).

NeMO: New Millennium Observatory (WWW site: http:// www.pmel.noaa.gov/vents/nemo).

NEMO: NEutrino Mediterranean Observatory (WWW site: http://nemoweb.lns.infn).

NEPTUNE: North East Pacific Time-series Undersea Networked Experiments (WWW site: http://www.neptune.washington.edu).

NERC: Natural Environment Research Council (WWW site: http://www.nerc.ac.uk).

NEREID: Neath Seafloor Equipment for Recording Earth's Internal Deformation

NERO: Ninety East Ridge Observatory (WWW site: http://www.ifre-mer.fr/dtmsi/programmes/nero.htm).

NESTOR: NEutrino experimental Submarine Telescope with Oceanographic Research (WWW site: http:// www.nestor.org.gr).

NGI: Norges Geotekniske Institutt (WWW site: http:// www.ngi.no).

NIED: National research Institute for Earth science and Disaster prevention (WWW site: http://www.bosai.go.jp).

NOAA: National Oceanic and Atmospheric Administration (WWW site: http://www.noaa.gov).

NOC: National Oceanography Centre, Southampton (WWW site: http://www.noc.soton.ac.uk).

NRC: National Research Council (WWW site: http:// www.nationalacademies.org/nrc).

NSF: National Science Foundation (WWW site: http:// www.nsf.gov).

OBEM: Ocean Bottom Electro Magnetometer.

OBH: Ocean Bottom Hydrophone.

OBS: Ocean Bottom Seismometer.

OceanSITES: OCEAN Sustained Interdisciplinary Time series Environment observation System (WWW site: http://www.ocean-sites.org/oceansites).

ODP: Ocean Drilling Programme (WWW site: http:// www.odp.tamu.edu).
OFM: Observatorie Fond de Mer (WWW site: http:// www.dt.insu.cnrs.fr/ ofm/ofm.php).

OGS: Istituto Nazionale di Oceanografia e Geofisica Sperimentale (WWW site: http://Www.ogs.trieste.it).

OHP: Ocean Hemisphere network Project (WWW site: http://eri-ndc.eri.u-tokyo.ac.jp/en/ohp/index.html).

OOI: Ocean Observatories Initiative (WWW site: http:// www.orionprogram.org/ooi).

ORION: Ocean Research Interactive Observatory Networks (WWW site: http://www.orionprogram.org).

ORION-GEOSTAR-3: Ocean Research by Integrated Observation Networks (WWW site: http://www.ingv.it/ geostar/orion.htm).

OSN: Ocean Seismic Network.

OSNPE: Ocean Seismic Network Pilot Experiment.

PNRA: Programma Nazionale di Ricerche in Antartide (WWW site: http://www.pnra.it).

RIDGE: Ridge InterDisciplinary Global Experiments.

ROPOS: Remote Operated Platform for Ocean Science (WWW site: http://www.ropos.com).

ROV: Remote Operated Vehicle (WWW site: http:// my.fit.edu/ swood/ rov_pg2.html).

Royal NIOZ: Royal Netherlands Institute for Sea Research (WWW site: http://www.nioz.nl).

R/V: Research Vessel.

SAPPI: Satellite-linked Autonomous Pore Pressure Instrument.

SEABASS: SEAfloor Borehole Array Seismic Network.

SEIZE: SEIsmogenic Zone Experiment (WWW site: http:// www.margins.wustl.edu/seize/seize.html\#webinfo).

SFEMS: SeaFloor Electro Magnetic Station.

SIO: Scripps Institution of Oceanography (WWW site: http://sio.ucsd.edu).

SN-1: Submarine Network-1 (WWW site: http://www.ingv.it/ geostar/sn.htm).

TAO: Tropical Atmosphere-Ocean array (WWW site: http://www.p-mel.noaa.gov/tao).

TeV: Tera electronVolt.

TFH: Techniche Fachhochschule Berlin (WWW site: http:// www.tfh-berlin.de).

TPC: Transoceanic Phone Cable.

TUB: Technische Universität Berlin (WWW site: http:// www.tu-berlin.de).

TYDE: TYrrhenian Deep-sea Experiment (WWW site: http://www.ingv.it/geostar/tyde.htm).

USGS: United States Geological Survey (WWW site: http://www.usgs.gov).

USSAC: United States Science Advisory Committee (WWW site: http://Www.usssp-iodp.org).

VENUS (CAN): Victoria Experimental Network Under the Sea (WWW site: http://Www.venus.uvic.ca).

VENUS (JP): Versatile Eco-monitoring Network by Undersea-Cable System (WWW site: http://wwweprc.eri.utokyo.ac.jp/haiiki/cable_eng.html).

VLF: Very Low Frequency.

WHOI: Woods Hole Oceanographic Institution (WWW site: http://www.whoi.edu).

WING: Western pacific Integrated Network of GPS (WWW site: http://sps.unavco.org/crustal_motion/dxdt).

WP: Western Pacific.

WWSSN: World-Wide Standardised Seismograph Network (WWW site: http://www.seismo.com/msop/msop79/ msop.html). 


\section{REFERENCES}

AdAIR, R.G., M.M. HARRIS, J.A. ORCUTT and T.H. JordAN (1987): Description and performance of the Marine Seismic System during the Ngendei Experiment, Init. Rep. DSDP, 91, 335-345.

Ahrens, J., J.N. BAHCALl, X. BAi, R.C. BAY, T. BECKA, K.H. Becker, D. Berley, E. Bernardini, D. Bertrand, D.Z. Besson, A. Biron, E. Blaufuss, D.J. Boersma, S. Böser, C. Bohm, O. Botner, A. Bouchta, O. Bouhali, T. Burgess, W. Carithers, T. Castermans, J. Cavin, W. Chinowsky, D. Chirkin, B. Collin, J. Conrad, J. Cooley, D.F. Cowen, A. Davour, C. De ClercQ, T. DeYoung, P. Desiati, R. Ehrlich, R.W. Ellsworth, P.A. Evenson, A.R. FAzely, T. Feser, T.K. Gaisser, J. Gallagher, R. Ganugapati, H. Geenen, A. Goldschmidt, J.A. Goodman, R.M. Gunasingha, A. Hallgren, F. Halzen, K. Hanson, R. Hardtke, T. Hauschildt, D. Hays, K. Helbing, M. Hellwig, P. Herquet, G.C. Hill, D. Hubert, B. Hughey, P.O. Hulth, K. Hultqvist, S. Hundertmark, J. Jacobsen, G.S. Japaridze, A. Jones, A. Karle, H. Kawai, M. Kestel, N. Kitamura, R. Koch, L. KöPKe, M. KowalSKi, J.I. LamoureuX, H. Leich, M. Leuthold, I. LIubarsky, J. Madsen, H.S. Matis, C.P. McParland, T. Messarius, P. Mészáros, Y. Minaeva, R.H. Minor, P. Mioinovi, H. Miyamoto, R. Morse, R. Nahnhauer, T. Neunhöffer, P. Niessen, D.R. Nygren, H. Ögelman, Ph. Olbrechts, S. Patton, R. Paulos, C. Pérez de los Heros, A.C. Pohl, J. Pretz, P.B. Price, G.T. PrzybylSki, K. Rawlins, S. RazZaque, E. Resconi, W. Rhode, M. Ribordy, S. Richter, H.-G. SANDER, K. SchINARAKIS, S. SCHLENSTEDT, T. SCHMIDT, D. SCHNEIDER, R. Schwarz, D. Seckel, A.J. Smith, M. Solarz, G.M. Spiczak, C. Spiering, M. Stamatikos, T. Stanev, D. Steele, P. Steffen, T. Stezelberger, R.G. Stokstad, K.-H. Sulanke, G.W. Sullivan, T.J. Sumner, I. TABOAda, S. TILAV, N. van EIJNDHOVEN, W. WAGNER, C. Walck, R.-R. Wang, C.H. Wiebusch, C. WiedeMANN, R. WISCHNEWSKI, H. Wissing, K. WOSCHNAGG and S. YoshIDA (2004): Sensitivity of the ICECUBE detector to astrophysical sources of high energy muon neutrinos, Astropart. Phys., 20, 507-532.

ANDo, M. (1975): Source mechanisms and tectonic significance of historical earthquakes along the Nankai Trough, Japan, Tectonophysics, 27, 119-140.

Andres, E., P. Askebjer, X. Bai, G. Barouch, S.W. BarWick, R.C. BAy, K.-H. Becker, L. Bergström, D. Bertrand, D. Bierenbaum, A. Biron, J. Booth, O. Botner, A. Bouchta, M.M. Boyce, S. CArius, A. Chen, D. Chirkin, J. Conrad, J. Cooley, C.G.S. CosTA, D.F. Cowen, J. Dailing, E. Dalberg, T. DeYoung, P. Desiati, J.-P. Dewulf, P. Doksus, J. Edsjoe, P. EkStröm, B. Erlandsson, T. Feser, M. Gaug, A. GoldSCHMidT, A. GoObar, L. Gray, H. HaAse, A. HAllgren, F. Halzen, K. Hanson, R. Hardtke, Y.D. He, M. Hellwig, H. Heukenkamp, G.C. Hill, P.O. Hulth, S. Hundertmark, J. Jacobsen, V. Kandhadai, A. Karle, J. Kim, B. Koci, L. KöpKe, M. Kowalski, H. Leich, M. Leuthold, P. Lindahl, I. LiUbarsky, P. Loaiza, D.M. Lowder, J. Ludvig, J. Madsen, P. Marciniewski, H.S. Matis, A. Mihalyi, T. MikolajsKi, T.C. Miller, Y. Minaeva, P. Mio, P.C. Mock, R.
Morse, T. Neunhoffer, F.M. Newcomer, P. Niessen, D.R. Nygren, H. Igelman, C. Perez de los Heros, R. Porrata, P.B. Price, K. Rawlins, C. Reed, W. Rhode, A. Richards, S. Richter, J. Rodriguez Martino, P. Romenesko, D. Ross, H. Rubinstein, H.-G. SANDER, T. Scheider, T. Schmidt, D. Schneider, E. SchneIder, R. Schwarz, A. Silvestri, M. Solarz, G.M. SpiczaK, C. Spiering, N. Starinsky, D. Steele, P. Steffen, R.G. Stokstad, O. Streicher, Q. Sun, I. Taboada, L. Thollander, T. Thon, S. TilaV, N. Usechak, M. VANDER DonckT, C. WALCK and C. WeINHEIMER (2001): Observation of high-energy neutrinos using Čerenkov detectors embedded deep in Antarctic ice, Nature, 410, 441-443.

Araki, E., M. Shinohara, S. Sacks, A. Linde, T. Kanazawa, H. Shiobara, H. Mikada and K. Suyehiro (2004): Improvement of seismic observation in the ocean by use of seafloor boreholes, Bull. Seismol. Soc. Am., 94, 678-690.

AsAKaWA, K., Y. ShIRASAKI, M. YoshidA and T. NishidA (2003): Feasibility study on long-term continuous monitoring from seafloor with underwater cable network, in Proceedings 4th International Workshop on Very Large Floating Structures, 350-357.

Asakawa, K., J. Kojima and J. Muramatsu (2005): Current-to-current converter for scientific cable networks, Sea Technol., 46 (7), 41-43.

Austin, T.C., J.B. Edson, W.R. McGillis, M. Purcell, R.A. Petitt Jr., M.K. McElroy, C.W. Grant, J. Ware and S.K. HuRst (2002): A network-based telemetry architecture developed for the Martha's Vineyard Coastal Observatory, IEEE J. Oceanic Eng., 27, 228-234.

BAHCALL, J. and E. WAXMAN (2001): High energy astrophysical neutrinos: the upper bound is robust, Phys. Rev., D64, 023002-1-8.

Barberi, G., L. Beranzoli, P. Favali, G. Neri and T. Sgroi (2006): Seismic location improvements from OBS/H temporary network in Sicily, Ann. Geophysics, 49 (2/3), 739-749 (this volume).

Beauduin, R., P. Lognonné, J.-P. Montagner, J.-F. KarCZEWSKI and M. MORAND (1996a): The effects of atmospheric pressure changes on seismometers: a matter of installation, Bull. Seismol. Soc. Am., 86, 760-1769.

Beauduin, R., J.-P. Montagner and J.-F. Karczewski (1996b): Time evolution of broad-band seismic noise during the French pilot experiment OFM/SISMOBS, Geophys. Res. Lett., 23, 2955-2998.

BECKER, K. and M.J. MALONE (Editors) (2001): CORK Hole 395A, Proc. ODP, Sci. Results, 174B (CD-ROM), (available from Ocean Drilling Program, Texas A\&M University, College Station, TX 77845-9547, U.S.A.).

Becker, K., M.J. Malone, E.M. Arnold, A.C.M. BarTEZKo, J. FARrell, M.D. Fuller, D. GoldBERG, R.N. Harris, S. Hirano, S.D. Hurst, T. Matsumoto, K. Moran, P.A. PEZARD and Y.-F. Sun (1998): CORK Hole 395A, Proc. ODP, Initial Rep., 174B (CD-ROM), (available from Ocean Drilling Program, Texas A\&M University, College Station, TX 77845-9547, U.S.A.).

Becker, K., E.E. DAvis, F.N. SpIESS and C.P. DEMoustier (2004): Temperature and video logs from the upper oceanic crust, Holes 504B and 896A, Costa Rica Rift flank: implications for the permeability of upper oceanic crust, Earth Planet. Sci. Lett., 222, 881-896. 
Begnaud, M.L. and D.S. Stakes (2000): Constraining continental margin seismicity by extending on-shore seismograph stations to critical off-shore sites, Bull. Seismol. Soc. Am., 90, 414-424.

Belolaptikov, I.A., L.B. Bezrukov, B.A. Borisovets, N.M. Budnev, E.V. Bugaev, A.G. Chensky, I.A. DanilCHENKo, J.-A.M. DJILKIBAEV, V.I. DobRYNIN, G.V. DoMOGATSKY, L.A. Donskych, A.A. Doroshenko, G.N. DudKIn, V.Yu. EgOROV, S.V. FialKovsky, A.A. Garus, A. Gaponenko, A.V. Golikov, O.A. Gress, T.A. Gress, M.N. Gushtan, R. Heller, V.B. Kabikov, H. Heukenkamp, A. Karle, A.M. Klabukov, A.I. Klimov, S.I. Klimushin, A.P. Koshechiin, J. Krabi, V.F. KulePOV, L.A. KuZMichov, O.Yu. LANIN, A.L. Lopin, B.K. Lubsandorzhiev, M.B. Milenin, T. Mikolajski, R.R. Mirgazov, A.V. Moroz, N.I. Moseiko, M.N. NeMCHENKo, S.A. NikIFOROV, N.V. OGIEVETSKY, E.A. OSIPOva, A.N. Padusenko, A.I. Panfilov, Yu.V. Parfenov, A.A. Pavlov, D.P. Petukhov, K.A. Pocheikin, P.G. Pokhil, P.A. Pokolev, M.I. Rosanov, V.Yu. Rubzov, A.V. Rzhestshitski, S.I. Sinegovsky, I.A. Sokalski, Ch. Spiering, O. Streicher, A.A. Sumanov, L. Tanko, T. Thon, B.A. Tarashanski, I.I. Trofimenko, CH. WIEBUSCH, R. WISCHNEWSKI and V.L. ZURBANOV (1997): The Baikal underwater neutrino telescope: design, performance, and first results, Astropart. Phys., 7, 263-282.

Beranzoli, L., A. De Santis, G. Etiope, P. Favali, F. FruGoni, G. Smriglio, F. Gasparoni and A. Marigo (1998): GEOSTAR: a GEophysical and Oceanographic STation for Abyssal Research, Phys. Earth Planet. Int., 108, 175-183.

Beranzoli, L., T. Braun, M. Calcara, D. Calore, R. Campaci, J.-M. Coudeville, A. De Santis, G. Etiope, P. Favali, F. Frugoni, J.-L. Fuda, F. Gamberi, F. Gasparoni, H.W. Gerber, M.P. Marani, J. Marvaldi, C. Millot, P. Palangio, G. Romeo and G. Smriglio (2000a): European seafloor observatory offers new possibilities for deep-sea study, Eos, Trans. Am. Geophys. Un., 81, 45-49.

Beranzoli, L., T. Braun, M. Calcara, A. De Santis, D. Di Mauro, G. Etiope, P. Favali, F. Frugoni, C. Montuori, P. Palangio, G. Romeo, G. Smriglio, F. GamBERI, M.P. MARANI, J.-L. FudA and C. Millot (2000b): GEOSTAR, an observatory for deep-sea geophysical and oceanographic researches: characteristics, first scientific mission and future activity, Mem. Soc. Geol. Ital., 55, 491-497.

Beranzoli, L., P. Favali and G. SMriglio (Editors) (2002): Science-technology synergy for research in marine environment: challenges for the XXI century, Developments in Marine Technology Series (Elsevier, Amsterdam), 12, pp. 268.

Beranzoli, L., T. Braun, M. Calcara, P. Casale, A. De Santis, G. D’Anna, D. Di Mauro, G. Etiope, P. Favali, J.-L. Fuda, F. Frugoni, F. Gamberi, M.P. Marani, C. Millot, C. Montuori and G. Smriglio (2003): Mission results from the first GEOSTAR Observatory (Adriatic Sea, 1998), Earth Planets Space, 55, 361-373.

Beranzoli, L., D. Calore, P. Favali, J. Marvaldi and M. NICOT (2004): ORION-GEOSTAR-3: A Prototype of seafloor network of observatories for geophysical, oceanographic and environmental monitoring, in Pro- ceedings 14th International Off-shore and Polar Engineering Conference (Toulon, France), vol. II, 371-376.

Berta, M., F. Gasparoni and M. Capobianco (1995): Abyssal Benthic Laboratory (ABEL): a novel approach for long-term investigation at abyssal depths, J. Mar. Syst., 6, 211-225.

Bialas, J., E.R. Flueh, J. Phipps Morgan, K. Schleisiek and G. NeuHAUSER (2002): Ocean-bottom seismology in the Third Millennium, in Science-Technology Synergy for Research in the Marine Environment: Challenges for the XXI Century, edited by L. BERANZOLI, P. FAVAli and G. SMriglio, Developments in Marine Technology Series (Elsevier, Amsterdam), 12, 37-44.

Blandin, J., R. Person, J.M. Strout, P. Briole, G. Etiope, M. Masson, S. SMOLdERS, V. LyKousis, G. Ferentinos and J. LEGRAND (2003): ASSEM: a new concept of regional observatory, in Proceedings 3rd International Workshop on Scientific Use of Submarine Cables and Related Technologies, Tokyo, Japan, edited by J. KASAHARA and A.D. CHAVE, IEEE Catalogue No. 03EX660, 240-243.

Boschi, E., E. Guidoboni, G. Ferrari, G. Valensise and P. GASPERINI (Editors) (1997): Catalogue of the Strong Earthquakes in Italy from 461 BC to 1990 (ING, Roma - SGA, Bologna), pp. 973.

Brewer, P.G., J. Pasteris, G. Malby, E. Peltzer, S. White, J. Freeman, B. Wopenka, M. Brown and D. Cline (2002): Laser Raman spectroscopy used to study the ocean at 3600-m depth, Eos, Trans. Am. Geophys. Un., 83, 469-470.

Brewer, P.G., G. Malby, J. Pasteris, N. Sheri, E. Peltzer, B. Wopenka, J. FreEman and M. Brown (2004): Development of a laser Raman spectrometer for deep-ocean science, Deep-Sea Res., 51, 739-753

Burns, R.F. (1999): Hawaii-2 Observatory, Sea Technol., 40 (9), 10-18.

Butler, R., A.D. Chave, F.K. Duennebier, D.R. Yoerger, R. Petitt, D. Harris, F.B. Wooding, A.D. Bowen, J. Bailey, J. Jolly, E. Hobart, J.A. Hildebrand and H. DodEman (2000): Hawaii-2 Observatory pioneers opportunities for remote instrumentation in ocean studies, Eos, Trans. Am. Geophys. Un., 81, 157 and 162-163.

Calcara, M., L. Beranzoli, T. Braun, D. Calore, A. De Santis, G. Etiope, P. Favali, F. Frugoni, F. GaspaRONi, C. MONTUORI and G. SMriglio (2001): MABEL: a multidisciplinary benthic laboratory for deep-sea, long-term monitoring in the Antarctic, Terra Antarcti$c a, 8,115-118$.

Capone, A., M. Ambriola, R. Bellotti, F. Cafagna, M. Circella, C. De Marzo, T. Montaruli, M. Romita, A. Gabrielli, E. Gandolfi, G. Giacomelli, A. Margiotta, M. Masetti, P. Ricci, M. Spurio, G. Canarini, R. Habel, S. Aiello, G. Andronico, F. Burgio, L. Caponnetto, G. Giansiracusa, L. Lo Nigro, D. lo Presti, L. Pappalardo, C. Petta, N. Randazzo, G.V. Russo, S. Trovato, M. Anghinolfi, M. Battaglieri, A. Bersani, S. Cuneo, R. De Vita, G. Ricco, M. Ripani, M. Taiuti, S. Zavatarelli, M. Cordelli, A. Martini, L. Trasatti, V. Valente R. Cocimano, R. Coniglione, C. Distefano, D. Garufi, E. MigneCo, M. Musumeci, R. Occhipinti, R. Papaleo, P. Piattelli, G. Raia, G. Riccobene, P. Sapienza, M. Sedita, E. Amato, V. D'Amico, A. Italiano, F. Ameli, M. Bonori, F. Massa, R. Fasullo and E. Salusti 
(2002): NEMO: a project for a $\mathrm{km}^{3}$-scale neutrino telescope in the Mediterranean Sea near the South Italy coasts, in Science-Technology Synergy for Research in the Marine Environment: Challenges for the XXI Centu$r y$, edited by L. Beranzoli, P. FAVAli and G. SMriglio, Developments in Marine Technology Series (Elsevier, Amsterdam), 12, 121-129.

Cenedese, S., M. Calcara, G. D’Anna, K.-U. Evers, P. FAVAli and F. GASPARONI (2004): MABEL: the first seafloor observatory for multidisciplinary long-term monitoring in polar environment, in Proceedings 14th International Off-shore and Polar Engineering Conference (Toulon, France), vol. I, 787-794.

Chave, A.D., R. Butler and T.E. Pyle (Editors) (1990): Proceedings 1st International Workshop on Scientific Uses of Undersea Cables, January 30-February 1, 1990, Honolulu, Hawaii (JOI, Washington DC), pp. 310.

Chave, A.D., F.K. Duennebier, R. Butler, R.A. Petitt JR., F.B. Wooding, D. Harris, J.W. Bailey, E. Hobart, J. Jolly, A.D. Bowen and D.R. YOERGER (2002): H2O: The Hawaii-2 Observatory, in Science-Technology Synergy for Research in the Marine Environment: Challenges for the XXI Century, edited by L. BERANZOLI, P. FAVAli and G. SMriglio, Developments in Marine Technology Series (Elsevier, Amsterdam), 12, 83-91.

Chave, A.D., G. Waterworth, A.R. Maffei and G. MasSION (2004): Cabled ocean observatory systems, Mar. Tech. Soc. J., 38, 31-43.

Chave, A.D., E. Massion and H. Mikada (2006): Science requirements and the design of cabled ocean observatories, Ann. Geophysics, 49 (2/3), 569-579 (this volume).

Chiappini, M., G.P. Gregori, G. Paparo, C. Bellecci, G.M. Crisci, G. De Natale, P. Favali, I. Marson, A. Meloni, B. Zolesi and E. Boschi (2002): Stromboli: a natural laboratory of environmental science, J. Volcanol. Geotherm. Res., 113, 429-442.

Clauss, G. and S. Hoog (2002): Deep-sea challenges of marine technology and oceanographic engineering, in Science-Technology Synergy for Research in the Marine Environment: Challenges for the XXI Century, edited by L. Beranzoli, P. Favali and G. Smriglio, Developments in Marine Technology Series (Elsevier, Amsterdam), 12, 133-142.

Clauss, G., S. Hoog, F. Stempinski and H.W. Gerber (2004): Advanced deepwater intervention with MODUS - Latest results from model tests and full-scale operations, in Proceedings 14th International Off-shore and Polar Engineering Conference (Toulon, France), vol. II, 377-386.

Collins, J.A., F.L. Vernon, J.A. Orcutt, R.A. StePhen, K.R. Peal, F.B. Wooding, F.N. Spiess and J.A. HiLdeBRAND (2001): Broad-band seismology in the oceans: lessons from the ocean seismic network pilot experiment, Geophys. Res. Lett., 28, 49-52.

Collins, J.A., F.L. Vernon, J.A. Orcutt and R.A. StePhen (2002): Upper mantle structure beneath the Hawaiian swell: constraints from the ocean seismic pilot experiment, Geophys. Res. Lett., 29, 1522, doi: 10.1029/ 2001 GL013302.

Crawford, W.C. and S.C. WebB (2002): Removing tilt noise from low frequency $(<0.1 \mathrm{~Hz})$ seafloor vertical seismic data, Bull. Seismol. Soc. Am., 90, 952-963.

Dahm, T., M. Thorwart, E.R. Flueh, T. Braun, H. Her-
Ber, P. Favali, L. Beranzoli, G. D'Anna, F. Frugoni and G. SMriglio (2002): Ocean bottom seismometers deployed in Tyrrhenian Sea, Eos, Trans. Am. Geophys. Un., 83, 309-315.

Daughney, C.J., J.-P. Rioux, D. Fortin and T. PichleR (2004): Laboratory investigation of the role of bacteria in the weathering of basalt near deep-sea hydrothermal vents, Geomicrobiol. J., 21, 21-31.

Davis, E.E., K. BeCKer, T.L. PetTigrew, B. CARson and R. MACDONALD (1992): CORK: a hydrologic seal and downhole observatory for deep-ocean boreholes, Proc. ODP Initial Rep., 139, 43-53 (CD-ROM).

Delaney, J.R., D.S. Kelley, M.D. Lilley, D.A. ButterFIELD, J.A. BAROSS, W.S.D. WILCOCK, R.W. EMBLEY and M. Summit (1998): The quantum event of oceanic crustal accretion: impacts of diking at mid-ocean ridges, Science, 281, 222-230.

Delaney, J.R., G.R. Heath, B. Howe and A.D. Chave (2000): NEPTUNE: Real-time, long-term Ocean \& Earth studies at the scale of a tectonic plate, Oceanography, 13, 71-79.

De Martini, P.M., P. Burrato, D. Pantosti, A. Maramai, L. GraZiani and H. Abramson (2003): Identification of tsunami deposits and liquefaction features in the Gargano area (Italy): paleoseismological implication, Ann. Geophysics, 46 (5), 883-902.

De Paolo, D.J. and M. Manga (2003): Deep origin of hotspots; the mantle plume model, Science, 300, 920921.

De Santis, A., D. Di Mauro, L. Cafarella, R. D’Anna, L. Gaya-Pique, P. Palangio, G. Romeo and R. Tozzi (2006): Deep seafloor magnetic observations under GEOSTAR project, Ann. Geophysics, 49 (2/3), 681693 (this volume).

Driscoll, N., J.K. Weissel and J.A. GofF (2000): Potential for large-scale submarine slope failure and tsunami generation along the US Mid-Atlantic coast, Geology, 28, 407-410.

Duennebier, F.K., R.A. Stephen, J.F. Gettrust, F. AvediK, J.A. Ballard, D. Bibee, M. Fehler, A. Inderbitzen, R. Jacobsen, G. PAScal and J.H. NATland (Editors) (1987): Initial Reports of the DSDP, 88, pp. 165.

Duennebier, F.K., D.W. HARris, J. Jolly, J. CAPlan-AuerBach, R. Jordan, D. Copson, K. StifFel, J. Babinec and J. Bosel (2002a): HUGO: the Hawaii Undersea Geo-Observatory, IEEE J. Oceanic Eng., 27, 218-227.

Duennebier, F.K., D.W. Harris, J. Jolly, J. Babinec, D. COPSON and K. STIFFEL (2002b): The Hawaii-2 Observatory seismic system undersea geo-observatory, IEEE J. Oceanic Eng., 27, 212-217.

Dushaw, B.D., B.M. Howe, J.A. Mercer, R.C. SPIndel and THE ATOC GROUP (1999): Multimegameter-range acoustic data obtained by bottom-mounted hydrophone arrays for measurement of ocean temperature, IEEE $J$. Oceanic Eng., 24, 202-214.

Edson, J.B., W.R. McGillis and T.C. Austin (2000): A new coastal observatory is born, Oceanus, 42, 31-33.

Etiope, G. and P. FAVALI (Editors) (2004): GEM-Geologic Emissions of Methane from lands and seafloor: mud volcanoes and observing systems, Environ. Geol., 46 (8), 987-1135.

Etiope, G., P. Carnevale, F. Gasparoni, M. Calcara, P. FAVALI and G. SMrigLio (2002): Off-shore hydrocarbon 
leakage: hazard and monitoring, in Science-Technology Synergy for Research in the Marine Environment: Challenges for the XXI Century, edited by L. BERANZOLI, P. FAvali and G. Smriglio, Developments in Marine Technology Series (Elsevier, Amsterdam), 12, 217-228.

Etiope, G., P. Favali, J.-L. Fuda, F. Italiano, M. LaubenStein, C. Millot and W. Plastino (2006): The Benthic Boundary Layer: geochemical and oceanographic data from the GEOSTAR-2 Observatory, Ann. Geophysics, 49 (2/3), 705-713 (this volume).

Favali, P., G. Smriglio, L. Beranzoli, T. Braun, M. Calcara, G. D'Anna, A. De Santis, D. Di Mauro, G. Etiope, F. Frugoni, V. Iafolla, S. Monna, C. Montuori, S. Nozzoli, P. Palangio and G. Romeo (2002): Towards a permanent deep-sea observatory: the GEOSTAR European experiment, in Science-Technology Synergy for Research in the Marine Environment: Challenges for the XXI Century, edited by L. BERANZOLI, P. FAVAli and G. SMriglio, Developments in Marine Technology Series (Elsevier, Amsterdam), 12, 111-120.

Favali, P., SN-1 TEAm and NEMO Collaboration (2003): SN-1: the first node of the Italian seafloor observatory network - background and perspective, in Proceedings 3rd International Workshop on Scientific Use of Submarine Cables and Related Technologies, Tokyo, Japan, edited by J. KasAhara and A.D. CHAVE, IEEE Catalogue No. 03EX660, 19-24.

Favali, P., L. Beranzoli, M. Calcara, G. D'Anna, G. Etiope, F. Frugoni, N. Lo Bue, G. Marinaro, S. Monna, C. Montuori, T Sgroi, F. Gasparoni, S. Cenedese, F. Furlan, G. Ferentinos, G. Papatheodorou, D. Christodolou, J. Blandin, J. Marvaldi, J.-F. Rolin, G. Clauss, H.W. Gerber, J.-M. Coudeville, M. Nicot, E.R. Flueh, F. Gamberi, M.P. Marani and G. Neri (2004a): Single-frame multiparameter platforms for seafloor geophysical and environmental observations: projects and missions from GEOSTAR to ORION, in Proceedings OCEANS'04 (Kobe, Japan), 2000-2007.

Favali, P., L. Beranzoli and A. Maramai (2004b): Review of the Tyrrhenian Sea seismicity: how much is still to be unknown?, in From Seafloor to Deep Mantle: Architecture of the Tyrrhenian Back-arc Basin, edited by M.P. Marani, F. Gamberi and E. BonatTi, Mem. Descr. C. Geol. Ital., LXIV, 57-70.

Favali, P., L. Beranzoli, G. D’Anna, F. Gasparoni, J. Marvaldi, G. Clauss, H.W. Gerber, M. Nicot, M.P. Marani, F. Gamberi, C. Millot and E.R. Flueh (2006): A fleet of multiparameter observatories for geophysical and environmental monitoring at seafloor, Ann. Geophysics, 49 (2/3), 659-680 (this volume).

Frye, D., K. Von der Heydt, M. Johnson, A. Maffei., S. LERNER and B. BUTMAN (1999): New technologies for coastal observatories, Sea Technol., 40 (10), 29-35.

Fuda, J.-L., G. Etiope, C. Millot, P. Favali, M. Calcara, G. SMriglio and E. Boschi (2002): Warming, salting and origin of the Tyrrhenian deep water, Geophys. Res. Lett., 29, 18, 1898, 34/1-4.

Fuda, J.-L., C. Millot, S. Hoog and H.W. Gerber (2006): Analysis of ADCP data in a heterogeneous current field, Ann. Geophysics, 49 (2/3), 715-728 (this volume).

Fujimoto, H., K. Koizumi, Y. Osada and T. Kanazawa (1998): Developments of instruments for seafloor geodesy, Earth Planets Space, 50, 905-911.
Fujimoto, H., M. Mochizuki, K. Mitsuzawa, T. Tamaki and T. SATO (2003): Ocean bottom pressure variations in the south-eastern Pacific following the 1997-98 El Niño event, Geophys. Res. Lett., 30, 1456, doi: 10.1029/ 2002 GL016677.

GABLE, R. (1992): Introduction to the DIANAUT program: a scientific wireline re-entry in deep ocean boreholes, Geophys. Res. Lett., 19, 493-496.

Gagnon, K., C.D. Chadwell and E. Norabuena (2005a): Measuring the onset of locking in the Peru-Chile Trench with GPS and acoustic measurements, Nature, 434, 205-208.

Gagnon, K., C.D. Chadwell and F.N. SpIess (2005b): Evolving method to measure seafloor plate tectonic motions, Sea Technology, 45 (7), 49-52.

Gaisser, T.K., F. Halzen and T. Stanev (1995): Particle astrophysics with high energy neutrinos, Phys. Rep., 258,173-236.

Gasparoni, F., D. Calore and R. Campaci (2002): From ABEL to GEOSTAR: development of the first European deep-sea scientific observatory, in Science-Technology Synergy for Research in the Marine Environment: Challenges for the XXI Century, edited by L. Beranzoli, P. Favali and G. Smriglio, Developments in Marine Technology Series (Elsevier, Amsterdam), 12, 143-159.

Glenn, S.M., T.D. Dickey, B. PARKer and W. Boicourt (2000): Long-term real-time coastal ocean observation networks, Oceanography, 13, 24-34.

GOOS (Global Ocean Observing System) Project OfFice (1999): Welcome to the World of GOOS (available on line: http://ioc.unesco.org/goos/).

HickMAN, S., R. SiBSON and R. BRUHN (1995): Introduction to special session: mechanical involvement of fluids in faulting, J. Geophys. Res., 100B, 12831-12840.

Hino, R., T. KANAZAWA and A. HASEGAWA (1996): Intraplate seismic activity near the Northern Japan Trench deduced from ocean bottom and land-based seismic observations, Phys. Earth Planet. Int., 93, 37-52.

Hino, R., Y. Tanioka, T. Kanazawa, S. SaKai, M. Nishino and K. SUYEHIRO (2001): Micro-tsunami from a local intraplate earthquake detected by cabled off-shore tsunami observation in north-eastern Japan, Geophys. Res. Lett., 28, 3533-3536.

Hirata, K., M. Aoyagi, H. Mikada, K. Kawaguchi, Y. KaIho, R. Iwase, S. Morita, I. Fujisawa, H. SugioKa, K. Mitsuzawa, K. Suyehiro, H. Kinoshita and N. FujiSAWA (2002): Real-time geophysical measurements on the deep seafloor using submarine cable in the Southern Kurile subduction zone, IEEE J. Oceanic Eng., 27, 170-181.

Hirata, K., H. Takahashi, E. Geist, K. Satake, Y. TanioKa, H. SugioKa and H. Mikada (2003): Source depth dependence of micro-tsunamis recorded with oceanbottom pressure gauges: the January 28, $2000 M_{w} 6.8$ earthquake off-Nemuro Peninsula, Japan, Earth Planet. Sci. Lett., 208, 305-318.

Holland, C.W., G. Etiope, A.V. Milkov, E. Michelozzi and P. FAVALI (2003): Mud volcanoes discovered offshore Sicily, Mar. Geol., 199, 1-6.

Howe, B.M., H. KiRKHAM and V. VORPERIAN (2002): Power system consideration for undersea observatories, IEEE J. Oceanic Eng., 27, 267-274.

IAfolla, V. and S. Nozzoli (2002): Gravimeter for deep- 
sea measurements, in Science-Technology Synergy for Research in the Marine Environment: Challenges for the XXI Century, edited by L. Beranzoli, P. Favali and G. SMriglio, Developments in Marine Technology Series (Elsevier, Amsterdam), 12, 183-197.

Iafolla, V., S. Nozzoli, E. Fiorenza and V. Milyukov (2006): Deep-sea gravity measurements: GEOSTAR-2 mission results, Ann. Geophysics 49 (2/3), 695-704 (this volume).

Ingle Jr., J.C., K. Suyehiro, M.T. von Breymann, J.S. Bristow, L.H. Burkle, J. Charvet, B.A. CragG, P. DE Menocal, R.B. Dunbar, K.B. Follmi, J.R. GRIFFin, K.A. Grimm, Y. Hamano, N. Hirata, P. Holler, C.M. IsAaCs, M. Kato, R. KetTler, T. Kheradyar, K.A.O. Krumsiek, H. Ling, R. Matsumoto, J.P. MuZA, R.J. Parkes, A. Pouclet, S.D. Scott, R. Stein and A.A. Sturz (1989): Japan Sea, covering Leg 128 of the cruises of the drilling vessel JOIDES Resolution, Proc. ODP Init. Rep., 128, pp. 402.

IPCC (InTERgovernmental PANel on Climate Change) (1995): Climate Change 1995: The Science of Climate Change, Contribution of Working Group I to the Second Assessment of the IPCC, edited by J.T. HouGHTON, L.G. Meira Filho, B.A. Callender, N. Harris, A. KATTENBERG and A. MASKELl (Cambridge University Press, Cambridge, U.K.), pp. 572.

IRIS (INCORPORATED RESEARCH INSTITUTIONS FOR SEISMOLOGY) (1994): Science Plan for a New Global Seismographic Network (IRIS Incorporated, Washington DC).

ISERN, A.R. (2005): National science foundation's ocean observatory initiative, Sea Technol., 45 (6), 55 and 57-59.

JANNASCH, H.W, E.E. DAVIS, M. KASTNER, J.D. MORRIS, T.L. Pettigrew, J.N. Plant, E.A. Solomon, H.W. VILLINGER and C.G. WHEAT (2003): CORK-II: longterm monitoring of fluid chemistry, fluxes, and hydrology in instrumented boreholes at the Costa Rica subduction zone, in Fluid Flow and Subduction Fluxes across the Costa Rica Convergent Margin: Implications for the Seismogenic Zone and Subduction Factory, edited by J.D. Morris, H.W. Villinger, A. Klaus, D.M. Cardace, V.M.C. Chavagnac, P.D. Clift, M. Haeckel, T. Hisamitsu, M. KAstner, M. Pfender, D.M. SAFFER, C. Santelli, B. Schramm, E.J. Screaton, E.A. Solomon, M. Strasser, M. Kyaw Thu and P. VannuCCHI, Proc. ODP Init. Rep., 205, 1-36 (CD-ROM).

Jordan, T.H., H.W. Menard, J.H. Natland and J.A. ORCUTT (1987): Introduction: Objectives and results of Deep-Sea Drilling Project Leg 91 and the Ngendei seismic experiment, and explanatory notes for Volume 91, Init. Rep. DSDP, 91, 185-203.

JourdaIn, J.Y. (1999): First trial of GEOSTAR, the geophysical and oceanographic European station for abyssal research, in EC Project Information Booklet EUR18885, edited by G. OLLIER, pp. 31.

Kanazawa, T., W.W. Sager, C. Escutia, E. Araki, J.E. ArNEY, R.L. CARlson, W.S. Downey, F. EINAUdi, S.L. Haggas, Y. Hayasaka, K. Hirata, B.C. Horner-JohnSON, K.W. MANDERnACK, F.M.G. MCCARTHy, R. Moberly, M. Mochizuki, R. Ø. Pedersen, A.R.M. SALIMUllah, M. Shinohara and C.-D. Werner (2001): Northwest Pacific Seismic Observatory and Hammer drill tests, Proc. ODP Init. Rep., 191 (CD-ROM).
KASAHARA, J. (2002): Development of seismic real-time monitoring systems at subduction zones around Japanese islands using decommissioned submarine cables, in Science-Technology Synergy for Research in the Marine Environment: Challenges for the XXI Century, edited by L. Beranzoli, P. Favali and G. Smriglio, Developments in Marine Technology Series (Elsevier, Amsterdam), 12, 47-57.

Kasahara, J. and A.D. Chave (Co-chairs) (2003): Proceedings 3rd International Workshop on Scientific Use of Submarine Cables and Related Technologies, Tokyo, Japan, edited by J. KasAHARA and A.D. CHAVE, IEEE Catalogue No. O3EX660, pp. 315.

Kasahara, J., H. Utada and H. KinOshita (1995): GeOTOC project-reuse of sub-marine cables for seismic and geoelectrical measurements, J. Phys Earth, 43, 619-628.

Kasahara, J., T. SATO, H. Momma and Y. SHIRASAKI (1998a): A new approach to geophysical real-time measurements on a deep-seafloor using decommissioned submarine cables, Earth Planets Space, 50, 913-925.

Kasahara, J., H. Utada, T. Sato and H. Kinoshita (1998b): Submarine cable OBS using a retired telecommunication cable: GeO-TOC Program, Phys. Earth Planet. Int., 108, 113-128.

Kasahara, J., Y. Shirasaki and H. Momma (2000): Multidisciplinary geophysical measurement on the ocean floor using decommissioned submarine cables: VENUS Project, IEEE J. Oceanic Eng., 25, 111-120.

Kasahara, J., R. Iwase, T. Nakatsuka, Y. Nagaya, Y. ShIRASAKI, K. HaWAGUCHI and J. KoJIMA (2006): Multidisciplinary VENUS observations at the Ryuku Trench using Guam-Okinawa geophysical submarine cable, Ann. Geophysics, 49 (2/3), 595-606 (this volume).

Kato, T., Y. Kotake, S. Nakao, J. Beavan, K. Hirahara, M. OKada, M. Hoshiba, O. Kamigaichi, R.B. Feir, P.H. PARK, M.D. GERASimenKo and M. Kasahara (1998): Initial results from WING, the continuous GPS network in the Western Pacific area, Geophys. Res. Lett., 25, 369-372.

Katz, U.F., J.A. Agullar, A. Albert, P. Amram, M. Anghinolfi, G. Anton, S. Anvar , F.E. Ardellier-Desages, E. Aslanides, J.-J. Aubert, R. Azoulay, D. Bailey, S. Basa, M. Battaglieri, Y. Becherini, R. Bellotti, J. Beltramelli, V. Bertin, M. Billault, R. Blaes, F. Blanc, R.W. Bland, N. De Botton, J. Boulesteix, M.C. Bouwhuis, C.B. Brooks, S.M. Bradbury, R. Bruijn, J. Brunner, F. Bugeon, G.F. Burgio, F. Cafagna, A. Calzas, L. Caponetto, E. Carmona, J. Carr, S.L. Cartwright, S. Cecchini, P. Charvis, M. Circella, C. Colnard, C. Compère, J. Croquette, S. Cooper, P. Coyle, S. Cuneo, G. Damy, R. van Dantzig, A. Deschamps, C. De Marzo, J.-J. Destelle, R. De Vita, B. Dinkelspiler, G. Dispau, J.-F. Drogou, F. Druillole, J. Engelen, S. Favard, F. Feinstein, S. Ferry, D. Festy, J. Fopma, J.-L. FudA, J.-M. Gallone, G. Giacomelli, N. Girard, P. Goret, J.-F. Gournay, G. Hallewell, B. Hartmann, A. Heijboer, Y. Hello, J.J. Hernandez-Rey, G. Herrouin, J. HößL, C. HofFMANN, J.R. HubBard, M. JaQuet, M. DE Jong, F. JouVENOT, A. KAPPES, T. KARG, S. KARKAR, M. KAROLAK, P. Keller, P. Kooljman, E.V. Korolkova, A. KouchnER, W. Kretschmer, V.A. Kudryavtsev, H. LafouX, P. Lagier, P. Lamare, J.-C. Languillat, L. Laubier, T. 
Legou, Y. Le Guen, H. Le Provost, A. Le Van Suu, L. Lo Nigro, D. Lo Presti, S. Loucatos, F. Louis, V. Lyashuk, P. Magnier, M. Marcelin, A. Margiotta, C. Maron, A. Massol, F. Mazéas, B. Mazeau, A. Mazure, J.E. McMillan, J.-L. Michel, C. Millot, A. Milovanovic, F. Montanet, T. Montaruli, J.-P. Morel, L. Moscoso, E. Nezri, V. Niess, G.J. Nooren, P. Ogden, C. Olivetto, N. Palangue-Delabroullle, P. Payre, C. Petta, J.-P. Pineau, J. Poinsignon, V. Popa, R. Potheau, T. Pradier, C. Racca, N. RandaZZO, D. REAL, B.A.P. van RENS, F. RÉTHORÉ, M. RiPANI, V. Roca-Blay, A. Romeyer, J.-F. Rolin, M. Romita and H.J. Rose (2004): Status of the ANTARES project, Eur. Phys. J., C33, S971-S974.

Kaul, N., H.W. Villinger and M. KRuSE (2004): Satellitelinked Autonomous Pore Pressure Instrument (SAPPI), Sea Technol., 45 (8), 54-58.

Kawaguchi, K., K. Hirata and H. Mikada (2001): An expandable deep seafloor monitoring system, Sea Technol., 42 (10), 49-54.

Kawaguchi, K., K. Hirata, T. Nishida, S. Obana and H. MikAdA (2002): A new approach for mobile and expandable real time deep seafloor observation - adaptable observation system, IEEE J. Oceanic Eng., 27, 182-192.

Kodaira, S., N. Takahashi, J. Park, K. Mochizuki, M. SHINOHARA and S. KimURA (2000): Western Nankai Trough seismogenic zone: results from a wide-angle ocean bottom seismic survey, J. Geophys. Res., 105, 5887-5905.

Legrand, J., A. Echardour, H. Floc'h, L. Floury, J. Gieskes, F. HARMEGNIES, G. LOAËC, J.-P. POZZI, Y. RAER and R.A. STEPHEN (1989): Campagne FARE: wireline reentry of DSDP Hole 396B using the NADIA system, Eos, Trans. Am. Geophys. Un., 70, 729-730 and 741.

LomnitZ, C. and S. NILSEN-Hofseth (2005): The Indian Ocean disaster: tsunami physics and early warning dilemmas, Eos, Trans. Am. Geophys. Un., 86, 65 and 70.

Lowes, F.J. (2002): Why global geomagnetism needs oceanbottom observatories, in Science-Technology Synergy for Research in the Marine Environment: Challenges for the XXI Century, edited by L. BERANZOLI, P. FAVALI and G. SMriglio, Developments in Marine Technology Series (Elsevier, Amsterdam), 12, 27-35.

Malinverno, E., F. Gasparoni, H.W. Gerber and C. CoRsElli (2006): The exploration of Eastern Mediterranean deep hypersaline anoxic basins with MODUS: a significant example of technology spin-off of GEOSTAR program, Ann. Geophysics, 49 (2/3), 729-737 (this volume).

Maramai, A., A. Piscini, G. D'Anna and L. Graziani (2002): The Italian tsunami warning system: state of the art, in Science-Technology Synergy for Research in the Marine Environment: Challenges for the XXI Century, edited by L. Beranzoli, P. FAVAli and G. SMRIGLIO, Developments in Marine Technology Series (Elsevier, Amsterdam), 12, 247-259.

Marani, M.P., F. Gamberi and E. Bonatti (Editors) (2004): From seafloor to deep mantle: architecture of the Tyrrhenian back-arc basin, Mem. Descr. C. Geol. d'It., LXIV, pp. 195.

MARGINS (2003): NSF MARGINS Program Science Plans 2004 (MARGINS office at LDEO of Columbia
University, New York), pp. 170 (available on line: http://www.margins.wustl.edu).

Marinaro, G., G. Etiope, F. Gasparoni, D. Calore, S. Cenedese, F. Furlan, M. Masson, P. Favali and J. BLANDIN (2004): GMM-a gas monitoring module for long-term detection of methane leakage from the seafloor, in GEM-Geologic Emissions of Methane from Lands and Seafloor: Mud Volcanoes and Observing Systems, edited by G. ETIOPE and P. FAVALI, Environ. Geol., 46 (8), 1053-1058, doi: 10.1007/s00254-004-1092-2.

Marvaldi, J., Y. Aoustin, G. Ayela, D. Barbot, J. Blandin, J.-M. Coudeville, D. Fellmann, G. LoAËc Ch. Podeur and A. PRIOU (2002): Design and realisation of communication systems for the GEOSTAR project, in ScienceTechnology Synergy for Research in the Marine Environment: Challenges for the XXI Century, edited by L. BERanzoli, P. Favali and G. Smriglio, Developments in Marine Technology Series (Elsevier, Amsterdam), 12, 161-181.

Massion, G., K. Asakawa, A.D. Chave, B. Howe, T. McGinnis, P. Phibbs, D. Rodgers, Y. Shirasaki, H. MiKADA and K. KAWAGUCHI (2004): New scientific cabled observing systems: NEPTUNE and ARENA, Suboptic2004, Th B2.1, 197-199.

Merrifield, M.A., Y.L. Firing, T. Aarup, W. Agricole, G. Brundrit, D. Chang-Seng, R. Farre, B. Kilonsky, W. Knight, L. Kong, C. Magori, P. Manurung, C. MCCreery, W. Mitchell, S. Pillay, F. Schindele, F. Shillington, L. Testut, E.M.S. Wijeratne, P. CaldWEll, J. JARDin, S. NAKAhara, F.-Y. Porter and N. TURETSKY (2005): Tide gauge observations of the Indian Ocean tsunami, December 26, 2004, Geophys. Res. Lett., 32, L09603, doi: 10.1029/2005GL022610.

Migneco, E., S. Aiello, E. Amato, M. Ambriola, F. Ameli, G. Andronico, M. Anghinolfi, M. Battaglieri, R. Bellotti, A. Bersani, A. Boldrin, M. Bonori, F. Cafagna, A. Capone, L. Caponnetto, T. Chiarusi, M. Circella, R. Cocimano, R. Coniglione, M. Cordelli, M. Costa, S. Cuneo, A. D'Amico, V. D'Amico, C. De Marzo, R. De Vita, C. Distefano, A. Gabrielli, E. Gandolfi, A. Grimaldi, R. Habel, A. Italiano, M. Leonardi, L. Lo Nigro, D. Lo Presti, A. Margiotta, A. Martini, M. Masetti, R. Masullo, T. Montaruli, R. Mosetti, M. Musumeci, C.A. Nicolau, R. Occhipinti, R. Papaleo, C. Petta, P. Piattelli, G. Raia, N. RanDAZzo, S. Reito, G. Ricco, G. Riccobene, M. Ripani, M. Romita, A. Rovelli, M. RupPI, G.V. Russo, M. RusSo, P. SAPIENZa, J.P. Schuller, M. Sedita, I. SOKAlSKi, M. Spurio, M. Taiuti, L. Trasatti, L. Ursella, V. VALENTE, P. ViCINI and G. CANARINI (2004): NEMO: status of the project, Nucl. Phys., 136B (Proc. Suppl.), 61-68.

Migneco, E., A. CAPONE and P. Piattelli (2006): Underwater laboratories for astroparticle physics and deep-sea science, Ann. Geophysics, 49 (2/3), 643-658 (this volume).

Mikada, H., K. BeCKer, J.C. Moore, A. Klaus, G.L. Austin, N.L. Bangs, S. Bourlange, J. Broilliard, W. BrücKMANn, E.R. Corn, E.E. Davis, P.B. Flemings, D.S. GoldberG, S.S. Gulick, M. BAK Hansen, N. Hayward, D.J. Hills, S. Hunze, M. IEnaga, H. Ishiguro, M. KINoshita, R.D. Macdonald, L. McNeill, S. Obana, O. Swee Hong, S. Peacock, T.L. Pettigrew, S. Saito, T. SAWA, N. Thaiprasert, H.J. Tobin and H. TSURUMI (2002): Deformation and fluid flow processes in the 
Nankai trough accretionary prism: logging while drilling and advanced CORKs, Proc. ODP Init. Rep., 196 (CDROM).

MiLlot, C. (2002): Deep physical oceanography, experimentation and benefits from bottom observatories, in Science-Technology Synergy for Research in the Marine Environment: Challenges for the XXI Century, edited by L. Beranzoli, P. Favali and G. Smriglio, Developments in Marine Technology Series (Elsevier, Amsterdam), 12, 19-26.

Momma, H., R. Iwase, K. Mitsuzawa, Y. Kaino and Y. FuJIWARA (1998): Preliminary results of a three-year continuous observation by a deep seafloor observatory in Sagami Bay, Central Japan, Phys. Earth Planet. Int., 108, 263-274.

Momma, H., K. Kawaguchi and R. Iwase (2001): Longterm seafloor monitoring data recovery - New approach, Sea Technol., 42 (7), 55-59.

Monna, S., L. FilipPi, L. Beranzoli and P. Favali (2003): Rock properties of the upper-crust in Central Apennines (Italy) derived from high-resolution 3D tomography, Geophys. Res. Lett., 30 (7), 1408, doi: 10.1029/ 2002 GL016780.

Monna, S., F. Frugoni, C. Montuori, L. Beranzoli and P. FAVALI (2005): High quality seismological recordings from the SN-1 deep seafloor observatory in the Mt. Etna region, Geophys. Res. Lett., 32, L07303, doi: 10.1029/ 2004GL021975.

Montagner, J.-P. and Y. LANCElot (Editors) (1995): Proceedings International Workshop Multidisciplinary $\mathrm{Ob}$ servatories on the Deep Seafloor (INSU/CNRS, IFREMER, OSN/USSAC, ODP-France and ODP-Japan, Marseille, France), pp. 229.

Montagner, J.-P., J.-F. Karczewski, B. Romanowicz, S. Bouaricha, P. Lognonné, G. Roult, E. Stutzmann, J.L. Thirot, J. Brion, B. Dole, D. Fouassier, J.-C. Koenig, J. Savary, L. Floury, J. Dupond, A. Echar-dour and H. Floc'H (1994a): The French pilot experiment OFM/SISMOBS: first scientific results on noise level and event detection, Phys. Earth Planet. Int., 84, 321-336.

Montagner, J.-P., B. Romanowicz and J.-F. KARCZEWSKI (1994b): A first step toward an oceanic geophysical observatory, Eos, Trans. Am. Geophys. Un., 75, 150-151 and 154.

Montagner, J.-P., J.F. KARCZEwski, L. Floury and P. TARITS (1994c): Towards a geophysical ocean bottom observatory, Seismic Waves, 3, 7-9.

Montagner, J.-P., P. Lognonné, R. Beauduin, G. Roult, J.-F. Karczewski and E. Stutzmann (1998): Towards multiparameter networks for the next century: the French efforts, Phys. Earth Planet. Int., 108, 155-174.

Montagner, J.-P., J.-F. Karczewski, E. Stutzmann, G. Roult, W. Crawford, P. Lognonné, L. Beguery, S. CACHO, J.-C. Koenig, J. SAVAry, B. Romanowicz and D.S. STAKES (2002): Geophysical ocean bottom observatories or Temporary portable networks?, in Science-Technology Synergy for Research in the Marine Environment: Challenges for the XXI Century, edited by L. BERANZOLI, P. FAvali and G. SMriglio, Developments in Marine Technology Series (Elsevier, Amsterdam), 12, 59-81.

MontuORI, C. (2004): Geodynamic characterisation of the Southern Tyrrhenian Basin, Ph.D. Thesis (Chieti University, Italy), pp. 118.
Moore, G. and C. Moore (1998): The SEIsmogenic Zone Experiment (SEIZE) Workshop, June 3-6, 1997, Waikoloa, Hawaii, Final Report (published on the web http://www.soest.hawaii.edu/moore/seize/).

Morris, J.D., H.W. Villinger, A. Klaus, D.M. Cardace, V.M.C. Chavagnac, P.D. Clift, M. HaEckel, T. HisamitSu, M. Kastner, M. Pfender, D.M. SAFFer, C. SANTElli, B. Schramm, E.J. Screaton, E.A. Solomon, M. StrasSER, M. KYAW Thu and P. VANNUCCHI (2003): Fluid flow and subduction fluxes across the Costa Rica convergent margin: implications for the seismogenic zone and subduction factory, Proc. ODP Init. Rep., 205 (CD-ROM).

NAGUMO, S. and D.A. WALKER (1989): Ocean bottom geoscience observatories: re-use of transoceanic telecommunication cables, Eos, Trans. Am. Geophys. Un., 70, 673-677.

NEPTUNE (NoRTh EAst PacIFIC TIME-SERIES Undersea NETWORKED EXPERIMENTS) (2000): NEPTUNE: a Fiberoptic Telescope to Inner Space (available on line: http:// www.neptune.washington.edu).

Nishizawa, A., T. Kono, A. Hasegawa, T. Hirasawa, T. KANAZAWA and T. IWASAKI (1990): Spatial distribution of earthquakes off Sanriku, north-eastern Japan, in 1989 determined by ocean-bottom and land-based observation, J. Phys. Earth, 38, 347-360.

Nishizawa, A., T. Kanazawa, T. IwasaKi and H. SHimamuRA (1992): Spatial distribution of earthquakes associated with the Pacific plate subduction off north-eastern Japan revealed by ocean bottom and land observation, Phys. Earth Planet. Int., 75, 165-175.

NRC (NATIONAL Research CounciL) (1997): The Global Ocean Observing System: Users, Benefits and Priorities (National Academy Press, Washington DC), pp. 92.

NRC (NATIONAL Research Council) (1998a): A Scientific strategy for US Participation in the GOALS Component of the CLIVAR Programme (National Academy Press, Washington DC), pp. 88.

NRC (NATIONAL RESEARCH COUNCIL) (1998b): Decade-toCentury-Scale Climate Variability and Change (National Academy Press, Washington DC), pp. 160.

NRC (NATIONAL RESEARCH COUNCIL) (1999): Global Ocean Science: Toward an Integrated Approach (National Academy Press, Washington DC), pp. 184.

NRC (NATIONAL RESEARCH COUNCIL) (2000): Illuminating the Hidden Planet. The Future of Seafloor Observatory Science (National Academy Press, Washington DC), pp. 135.

NRC (NATIONAL ReseARCh COUNCIL) (2003a): Enabling Ocean Research in the 21st Century: Implementation of a Network of Ocean Observatories (National Academy Press, Washington DC), pp. 240.

NRC (NATIONAL RESEARCH COUNCIL) (2003b): Estimating Climate Sensitivity: Report of a Workshop (National Academy Press, Washington DC), pp. 62.

NRC (NATIONAL RESEARCH COUNCIL) (2003c): Exploration of the Seas: Interim Report (National Academy Press, Washington DC), pp. 48.

NRC (NATIONAL RESEARCH COUNCIL) (2004): Review of the US CLIVAR Project Office (National Academy Press, Washington DC), pp. 50.

Oebius, H.U. and H.W. Gerber (2002): The deep-sea as an area for geotechnical intervention, in Science-Technology Synergy for Research in the Marine Environment: Chal- 
lenges for the XXI Century, edited by L. Beranzoli, P. FAVALI and G. SMrIGLIO, Developments in Marine Technology Series (Elsevier, Amsterdam), 12, 201-216.

Ohmachi, T., H. Tsukiyama and H. Matsumoto (2001): Simulation of tsunami induced by dynamic displacement of seabed due to seismic faulting, Bull. Seismol. Soc. Am., 91, 1898-1909.

Ollier, G., P. Favali, G. Smriglio and F. Gasparoni (2002): Perspectives and challenges in marine research, in Science-Technology Synergy for Research in the Marine Environment: Challenges for the XXI Century, edited by L. Beranzoli, P. FAVALI and G. SMRIGLIO, Developments in Marine Technology Series (Elsevier, Amsterdam), 12, 3-9.

ORCUTt, J.A. and R.A. STEPHEN (1993): OSN seismograph system is underway, Seismic Waves, 2, 3-5.

Orcutt, J.A., A. Schultz, T.A. Davies, K. Artita, C. Bonadiman, A. Buysch, R.L. Carlson, J. Carlut, K.L. Heft, T. IshiI, R. Moberly, S. Revillon and X. ZHAO (2003): Dynamics of the Earth and Ocean Systems, Proc. ODP Init. Rep., 203 (CD-ROM).

Osada, Y., H. Fujimoto, S. Miura, A. Sweeney, T. Kanazawa, S. NaKao, S. SaKai, J.A. Hildebrand and C.D. Chadwell (2005): Estimation and correction for the effect of sound velocity variation on GPS/Acoustic seafloor positioning: an experiment off Hawaii Island, Earth Planets Space (in press)

Person, R., Y. Aoustin, J. Blandin, J. Marvaldi and J.-F. RoLIN (2006): From bottom landers to observatories networks, Ann. Geophysics, 49 (2/3), 581-593 (this volume).

Peterson, J.R. (1993): Observations and modelling of seismic background noise, US Geol. Surv. Open File Rep. 93-322, pp. 94.

Petitt, R.A., F.B. Wooding, D. Harris, J.W. Bailey, E. Hobart, J. Jolly, A.D. Chave, F.K. Duennebier and R. BUTLER (2002): The Hawaii-2 Observatory, IEEE J. Oceanic Eng., 27, 245-253.

Pettigrew, T.L., J.F. Casey, D. Jay Miller, E. Araki, R. Boissonnas, R. Busby, F. Einaudi, M. Gerdom, Z. Ping Guo, H. Hopkins, G. Myers, D. Gopala RaO, T. ShiBATA and P. THY (1999): Hammer drilling and NERO, Proc. ODP Init. Rep., 179 (CD-ROM).

Piatanesi, A. and S. Tinti (1998): A revision of the 1693 Eastern Sicily earthquake and tsunami, J. Geophys. Res., 103 (B2), 2749-2758.

Priede, I.G., M. Solan, J. Mienert, R. Person, T.C.E. van Weering, O. Pfannkuche, N. O’NeIll, A. Tselepides, L. Thomsen, P. Favali, F. Gasparoni, N. Zitellini, C. Millot, H.W. Gerber, J.M.A. DE Miranda and M. KLAGES (2003): ESONET - European Seafloor Observatory NETwork, in Proceedings 3rd International Workshop on Scientific Use of Submarine Cables and Related Technologies, Tokyo, Japan, edited by J. KASAHARA and A.D. Chave, IEEE Catalogue No. 03EX660, 263-265.

Priede, I.G., P. Favali, M. Solan, F. Gasparoni, J. Mienert, N. Zitellini, R. Person, C. Millot, T.C.E. van WeerInG, H.W. Gerber, O. Pfannkuche, J.M.A. DE MiranDA, N. O’Neill, M. Klages, A. Tselepides, P. Sigray and L. THOMSEN (2004): ESONET - European Seafloor Observatory NETwork, in Proceedings OCEANS'04 MTS/IEEE TECHNO-OCEAN'04, Kobe, Japan, IEEE Catalogue No. 04CH37600C, 2155-2163.

Purdy, G.M. (1995): A five year plan, in Broad-band Seis- mology in the Oceans - Towards a Five-Year Plan, edited by G.M. PURDY and J.A Orcutt (JOI, Washington, DC), 68-75.

Purdy, G.M. and A.M. DzIEwonski (Editors) (1988): Proceedings of the Workshop on Broad-band Downhole Seismometers in the Deep Ocean, Woods Hole, Massachusetts, pp. 331.

Rigaud, V., D. Semac, M. Nokin, DESIBEL Team, G. TietZE, H. Amann, V. Goetz and A. Pascoal (1998): New methods for Deep-Sea Intervention on future Benthic Laboratories, DESIBEL Project - Final Results, Comparison of concepts and at sea validation, in Proceedings of the IEEE Conference OCEANS '98 (Nice, France) (on CD-ROM).

RoBERTS, A. (1992): The birth of high-energy neutrino astronomy: a personal history of the DUMAND project, Rev. Modern Phys., 64, 259-312.

Romanowicz, B. and K. Suyehiro (2001): History of the International Ocean Network, in OHP/ION Joint Symposium Long-term Observations in the Oceans. Current Status and Perspectives for the Future. Workshop Report, Yamanashi Pref., Japan, edited by B. RoMANOWICZ, K. SuyehIRO and H. KaWAKATSU, 1-3

Romanowicz, B., D.S. Stakes, J.-P. Montagner, P. TARits, R. Uhrhammer, M. Begnaud, E. Stutzmann, M. Pasyanos, J.-F. Karczewski, S. Etchemendy and D. NEUHAUSER (1998): MOISE: a pilot experiment towards long-term seafloor geophysical observatories, Earth Planets Space, 50, 927-937.

Romanowicz, B., K. SUYEHIRO and H. KaWAKATSU (Editors) (2001): OHP/ION Joint Symposium Long-term Observations in the Oceans. Current Status and Perspectives for the Future. Workshop Report, Yamanashi Pref., Japan, pp. 188.

Romanowicz, B., D.S. Stakes, R. Uhrhammer, P. McGill, D. Neuhauser, T. Ramirez and D. Dolenc (2003): The MOBB experiment: a prototype permanent offshore ocean bottom broad-band station, Eos, Trans. Am. Geophys. Un., 84, 325-332.

Romanowicz, B., D.S. Stakes, D. Dolenc, D. Neuhauser, P. MCGILl, R. Uhrhammer and T. RAMIREZ (2006): The Monterey Bay broad band ocean bottom observatory, Ann. Geophysics, 49 (2/3), 607-623 (this volume).

Sacks, I.S., K. Suyehiro, G.D. Acton, M.J. Acierno, E Araki, M.V.S. Ask, A. Ikeda, T. Kanamatsu, G.Y. Kim, J. Li, A.T. Linde, P.N. McWhorter, G. Mora, Y.M.R. Najman, N. Nittsuma, B.K. Pandit, S. Roller, S. Saito, T. SaKamoto, M. Shinohara and Y.-F. Sun (2000): Western Pacific geophysical observatories, Proc. ODP Init. Rep., 186 (CD-ROM).

Sagalevitch, A. (2004): New birth for the MIR-1 and MIR-2 submersibles, Sea Technology, 45 (12), 27-33.

SAlisbury, M.H., M. SHinOHARA, C. Richter, E. ARAKI, S.R. Barr, M. D'Antonio, S.M. Dean, B. Diekmann, K.M. EdWARd, P.B. Fryer, P.J. GaIllot, W.S. Hammon III, D. HART, N. JANUSZCZAK, S.C. KOMOR, M.B. KRISTENSEN, J.P. LockWOOd, M.J. MotTL, C.L. MoyeR, K. NAKAHIGASHI, I.P. SAVOV, X. Su, K.-Y. WeI and T. YAMADA (2002): Seafloor observatories and the Kuroshio current, Proc. ODP Init. Rep., 195 (CD-ROM).

Schofield, O., T. Bergmann, P. Bisset, J.F. Grassle, D.B. Haidvogel, J. Kohut, M. Moline and S.M. Glenn (2002): The long-term ecosystem observatory: an inte- 
grated coastal observatory, IEEE J. Oceanic Eng., 27, 146-154.

SEno, T., S. Stein and A.E. Gripp (1993): A model for the motion of the Philippine Sea plate consistent with NUVEL-1 and geological data, J. Geophys. Res., 98, 17941-17948.

Sgroi, T., T. Braun, T. Dahm and F. Frugoni (2006): An improved seismicity picture of the Southern Tyrrhenian area by the use of OBS and land-based networks: the TYDE experiment, Ann. Geophysics, 49 (2/3), 801-817 (this volume).

Shinohara, M., T. Yamada, T. KanaZawa, N. Hirata, Y. Kaneda, T. Takanami, H. Mikada, K. Suyehiro, S. Sakai, T. Watanabe, K. Uehira, Y. Murai, N. Takahashi, M. Nishino, K. MochizUKi, T. SATO, E. ARAKI, R. Hino, K. Uhira, H. Shiobara and H. Shimizu (2004): Aftershock observation of the 2003 TokachiOki earthquake by dense ocean bottom seismometer network, Earth Planet Space, 56, 295-300.

Shinohara, M., E. Araki, T. KanaZawa, K. Suyehiro, M. Mochizuki, T. Yamada, K. Nakahigashi, Y. KaiHo and Y. FUKAO (2006): Deep-sea borehole seismological observatories in the Western Pacific: temporal variation of seismic noise level and event detection, Ann. Geophysics, 49 (2/3), 625-641 (this volume).

Shirasaki, Y., M. Yoshida, T. Nishida, K. Kawaguchi, H. MiKaDA and K. AsAKAWA (2003): ARENA: a versatile and multidisciplinary scientific cable network for next generation, in Proceedings 3rd International Workshop on Scientific Use of Submarine Cables and Related technologies (Tokyo, Japan), edited by J. KASAHARA and A.D. CHAVE, IEEE Catalogue No. O3EX660, 226231.

Sozer, E.M., M. Stojanovic and J.G. Proakis (2000): Underwater acoustic networks, IEEE J. Oceanic Eng., 25, 72-82.

Spiess, F.N., D.E. Boegeman and C.E. Lowenstein (1992): First ocean-research-ship-supported fly-in re-entry to a deep ocean drill hole, J. Mar. Technol. Soc., 26, 3-10.

Spiess, F.N., C.D. Chadwell, J.A. Hildebrand, L.E. Young, G.H. Purcell JR. and H. Dragert (1998): Precise GPS/Acoustic positioning of seafloor reference points for tectonic studies, Phys. Earth Planet. Int., 108, 101-112.

Stakes, D.S., J.S. McClain, T. VAn Zandt and P. McGill (1998a): Corehole seismometer development for lownoise seismic data in a long-term observatory setting, Geophys. Res. Lett., 25, 2745-2748.

Stakes, D.S., B. Romanowicz, J.-P. Montagner, P. Tarits, J.-F. KARCZEWski, S. ETChEMENDy, D. Neuhauser, P. McGill, J.C. Koenig, J. Savary, M.L. Begnaud and M. PAsyanos (1998b): MOISE: Monterey bay Ocean bottom International Seismic Experiment, Eos, Trans. Am. Geophys. Un., 79, 301-309.

Stakes, D.S., B. Romanowicz, M.L. BegnaUd, K.C. MCNaLLy, J.-P. Montagner, E. Stutzmann and M. Pasyanos (2002): The MBARI margin seismology experiment: a prototype seafloor observatory, in Science-Technology Synergy for Research in the Marine Environment: Challenges for the XXI Century, edited by L. BERANZOLI, P. FAvali and G. SMriglio, Developments in Marine Technology Series (Elsevier, Amsterdam), 12, 93-110.

STEPHEN, R.A. (1978): The oblique seismic experiment on
Deep-Sea Drilling Project Leg 52, Eos, Trans. Am. Geophys. Un., 59, 244.

STEPHEN, R.A. (1998): Ocean seismic network seafloor observatories, Oceanus, 41, 33-37.

Stephen, R.A., K.E. Louden and D.K. Matthews (1980a): The oblique seismic experiment on Deep-Sea Drilling Project Leg 52, Init. Rep. DSDP, 51-53, 675-704.

StePHEN, R.A., K.E. LoudEN and D.K. MATTHEWs (1980b): The oblique seismic experiment on Deep-Sea Drilling Project Leg 52, Geophys. J. R. Astr. Soc., 60, 289-300.

Stephen, R.A., D. Koelsch, H. Berteaux, A. Bocconcelli, S. Bolmer, J. Cretin, N. Etourmy, A. FAbre, R. Goldsborough, M. Gould, S. Kery, J. LAurent, G. Omnes, K. Peal, S. Swift, R. Turpuring and C. Zani (1994): The SEAfloor Borehole Array Seismic System (SEABASS) and VLF ambient noise, Mar. Geophys. Res., 16, 243-286.

Stephen, R.A., J.A. Collins, K.R. PeAl, J.A. Hildebrand, J.A. ORCUTT, F.N. SPIESS and F.L. VERNON (1999): Seafloor seismic stations perform well in study, Eos, Trans. Am. Geophys. Un., 80, 592.

Stephen, R.A., J. Kasahara, G.D. Acton, R.S. Calhoun, S. Haraguchi, H. Hoskins, S. KitTredge, M. LustriNo, W. Manz, M. Nakamura, J.H. Natland, I. Nielsen, H. Paul, G. Schumann-Kindel, S. Sherman, Y.-F. Sun and J. WiLSON (2003a): Drilling at the Hawaii-2 Observatory $(\mathrm{H} 2 \mathrm{O})$ and the Nuuanu Landslide, Proc. ODP Init. Rep., 200 (CD-ROM).

Stephen, R.A., F.N. Spiess, J.A. Collins, J.A. HildeBrand, J.A. Orcutt, K.R. Peal, F.L. Vernon and F.B. Wooding (2003b): Ocean Seismic Network pilot experiment, Geochem. Geophys. Geosys., 4 (10), 1092 doi: 10,1029/2002GC000485.

Stojanovic, M. (1996): Recent advances in high-speed underwater acoustic communications, IEEE J. Oceanic Eng., 21, 125-136.

Stutzmann, E., J.-P. Montagner, A. Sebai, W.C. CrawFORD, J.-L. Thirot, P. TARits, D.S. Stakes, B. RoMANOWICZ, J.-F. KARCZEWSKI, D. NeUhaUSER and S. ETCHEMENDY (2001): MOISE: a prototype multiparameter ocean-bottom station, Bull. Seismol. Soc. Am., 91, 885-892.

SUMMERHAYES, C.P. (1996): Ocean resources, in Oceanography: an Illustrated Guide, edited by C.P. SUMMERHAYES and S.A THORPE (Manson Publishing Ltd., London), 314-337.

SuMmerhaYeS, C.P. (2002): GOOS project update: implementation progress, Sea Technol., 43 (10), 46-49.

Summit, M. and J.A. Baross (1998): Thermophilic subseafloor microorganisms from the 1996 North Gorda Ridge eruption, Deep-Sea Res. II, 45, 2751-2766.

Sutherland, F.H., F.L. Vernon, J.A. Orcutt and R.A. STEPHEN (2004): Results from OSNPE: Low detection threshold magnitudes for ocean-bottom recording, Bull. Seismol. Soc. Am., 94, 1868-1878.

Sutton, G.H., W.G. McDonald, D.D. Prentiss and S.N. Thomson (1965): Ocean bottom seismic observatories, Proc. IEEE, 53, 1909-1921.

SuYEHIRO, K. and A. NishizAWA (1994): Crustal structure and seismicity beneath the forearc off north-eastern Japan, J. Geophys. Res., 99, 22331-22348.

SuyehiRo, K., T. Kanazawa, N. Hirata and M. Shinohara (1995): Ocean downhole seismic project, J. Phys. Earth, 43, 599-618. 
Suyehiro, K., E. Araki, M. Shinohara and T. Kanazawa (2002): Deep-sea borehole observatories ready and capturing seismic waves in the Western Pacific, Eos, Trans. Am. Geophys. Un., 83, 621.

TAmaki, K., K.A. PisciotTo, J. Allan, J.M. AleXandrovich, D.A. Barnes, S. Boggs, H.-J. Brumsack, C.A. BrunNER, A. Cramp, L. Jolivet, O.E. KawkA, I. Koizumi, S. Kuramoto, M.G. LangSeth, J. McEvoy, J.A. MeredITH, K.A. Mertz JR., R.W. Murray, D.C. Nobes, A. RAHMAN, R. SCHAAR, K.P. StEWART, R. TADA, P. Thy, L. VigliotTI, L.D. White, J.J.M. WiPPERN, S. YAMASHITA, J.C, Ingle JR., K. SuyehiRo, M.T. von BreymanN, J.S. Bristow, L.H. Burckle, J. Charvet, B.A. CragG, P.B. DEMENOCAL, R.B. Dunbar, K.B. Foellmi, J.R. GRIFFIn, K.A. Grimm, Y. Hamano, N. Hirata, P. Holler, C.M. IsaAcs, M. Kato, R. Kettler, T. Kheradyar, K.A.O. KrumsieK, H.-Y. Ling, R. Matsumoto, J.P. MuZA, R.J. Parkes, A. Pouclet, S.D. Scott, R. Stein and A.A. STURZ (1992): Japan Sea, covering Legs 127 and 128 of the cruises of the Drilling Vessel JOIDES Resolution, Proc. ODP Sci. Results, 127 (128), pp. 1427.

THIEL, H. (2002): Research for the protection of the deepsea, in Science-Technology Synergy for Research in the Marine Environment: Challenges for the XXI Century, edited by L. Beranzoli, P. FAVAli and G. Smriglio, Developments in Marine Technology Series (Elsevier, Amsterdam), 12, 11-18.

Thiel, H., K.O. Kirstein, C. Luth, U. Luth, G. Luther, L.A. Meyer-ReIL, O. Pfannkuche and M. Weydert (1994): Scientific requirements for an abyssal benthic laboratory, J. Mar. Syst., 4, 421-439.

Tinti, S., A. Maramai and P. Favali (1995): The Gargano promontory: an important Italian seismogenic-tsunamigenic area, Mar. Geol., 122, 227-241.

Tinti, S., A. Maramai and L. Graziani (2004): The new catalogue of Italian tsunamis, Natural Hazards, 33, 439-465.

Toн, H., T. Goto and Y. Hamano (1998): A new seafloor electromagnetic station with an Overhauser magnetometer, a magnetotelluric variograph and an acoustic telemetry modem, Earth Planets Space, 50, 895-903.

TORSVIK, T.H., R. VAN DER VOO and T.F. REDFIELD (2002): Relative hotspot motions versus true polar wander, Earth Planet. Sci. Lett., 202, 185-200.

Traykovski, P., A.E. HaY, J.D. IRISH and J.F. LYNCH (1999):
Geometry, migration and evolution of wave orbital scale ripples at LEO-15, J. Geophys. Res., 104, 1505-1524.

Utada, H., K. Noguchi, C. Harayama and N. Natsushima (Editors) (1997): Proceedings International Workshop on Scientific Use of Submarine Cables (Okinawa, Japan), pp. 234.

WATERworth, G. (2004): Connecting long-term seafloor observatories to the shore, Sea Technol., 45 (9), 10-13.

WEBB, S.C. (1998): Broad-band seismology and noise under the ocean, Rev. Geophys., 36 (1), 105-142.

WebB, S.C. and W.C. CRAWFord (1999): Long period seafloor seismology and deformation under ocean waves, Bull. Seismol. Soc. Am., 89, 1535-1542.

Weiland, C.M., G.A. Barth, B. Chadwick, R.W. EMbley and J. GETSIV (2000): Virtual exploration of the New Millennium Observatory (NeMO) at Axial Volcano, Juan de Fuca Ridge, Eos, Trans. Am. Geophys. Un., 81, 1265-1266.

YADA, T., N. NAMBA and T. URA (Co-chairs) (2004): Proceedings OCEANS'04 MTS/IEEE TECHNO-OCEAN'04, Kobe, Japan, IEEE Catalogue No. 04CH37600C, pp. 2365 .

ZHAO, D. (2001): Seismic structure and origin of hotspots and mantle plumes, Earth Planet. Sci. Lett., 192, 251-265.

Zhukov, V.A., A. Aloupis, E.G. Anassontzis, N. Arvanitis, A. Babalis, A. Ball, L.B. Bezrukov, G. Bourlis, A.V. Butkevich, W. Chinowsky, P.E. Christopoulou, A. Darsaklis, L.G. Dedenko, D. Eilstrup, E. Fahrun, G. Gialas, C. Goudis, G. Grammatikakis, C. Green, P.K.F. Grieder, S.K. Karaevsky, P. Katrivanos, U. Keusen, J. Kiskiras, T. Knutz, D. Kolostelov, K. Komlev, J. Kontaxis, P. Koske, J.G. Learned, V.V. LedeneV, A. Leisos, G. Limberopoulos, J. Ludvig, J. MAKRIS, A. ManOUSAKIS-KatSIKAKIS, E. MarKOPOUlos, S. Matsuno, J. Mielke, T. Mihos, P. Minkowski, A.A. Mironovich, R. Mitiguy, S. Nounos, D.R. Nygren, K. Papageorgiou, M. Passera, C. Politis, P. Preve, G.T. Przybylski, J. Rathlev, L.K. Resvanis, M. Rosen, N. Schmidt, T. Schmidt, I. Siotis, A.E. Shnyrev, J. Sopher, T. Staveris, G. Stavrakakis, R. Stokstad, N.M. Surin, V. Tsagli, A. Tsirigotis, J. Tsirmpas, S. TZamarias, O. Vasilev, O. Vaskine, W. Voigt, A. Vougioukas, G. Voulgaris, L.M. ZAKHAROV and N. ZIABKO (2004): NESTOR experiment in 2003, Phys. At. Nucl., 67, 2054-2057. 